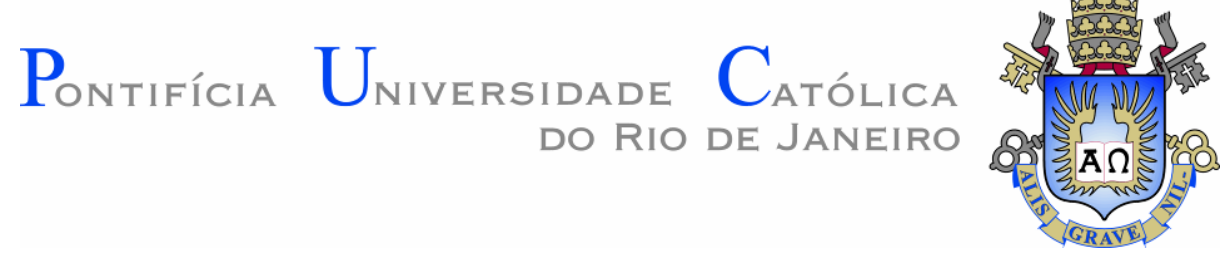

Thalita Costa de Moraes

Análise de ruptura de encosta e interação com estruturas usando Método do Ponto Material

Dissertação de Mestrado

Dissertação apresentada como requisito parcial para obtenção do grau de Mestre pelo Programa de PósGraduação em Engenharia Civil do departamento de Engenharia Civil e Ambiental da PUC-Rio.

Orientadora: Prof. Raquel Quadros Velloso

Rio de Janeiro

Fevereiro de 2019 


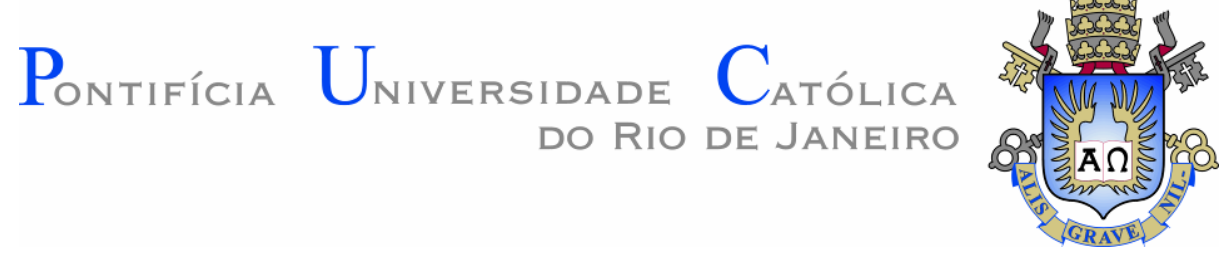

Thalita Costa de Moraes

\title{
Análise de ruptura de encosta e interação com estruturas usando Método do Ponto Material
}

Dissertação apresentada como requisito parcial para obtenção do grau de Mestre pelo Programa de PósGraduação em Engenharia Civil da PUC-Rio. Aprovada pela Comissão Examinadora abaixo.

\begin{abstract}
Raquel Quadros Velloso Orientador Departamento de Engenharia Civil e Ambiental - PUC-Rio

Eurípedes Vargas Júnior Departamento de Engenharia Civil e Ambiental - PUC-Rio

André Luíz Muller Instituto Tecgraf/PUC-Rio
\end{abstract}

Rio de Janeiro, 21 de fevereiro de 2019 
Todos os direitos reservados. É proibida a reprodução total ou parcial do trabalho sem autorização da universidade, da autora e do orientador.

Thalita Costa de Moraes

Graduou-se em Engenharia Civil pela Universidade Federal Fluminense.

Ficha Catalográfica

Moraes, Thalita Costa de

Análise de ruptura de encosta e interação com estruturas usando método do ponto material / Thalita Costa de Moraes ; orientadora: Raquel Quadros Velloso. - 2019.

75 f. : il. color. ; $30 \mathrm{~cm}$

Dissertação (mestrado)-Pontifícia Universidade Católica do Rio de Janeiro, Departamento de Engenharia Civil e Ambiental, 2019.

Inclui bibliografia

1. Engenharia Civil e Ambiental - Teses. 2. Material point method. 3. Força de impacto. 4. Modelo constitutivo. 5. Fator de segurança. I. Velloso, Raquel Quadros. II. Pontifícia Universidade Católica do Rio de Janeiro. Departamento de Engenharia Civil e Ambiental. III. Título.

CDD: 624 
Para meus colegas, contemporâneos e sucessores. 


\section{Agradecimentos}

Em primeiro lugar, gostaria de agradecer à minha orientadora Raquel Velloso, pelo apoio e auxílio sempre, por toda conversa encorajadora e por ter me apresentado o MPM que tem estado em grande parte dos meus dias e continuará na minha vida mesmo após a conclusão do mestrado. Ao professor Eurípedes Vargas, por todo o conhecimento transmitido e disponibilidade.

Ao colega Fabricio Fernández, pela paciência, pelas conversas construtivas seja relacionado ao tema estudado ou à programação e computação, seja a temas do dia a dia, e por contribuir com parte fundamental para desenvolvimento dessa dissertação. Aos colegas de sala Karl, Miguel, Bárbara, Raphael, Vinícius, Carlos, Kevin, Jéssica, Marcela, Erland, Jhonatan, Celso, Bruno, Thamiris, Rebeca, Raul, Lizardo, Paula, Gabriela, Rômulo, Cristina e tantos outros, que dividiram seus dias comigo e tornaram os meus, mais agradáveis.

Ao Felipe, por dar ideias descabidas que me deixavam enrolada só para explicar porque não dariam certo. Mas também por dar ideias adequadas que me fizeram pensar em soluções factíveis. Mas principalmente por me dar ideias.

Especialmente aos meus pais, Gisela e Bruce, por me ouvirem e me apoiarem mesmo sem entender nada do que estava dizendo. Ao meu irmão João Paulo, pelas eventuais mensagens, mesmo que não tivéssemos tempo para encontrar. À minha vó Olguinha, por perguntar sempre que comida eu queria. E à minha família, que esteve comigo quando precisei.

Por fim, à PUC-Rio, pela bolsa de isenção, sem a qual não teria sido possível obter este título. O presente trabalho foi realizado com apoio da Coordenação de Aperfeiçoamento de Pessoal de Nível Superior - Brasil (CAPES) - Código de Financiamento 001. 


\section{Resumo}

Moraes, Thalita Costa de; Velloso, Raquel Quadros. Análise de ruptura de encosta e interação com estruturas usando Método do Ponto Material. Rio de Janeiro, 2019. 75p. Dissertação de Mestrado - Departamento de Engenharia Civil e Ambiental, Pontifícia Universidade Católica do Rio de Janeiro.

Essa pesquisa usa o Método do Ponto Material (MPM), para avaliar diferentes aspectos de deslizamentos de encosta. Esse tema é de suma importância, visto que os deslizamentos de terra são o desastre natural que mais causa perdas humanas no Brasil. Esse método numérico foi verificado a fim de que fosse encontrado o fator de segurança e a superfície de ruptura em um talude infinito com solo representado pelo modelo constitutivo de Drucker-Prager. Além disso, foi validado para calcular a força de impacto em um anteparo, sendo o volume impactante um objeto qualquer elástico ou um solo com modelo de Drucker-Prager. Os cálculos foram executados com o código desenvolvido pela PUC-Rio e produziram excelentes resultados. Foi observada uma grande dependência dos resultados com a malha, e assim como no Método dos Elementos Finitos, o refinamento da malha gera convergência para um resultado. O método foi considerado satisfatório para cálculo de uma parede de retenção em locais de risco.

\section{Palavras-chave}

Material Point Method; força de impacto; modelo constitutivo; fator de segurança 


\section{Abstract}

Moraes, Thalita Costa de; Velloso, Raquel Quadros (Advisor). Slope rupture and interaction with structures analysis using the Material Point Method. Rio de Janeiro, 2019. 75p. Dissertação de Mestrado Departamento de Engenharia Civil e Ambiental, Pontifícia Universidade Católica do Rio de Janeiro.

This research uses a numerical method, the Material Point Method, to evaluate different aspects of slope landslides. This theme is of paramount importance since landslides are the natural disaster that shows the highest number of deaths in Brazil. The method was verified so that it could find the safety factor and rupture surface in an infinite slope with soil represented by the Drucker-Prager constitutive model. In addition, the method was validated to calculate impact force in a bulkhead; the impacting volume could be any elastic object or soil with the Drucker-Prager model. The calculations were performed using the code developed by PUC-Rio and showed excellent results. It was observed high dependence on the mesh discretization, as well as the Finite Element Method, the refinement of the mesh generates convergence for a result. The method was considered satisfactory for calculating a retention wall at risk locations.

\section{Keywords}

Material Point Method; impact force; constitutive model; safety factor 


\section{Sumário}

1. Introdução 15

1.1. Objetivos 18

1.2. Escopo 18

2. Revisão Bibliográfica 20

3. Metodologia 27

3.1 Métodos euleriano e lagrangiano 27

3.2 Método do ponto material 27

3.3 Formulação simplificada 28

3.4 Integração explícita no tempo 32

3.5 Critério de Drucker-Prager 34

3.6 Fator de redução 35

3.7 Força de impacto 36

4. Resultados e Discussão 38

4.1 Talude infinito 2D 38

4.2 Bloco em queda livre $\quad 44$

4.2.1 Discretização da malha 46

4.2.2 Força de impacto do bloco em queda livre 48

4.2.3 Geometria do bloco impactado 50

4.3 Areia em plano inclinado 2D 53

4.3.1 Contorno livre em x com malha de $0,1 \mathrm{~m}$

4.3.2 Contorno livre em x com malha de $0,05 \mathrm{~m}$

4.3.3 Contorno livre em x com malha de 0,025 m 60

4.3.4 Análise do refinamento da malha 61

4.3.5 Contorno fixo em x com malha de 0,05 m 63

4.4 Areia em plano inclinado 3D 67

5. Conclusão 70 
6. Referências Bibliográficas 


\section{Lista de tabelas}

Tabela 1 - Requisitos básicos para soluções satisfatórias por vários métodos de análise (traduzidos de: Potts and Zdravkovic, 1999) 22

Tabela 2 - Parâmetros do Solo 39

Tabela 3 - Especificações dos blocos 45

Tabela 4 - Tabela de resultados de força e momento do impacto pela altura do bloco 50

Tabela 5 - Tabela de resultados de força e momento do impacto pela geometria do bloco impactado $\quad 52$

Tabela 6 - Medidas de força de impacto máxina (em Newtons) em função da inclinação da calha (Moriguchi et al., 2009) 54

Tabela 7 - Análise do refinamento da malha Força de impacto e desvio entre malhas sucessivas $\quad 62$

Tabela 8 - Comparação entre a força de impacto em Newtons calculada pelo MPM $(0,05 \mathrm{~m})$ e ensaio de laboratório 63

Tabela 9 - Comparação entre a força de impacto em Newtons calculada pelo MPM e ensaio de laboratório 


\section{Lista de Figuras}

Figura 1 - Modelagem com elementos discretos para cálculo de ângulo de repouso da areia (NAKASHIMA et al., 2011)

Figura 2 - Barragem de terra dividida em malha de elementos finitos deformada (XU and LOW, 2006)

Figura 3 - Deslizamento no Morro da Carioca (foto de cima: Danielle

Bartholomeu) e Praia do Bananal (foto de baixo: Custódio Coimbra), em Angra dos Reis. (G1, 2010)

Figura 4 - Procedimento para técnicas de aplicação de simulação numérica para

solução de problemas de engenharia (traduzido de: Schäfer, 2006)

Figura 5 - Ciclo Computacional do Método do ponto Material (Fernandéz et al., 2019)

Figura 6 - Superfícies de ruptura de Mohr-Coulomb e Drucker-Prager,

Modificado de Zhang et. al (2017)

Figura 7 - Talude infinito considerado 39

Figura 8 - Talude infinito não saturado 40

Figura 9 - Talude infinito metade superior saturada 40

Figura 10 - Talude infinito todo saturado 41

Figura 11 - Talude infinito metade inferior saturada

Figura 12 - Gráficos de Deformação e Taxa de Deformação pelo fator de redução

Figura 13 - Gráfico comparativo entre os Fatores de segurança

Figura 14 - Deformações plásticas talude (a) não saturado, (b) superior saturado,

(c) todo saturado e (d) inferior saturado

Figura 15 - Bloco superior em queda livre e bloco inferior atuando como célula de carga

Figura 16 - Apresentação da discretização para primeira análise,

Figura 17 - Força no tempo para bloco caindo em queda livre variando a

Figura 18 - Gráfico da força de impacto x Inverso do espaçamento da malha 
Figura 19 - Apresentação da altura dos blocos para segunda análise: $\quad 48$

Figura 20 - Força no tempo para bloco caindo em queda livre 49

Figura 21- Gráfico da Força de impacto x Altura do bloco em queda livre 50

Figura 22 - Apresentação da geometria dos blocos inferiores para terceira análise: a. 1 x 1 b. $3 \times 1$ c. $1 \times 0,3$ e d. $3 \times 0,3$

Figura 23 - Força no tempo para bloco caindo em queda livre variando a geometria do bloco impactado: a. $1 \times 1$ b. $3 \times 1$ c. $1 \times 0,3$ e d. $3 \times 0,3$

Figura 24 - Foto do experimento e esquema (Moriguchi et al., 2009) 53

Figura 25 - Foto da caixa de areia e esquema (Moriguchi et al., 2009) 54

Figura 26 - Foto da célula de carga e esquema (Moriguchi et al., 2009) 54

Figura 27 - Medidas de força de impacto no tempo para diferentes inclinações de rampa (Moriguchi et al., 2009) 55

Figura 28 - Representação esquemática do modelo para simulações numéricas (Moriguchi et al., 2009) 56

Figura 29 - Representação do modelo MPM (grid 0,1 m) com escala de cores por material

Figura 30 - Força de Impacto (N) no tempo com inclinação de: a. $45^{\circ}$ b. $50^{\circ}$ c. $55^{\circ}$ d. $60^{\circ}$ e. $65^{\circ}$

Figura 31 - Representação do modelo MPM (grid 0,05 m) com escala de cores por material

Figura 32 - Força de Impacto (N) no tempo com inclinação de: a. $45^{\circ}$ b. $50^{\circ}$ c. $55^{\circ}$ d. $60^{\circ}$ e. $65^{\circ}$

Figura 33 - Representação do modelo MPM (grid 0,025 m) com escala de cores por material

Figura 34- Força de Impacto (N) no tempo com inclinação de: a. $45^{\circ}$ b. $50^{\circ}$ c. $55^{\circ}$ d. $60^{\circ}$ e. $65^{\circ}$

Figura 35 - Análise do refinamento da malha Força de Impacto x Inverso do espaçamento da malha

Figura 36 - Representação do modelo MPM (grid 0,05 m) com escala de cores por material

Figura 37 - Força de Impacto (N) no tempo com inclinação de: a. $45^{\circ}$ b. $50^{\circ}$ c. $55^{\circ}$

d. $60^{\circ}$ e. $65^{\circ}$

Figura 38 - Resultados com cálculo pelo MPM (esquerda) e experimental (direita) 
Figura 39 - Força na parede para $55^{\circ}$ de inclinação no instante de pico 1,8 segundos

Figura 40 - Representação do modelo 3D MPM (grid 0,05 m) com escala de cores por material

Figura 41 - Força de Impacto (N) no tempo com inclinação de: a. $45^{\circ}$ b. $50^{\circ}$ c. $55^{\circ}$ d. $60^{\circ}$ e. $65^{\circ}$

Figura 42 - Resultados com cálculo pelo MPM 2D (esquerda) e MPM 3D (direita) 
Na Ciência (...) o trabalho científico do indivíduo está tão inseparavelmente conectado ao de seus antecessores e contemporâneos, que parece ser quase um produto impessoal de sua geração.

Albert Einstein 


\section{1. Introdução}

Os métodos numéricos têm transformado a engenharia civil e muitas outras áreas intensamente, tendo a tecnologia um papel primordial esse avanço. A velocidade com que os cálculos são feitos e a acurácia de seus resultados são os mais importantes aspectos a serem considerados nessa evolução.

Diferentes métodos que calculam tensões e deformações têm sido propostos nos últimos 70 anos e estes passaram por um processe de aperfeiçoamento desde então. Em geral, podem ser divididos em métodos que utilizam o modelo lagrangiano ou euleriano.

A proposta de Euler sugere acompanhar um volume de controle fixo, assim pode-se calcular o movimento do material no tempo. Esse modelo é usado especialmente na modelagem de fluidos. O modelo euleriano pode aparecer combinado com modelos lagrangianos.

A proposta de Lagrange é acompanhar o movimento de cada ponto ou partícula no tempo, como nos Métodos dos Elementos Discretos (MED ou DEM) que usam as leis da mecânica básica para calcular os deslocamentos de partículas. A Figura 1 mostra um exemplo simples de cálculo de ângulo de repouso usando elementos discretos proposto por Nakashima (2011).

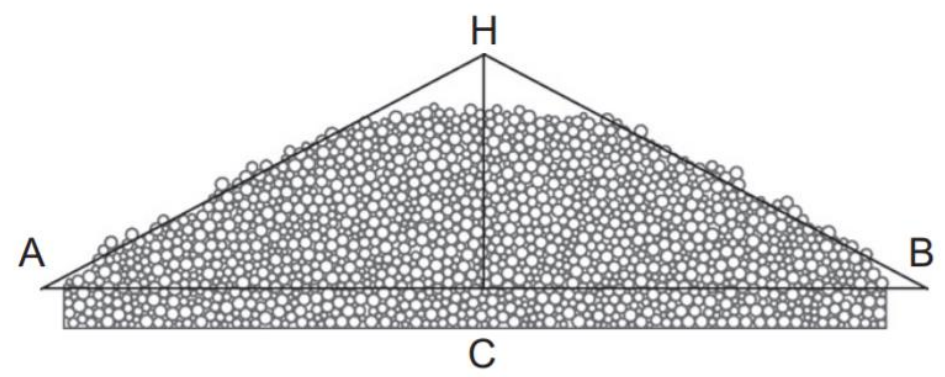

Figura 1 - Modelagem com elementos discretos para cálculo de ângulo de repouso da areia (NAKASHIMA et al., 2011)

Em engenharia, o modelo lagrangiano também é amplamente representado pelo Método dos Elementos Finitos (MEF ou FEM) para cálculos de tensãodeformação, sendo necessário, para isso, dividir o volume que se pretende 
1.

considerar em uma malha e calcular os deslocamentos nos nós, devido às tensões desenvolvidas no corpo. Enquanto a malha se deforma, há uma restrição geométrica para os elementos. Sendo assim, esse método apresenta dificuldades para problemas com grandes deformações.

A Figura 2(a) exibe uma barragem dividida em malha de elementos finitos e sua distorção e a Figura 2(b) mostra vetores de incremento de deformação nodal, sendo os dois exemplos retirados do estudo conduzido por Xu e Low (2006) para cálculo de fator de segurança.

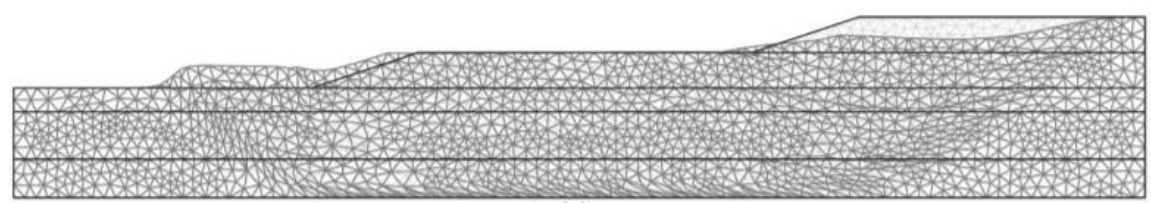

(a)

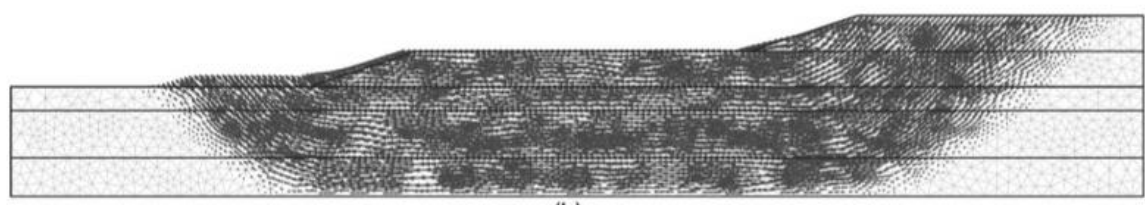

(b)

Figura 2 - Barragem de terra dividida em malha de elementos finitos deformada (XU; LOW, 2006)

A grande variedade de materiais encontrados, desde rochas e blocos até partículas muito pequenas - que podem ter ou não coesão, e serem imersas em água variando, assim, seu comportamento -, torna a escolha da abordagem de suma importância para modelagem. Essa diversidade requer, portanto, a experiência do engenheiro ao se escolher o método para modelar em cada situação considerando as vantagens e desvantagens de cada caso.

É importante destacar que métodos que integram os modelos euleriano e lagrangiano podem refinar a proposta dos dois modelos. O Método do Ponto Material (MPM) foi proposto por Sulsky et al. (1993) e visa descrever materiais que dependem da trajetória de tensões. Esse método foi baseado no Método Partícula em Célula (PIC, sigla em inglês) e teria como intuito reduzir a dissipação numérica.

O MPM é considerado um método contínuo porque os cálculos de equilíbrio são executados nos nós que tem continuidade garantida pela matriz de rigidez, porém não apresentam restrição de movimento visto que as velocidades $\mathrm{e}$ deslocamentos são atualizados nos pontos materiais e a malha não apresenta distorção. 
Ressalta-se que os movimentos de massa, principalmente provocados pela chuva, são os desastres ambientais que mais causam acidentes e mortes no Brasil, por isso têm grande relevância nas pesquisas de engenharia geotécnica. Um país, que cresce rapidamente e sem planejamento, apresenta povoação em locais inadequados, como próximo a encostas cujo movimento é esperado. Para garantir a segurança da população que vive sob uma encosta com elevado risco de deslizamento, é possível a construção de um anteparo estrutural na base do talude para conter o solo, caso este venha a deslizar.

Deve-se notar que é ideal que a população não povoe áreas em tais riscos, porém devido à geografia do país e crescimento desordenado já existem muitas famílias nessa situação e, por isso, o desalojamento pode ser inviável. A Figura 3 mostra duas fotos da página online do jornal $\mathrm{O}$ Globo como exemplo de deslizamento de terra em encosta. No caso mostrado, sete pessoas morreram no deslizamento do Morro do Carioca e 15 na praia da Bananal, no réveillon de 2010.
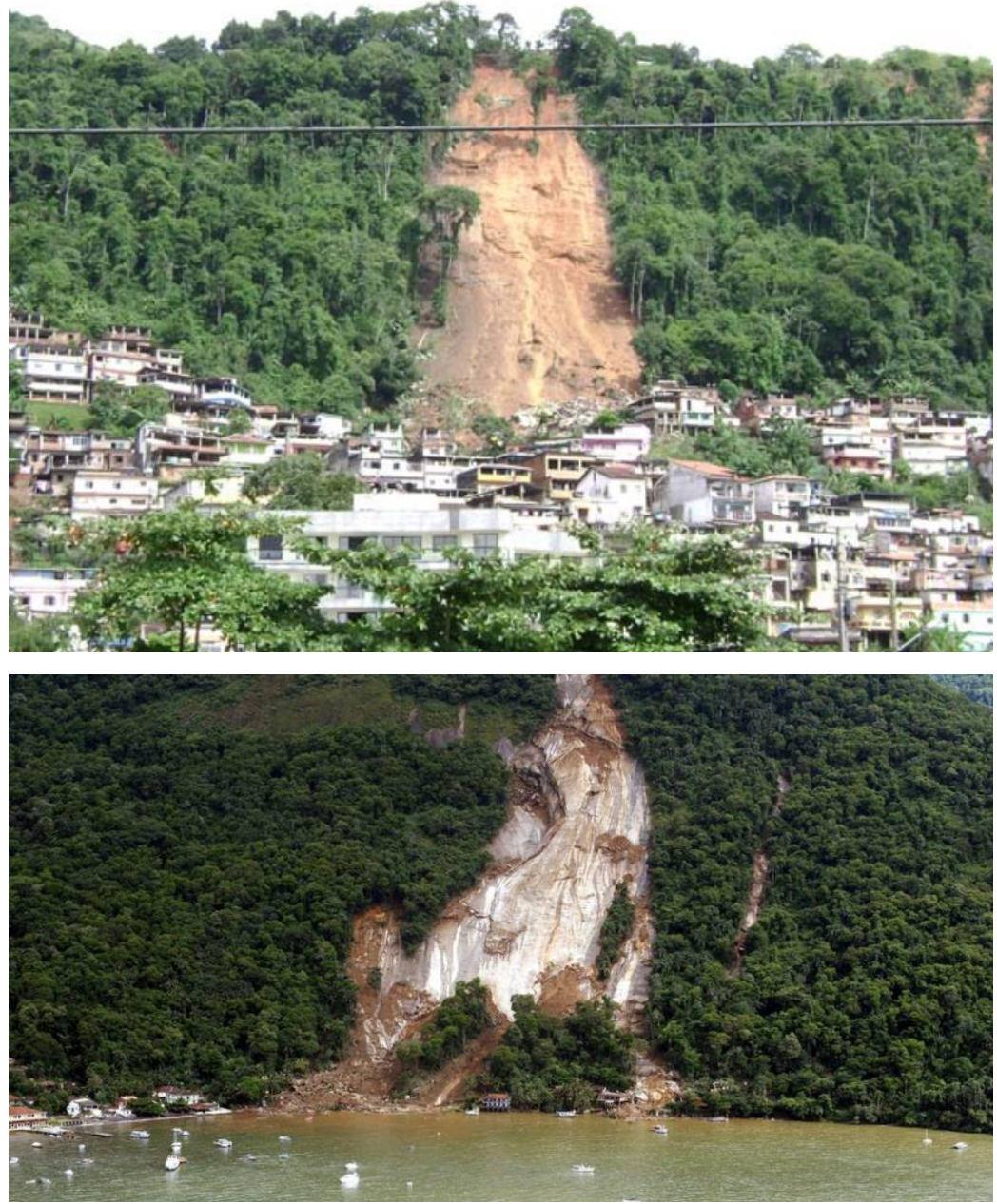

Figura 3 - Deslizamento no Morro da Carioca (foto de cima: Danielle Bartholomeu) e Praia do Bananal (foto de baixo: Custódio Coimbra), em Angra dos Reis. (G1, 2010) 
Como esse tipo de trabalho deve ser de prevenção, é necessário um método que além de conseguir computar grandes deformações, também encontre a superfície de ruptura naturalmente. Também é necessário que se encontre o local de deposição de toda a massa rompida, para que se possa colocar um anteparo no modelo e calcular a força de impacto em uma parede de retenção. Esse estudo demonstra que já há um método que pode ser utilizado como ferramenta para os mais diversos casos de construção, especialmente em políticas públicas.

\section{1.}

\section{Objetivos}

O objetivo principal deste estudo é o cálculo da força de impacto em uma parede de retenção para massas de solo em movimento, usando o Método do Ponto Material. Para atingir esse objetivo, foram avaliados diferentes casos de movimento de massa usando o método em questão.

Os objetivos específicos para alcança-lo foram:

- Verificar o cálculo do fator de segurança e superfície de ruptura pelo MPM, comparando-o com resultados obtidos pelo método do equilíbrio limite e análise limite encontrados na literatura;

- Avaliar a resposta do cálculo da força de impacto em um caso simples de queda livre, considerando a variação de parâmetros, como discretização do grid, altura de queda e geometria do bloco impactado;

- Validar o cálculo da força de impacto usando experimentos encontrados na literatura para diferentes inclinações, por meio da modelagem 2D e 3D.

\section{2.}

Escopo

Esta dissertação é dividida em cinco capítulos, sendo o primeiro a introdução ao tema. Nele estão evidenciadas a motivação para o estudo de deslizamento de encostas e para o uso do MPM, assim como os objetivos a serem atingidos e a estrutura da dissertação.

O segundo capítulo traz a revisão bibliográfica que descreve os avanços no tema nos últimos anos. Nele estão detalhados alguns trabalhos importantes para a melhor compreensão das respostas e dificuldades nesse campo de estudo. 
1.

O terceiro capítulo apresenta a metodologia como parte da fundamentação teórica e modelagem numérica para o código do MPM. Advertimos desde já que o código é muito mais extenso que as expressões apresentadas. Contudo, não é o foco deste estudo descrever todo o roteiro, já que isso demandaria um aprofundamento que não cabe a esta dissertação.

O quarto capítulo mostra os resultados obtidos com as diferentes simulações e a sua discussão. Eles estão expostos em termos de fator de redução de resistência, deslocamento e força de impacto no tempo. A discussão abrange as dificuldades experimentadas pelo modelo e, consequentemente, algumas divergências que podem ser evidenciadas em relação aos outros modelos e experimentos usados para validação.

Finalmente, o último capítulo contém as conclusões e sugere linhas de pesquisas relacionadas ao tema para futuras pesquisas em cálculo de forças de impacto utilizando o MPM. 


\section{2. Revisão Bibliográfica}

Para compreender o planeta em que vivemos, os estudos realizados pela física têm sido fundamentais ao longo dos séculos. Soluções analíticas de equações diferenciais, que descrevem os problemas de física, em geral, e de engenharia, só podem ser aplicadas para casos muito simples e específicos. Os métodos numéricos são uma ferramenta matemática desenvolvida para solucionar problemas numéricos. A solução de problemas através de métodos numéricos já era conhecida no século XIX. Gauss e Euler podem ser considerados pioneiros dessa área, mas não se tinha computadores capazes de solucioná-los. Além disso, o desenvolvimento de algoritmos numéricos contribuiu significativamente, eles aumentaram a competência com respeito à realidade modelada a ser investigada (Schäfer, 2006).

A Figura 4 ilustra os diferentes aspectos do desenrolar de uma técnica de simulação numérica para solução de um problema de engenharia, processo esse que é usado nesta dissertação. Os erros que podem resultar da modelagem são devido à aproximação feita pelo modelo, para refinar o resultado aumentamos a discretização, esta pode ser referente à discretização do grid ou discretização das equações. 
2.

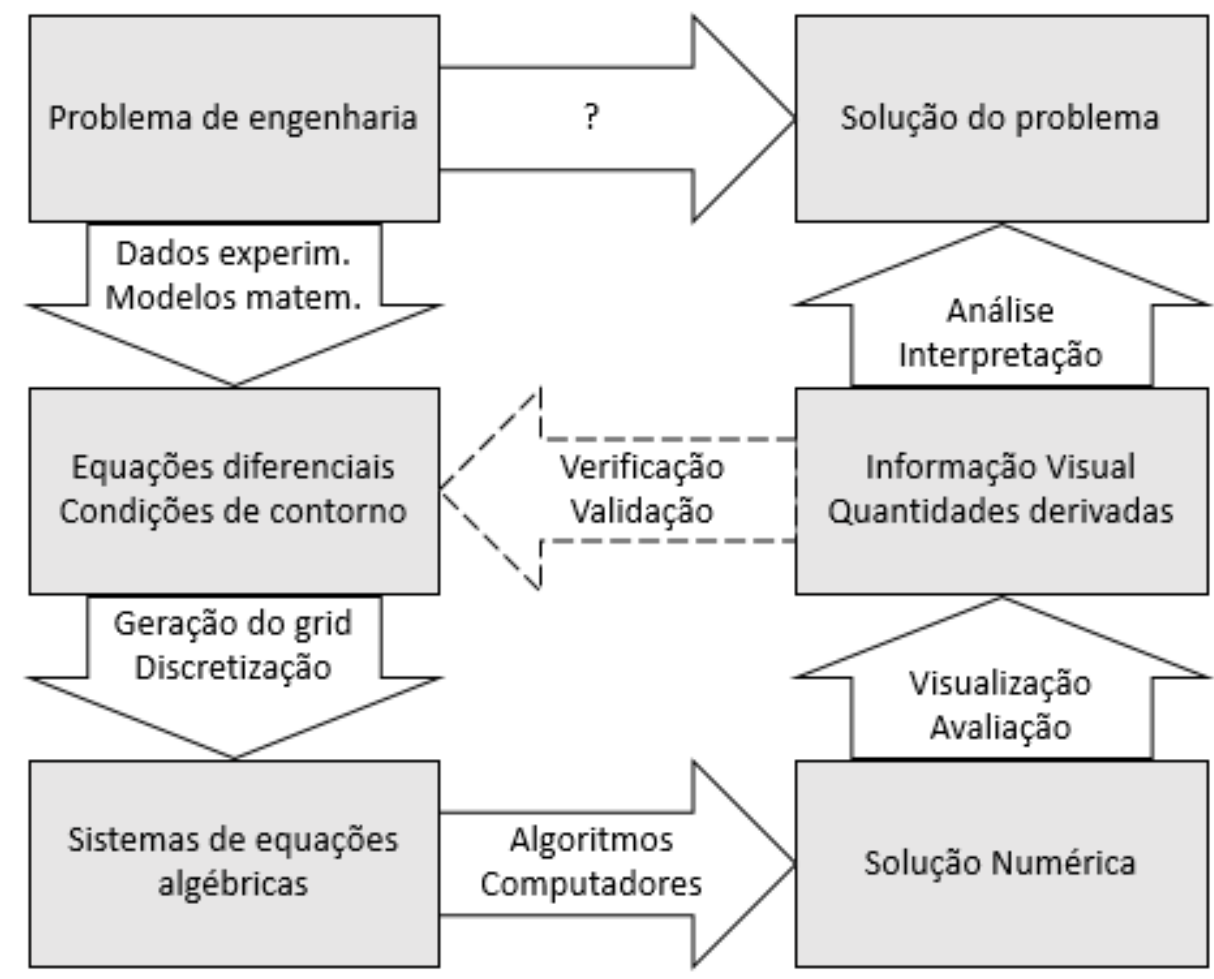

Figura 4 - Procedimento para técnicas de aplicação de simulação numérica para solução de problemas de engenharia (traduzido de: Schäfer, 2006)

Quase todos os problemas de engenharia civil envolvem o solo de alguma forma, a engenharia geotécnica tem papel primordial nas construções. Em muitos casos o solo fornece ambas as forças atuante e resistente, o engenheiro deve conhecer as forças impostas e potencial movimentação do solo e estrutura em condições de funcionamento e carga máxima. Tradicionalmente o dimensionamento considera análises simplificadas e abordagem empírica, a introdução da computação barata e sofisticada resultou em avanços na análise e design de estruturas geotécnicas.

As soluções desses problemas devem obrigatoriamente satisfazer equilíbrio, continuidade do material, comportamento constitutivo e condições de contorno, para força e deslocamento (Potts and Zdraxkovic, 1999). A Tabela 1 apresenta alguns métodos de análise, e compara requisitos básicos para solução do problema de engenharia. 
2.

Tabela 1 - Requisitos básicos para soluções satisfatórias por vários métodos de análise (traduzidos de: Potts and Zdravkovic, 1999)

\begin{tabular}{|c|c|c|c|c|c|c|}
\hline & & & & equisitos para soluç & & \\
\hline \multirow{2}{*}{\multicolumn{2}{|c|}{$\begin{array}{l}\text { Método de } \\
\text { Análise }\end{array}$}} & \multirow{2}{*}{ 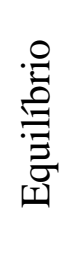 } & \multirow{2}{*}{ 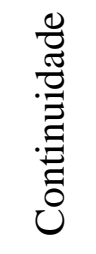 } & \multirow{2}{*}{$\begin{array}{c}\text { Comportamento } \\
\text { constitutivo }\end{array}$} & \multicolumn{2}{|c|}{$\begin{array}{l}\text { Condições de } \\
\text { contorno }\end{array}$} \\
\hline & & & & & Força & Desloc. \\
\hline Forma & Gechada & $\mathrm{S}$ & $\mathrm{S}$ & Linear Elástico & $S$ & $S$ \\
\hline \multicolumn{2}{|c|}{ Equilíbrio limite } & $\mathrm{S}$ & NS & $\begin{array}{l}\text { Rígido com } \\
\text { critério de ruptura }\end{array}$ & $\mathrm{S}$ & NS \\
\hline \multicolumn{2}{|c|}{$\begin{array}{c}\text { Campo de } \\
\text { tensões }\end{array}$} & $\mathrm{S}$ & NS & $\begin{array}{l}\text { Rígido com } \\
\text { critério de ruptura }\end{array}$ & $\mathrm{S}$ & NS \\
\hline \multirow{2}{*}{$\begin{array}{l}\text { Análise } \\
\text { limite }\end{array}$} & $\begin{array}{l}\text { Limite } \\
\text { superior }\end{array}$ & $\mathrm{S}$ & NS & \multirow{2}{*}{$\begin{array}{l}\text { Plasticidade ideal } \\
\text { com lei de fluxo } \\
\text { associado }\end{array}$} & $S$ & NS \\
\hline & $\begin{array}{l}\text { Limite } \\
\text { inferior }\end{array}$ & NS & $\mathrm{S}$ & & NS & $\mathrm{S}$ \\
\hline \multicolumn{2}{|c|}{$\begin{array}{c}\text { Sistema } \\
\text { massa-mola }\end{array}$} & $\mathrm{S}$ & $\mathrm{S}$ & $\begin{array}{l}\text { Solo modelado } \\
\text { por molas ou } \\
\text { fatores de } \\
\text { interação elástica }\end{array}$ & $\mathrm{S}$ & $\mathrm{S}$ \\
\hline \multicolumn{2}{|c|}{$\begin{array}{c}\text { Análise Numérica } \\
\text { Completa }\end{array}$} & $\mathrm{S}$ & $\mathrm{S}$ & Qualquer & $\mathrm{S}$ & $\mathrm{S}$ \\
\hline \multicolumn{7}{|c|}{ S - Satisfeito; NS - Não Satisfeito } \\
\hline \multicolumn{7}{|c|}{$\begin{array}{l}\text { geotécnica deve escolher um modelo constitutivo que represente com precisão o } \\
\text { comportamento do solo e impor as condições de contorno corretamente. Vários }\end{array}$} \\
\hline \multicolumn{7}{|c|}{$\begin{array}{l}\text { Estruturas podem ser adicionadas ou retiradas, a interação entre grampos ou tirantes } \\
\text { e solo podem ser considerados, e o efeito do tempo no desenvolvimento da }\end{array}$} \\
\hline
\end{tabular}


2.

Potts e Zdravkovic (1999) advertem que informações detalhadas do solo e conhecimento dos processos de construção são necessárias e, às vezes, podem ser difíceis de serem obtidas, porém não são consideradas limitações do método.

Os métodos contínuos são os métodos numéricos mais utilizados na engenharia geotécnica há décadas, desde KO unidimensional (Wilkins et al., 1962), HEMP 2D (Wilkins, 1969) e EPIC 2D e 3D (Johnson, 1977 e Johnson, 1978). Eles usam uma malha lagrangiana que se deforma com o desenvolvimento do programa. Já os métodos discretos, que apresentam abordagem diferente, também foram desenvolvidos na mesma época, como HELP (Hageman; Walsh, 1971).

Destacamos que os métodos contínuos envolvem a discretização do domínio em elementos, sendo seu tamanho relacionado à precisão de resultados que se deseja garantir. Uma variável primária é definida e controlada no tempo, essa variável é expressa para cada ponto nodal. Princípios variacionais apropriados são usados para derivar equações do elemento, cuja combinação forma as equações globais, que, a partir das condições de contorno, são transformadas no sistema definido que se deseja solucionar.

O método PIC (Particle in a Cell) usa aspectos da abordagem lagrangiana e euleriana, discretiza o material em partículas lagrangianas com informações de posição, massa e forma, mas a malha computacional é euleriana. Harlow publicou a primeira idealização do PIC para dinâmica dos fluídos em 1955, que foi corrigida em 1957. Depois disso o PIC foi desenvolvido por outros pesquisadores que contribuíram para melhores análises e correção de erros.

Esse método foi base para o MPM desenvolvido na década de 90. Deborah Sulsky, matemática e pesquisadora do Laboratório Nacional de Los Alamos contribuía com proposições de avanços no PIC em mecânica dos fluidos e se uniu a Zhen Chen e a seu orientador, Buck Schreyer, quando perceberam que os problemas de movimento nos fluidos eram semelhantes ao movimento de penetração do sólido do ponto de vista de interação corpo rígido-flexível. Os pesquisadores do Laboratório Nacional de Sandia estavam tendo problemas de modelar penetração com o Método dos Elementos Finitos. Desse modo, essa união combinou dinâmica dos fluidos computacional com dinâmica dos solos computacional para desenvolver um método de partícula baseado em contínuo, que mais tarde foi chamado de Método do Ponto Material (Zhang et al., 2017). 
2.

Sulsky et al. (1993) foram os primeiros a propor o Método do Ponto Material na apostila da Universidade do Novo México, sendo depois dividido para publicação em vários artigos nos anos seguintes (Sulsky et al., 1993; Sulsky et al., 1993; Sulsky et al., 1994; Sulsky et al., 1995; Sulsky et al., 1996). Esse método visa descrever o comportamento de materiais plásticos, ou seja, materiais que dependem do histórico de tensões. Para comprovar a validade do modelo, apresentou-se os seguintes exemplos: teste de rotação, vibração de um cilindro sólido elástico, impacto de dois corpos elásticos, uma barra ricocheteando, impacto de dois corpos inelásticos e impacto de um disco elástico com um disco com endurecimento por deformação.

Desde então, ele foi testado por diferentes autores em diferentes casos. Ma et al. (2009) compararam a modelagem MPM com o método de Hidrodinâmica Suavizada de Partículas (SPH, sigla em inglês), um método de elementos discretos sem malha, chegando à conclusão da eficiência do método. Lian et al. (2012) mostraram vantagens da modelagem com MPM e ressaltaram precisão em modelagem com elementos finitos para pequenas deformações. Gutierrez (2016) apresentou aplicações em problemas de geotecnia em condições estáticas e dinâmicas.

Além disso, alguns autores fizeram estudos que contribuíram para a implementação de novas tecnologias para o desenvolvimento do método. Mackenzie-Helnwein et al. (2010) investigaram estratégias para lidar com interações de fases dissipativas em formulações de MPM, percebendo, com isso, que cada fase tem seu próprio movimento. Zhang et al. (2009), com o uso das equações governantes de meios porosos saturados, desenvolveram o Método do Ponto Material Acoplado (CMPM, sigla em inglês) para prever respostas de solos saturados.

York et al. (1999) apresentaram um algoritmo de contato simples para permitir uma restrição de deslizamento no contato entre dois corpos. Em 2000, Bardenhagen et al. apresentaram um algoritmo de contato para aplicar o modelo de atrito de Coulomb no movimento de material granular, que calcula eficientemente contato, atrito e separação usando um campo de multivelocidades, ou seja, o cálculo de diferentes velocidades em um mesmo nó. A ideia é usar uma estrutura de interações em comum onde as restrições de atrito são aplicadas para todos os grãos de uma vez, com um passo no domínio computacional. Quando incorporado ao 
2.

MPM, o resultado é um algoritmo linear em número de grãos, que considera interações entre um grande número de grãos, assim como a deformação interna do cada grânulo. Um ano mais tarde, Bardenhagen et al. (2001) apresentaram melhorias retirando dificuldades numéricas associadas ao registro de informações da partícula no grid computacional.

Pouco depois, Hu e Chen (2003) propuseram um algoritmo de contato/atrito e separação em um ambiente multi-malhas. O estudo do impacto com MPM passou, com isso, a ser mais comum e adequado com o desenvolvimento desses algoritmos. Hu e Chen (2005) previram explosão e fragmentação em uma parede de concreto. Devido à falta de dados na literatura, que possibilitassem a validação dessa modelagem, o intuito dos estudiosos foi apenas demonstrar qualitativamente a evolução da ruptura.

Wang et al. (2011) simularam sondagem por explosão com MPM e compararam os resultados aos resultados de ensaios experimentais. Eles explicitaram que a opção pelo uso do MPM foi devido às limitações de grandes deformações dos métodos com malha, como o FEM. Nesse caso, os resultados em termos qualitativos foram comparados às imagens do experimento e os resultados de velocidade e pressão na placa à solução teórica de Richter.

Li et al. (2011) consideraram incluir a teoria de Weibull no método para simular ruptura frágil, visto que ela é baseada na tensão máxima principal, que calcula a probabilidade de uma amostra permanecer íntegra. A comparação se mostrou eficiente quando comparados os resultados aos experimentais. A incorporação de algoritmos para melhorar as respostas foi parte do processo de avanço dos métodos e aparece com frequência na maioria dos estudos.

Para solucionar problema de anti-locking, Mast (2013) propôs algoritmos que controlavam volume na partícula ou no nó. Ele comparou resultado e tempo de processamento para discutir as vantagens de cada proposta. Então, simulou o controle de avalanche por impacto com estruturas, a fim de mostrar a redução da velocidade de queda do gelo. Ele também simula o impacto do solo em uma coluna e compara os resultados com resultados experimentais.

Ceccato e Simonini (2016) compararam simulação de impacto usando MPM com modelos constitutivos elastoplástico e viscoplástico para material granular. O estudo mostrou que, quando considerado o modelo elastoplástico, com critério de ruptura de Mohr-Coulomb, a variação do módulo de elasticidade e do coeficiente 
2.

de Poisson não interferem de forma radical no resultado, contudo, esse modelo é extremamente dependente do ângulo de atrito. Já para o modelo viscoplástico, a força não varia com alteração do ângulo de atrito mas é extremamente dependente da viscosidade. O modelo de Mohr-Coulomb apresenta um sinal com alto ruído, enquanto o modelo viscoplástico é mais estável para cálculo de força. Nesse trabalho as forças superestimaram os resultados experimentais.

Gabrielli e Ceccato (2016) modelaram uma rampa com deslizamento de areia em uma malha adaptativa em MPM. Eles comparam modelagem em MPM com DEM para mostrar que fluxo de materiais granulares alcança uma velocidade maior para elementos discretos.

Os estudos em MPM são tão abrangentes que Liu et al. (2016) usaram modelagem em MPM para modelar a resposta do impacto gerado no cérebro de um pica-pau durante o processo de bicar a madeira. Uma tomografia computadorizada foi feita no pássaro para que o modelo fosse completo e o estudo revelou que a energia de deformação no cérebro permanece baixa e as tensões se desenvolvem exclusivamente no bico do animal.

Cabe destacar que todas essas pesquisas mostram que, apesar de apenas 25 anos desde seu desenvolvimento, o MPM tem apresentado resultados eficientes, em diferentes campos e com enorme potencial a ser atingido. 


\section{3. \\ Metodologia}

\section{1 Métodos euleriano e lagrangiano}

Nguyen (2010) descreve que no modelo euleriano, as equações governantes são resolvidas em um grid fixo e o material se move na malha. Já no lagrangiano, a malha está ligada ao material, a malha se move e se distorce com o material.

A maior vantagem de um método euleriano é a habilidade de lidar com movimentos muito distorcidos. Porém, ele tem dificuldades com materiais dependentes da história de tensões e na definição do contorno do material. Além disso, a derivada no tempo é a soma das derivadas espaciais e um termo convectivo (termo excluído na formulação lagrangiana). Esse termo é caro em termos computacionais. Quando é necessário que se faça esse cálculo, leva-se muito tempo, tornando o modelo mais lento.

Existem métodos que combinam as metodologias, como o ALE (Arbitrary Lagrangean-Eulerian). Nesse caso, a malha é movida continuamente, independente da deformação do material, para otimizar as formas dos elementos e descrever as fronteiras precisamente. No entanto, observa-se o termo de convecção, que causa dificuldades numéricas. Além disso, ainda há o desafio de se criar uma malha eficiente que mantenha regularidade em domínios tridimensionais, com materiais complexos, sendo esse também um desafio para o MPM.

\section{2 \\ Método do ponto material}

O MPM discretiza um corpo contínuo $\boldsymbol{\Omega}$ com um conjunto finito de $\mathbf{n}_{\mathbf{p}}$ pontos materiais na configuração inicial, que são rastreados durante o processo de deformação. A massa e o volume de sub-regiões que as partículas representam são memorizados para esses pontos. Temos $\mathbf{x}_{\mathbf{p}}^{\mathbf{t}}\left(\mathbf{p}=\mathbf{1}, \mathbf{2}, \ldots, \mathbf{n}_{\mathbf{p}}\right)$ indicando a posição atual do ponto material $\mathbf{p}$ no tempo t. Cada ponto material está associado a uma massa $\mathbf{M}_{\mathbf{p}}$, massa específica $\boldsymbol{\rho}_{\mathbf{p}}$, velocidade $\mathbf{v}_{\mathbf{p}}$, tensor de tensões $\boldsymbol{\sigma}_{\mathbf{p}}$ e outras variáveis de 
3.

estado interno necessárias para o modelo constitutivo. Portanto, esse ponto material fornece uma descrição lagrangiana do corpo contínuo. Já que o número de partículas não muda, a conservação de massa é satisfeita. No MPM, as equações de balanço de momento são resolvidas em uma malha euleriana fixa.

O grid cobre a área onde o sólido se encontra e onde se espera que ele se mova. Os pontos materiais interagem uns com os outros, do mesmo corpo, de outros sólidos, e de fluidos através da malha euleriana no fundo. Em geral, a cada passo de tempo a malha é descartada e recolocada como na configuração inicial.

Essa é a principal diferença para o $\mathrm{MEF}$, tornando o método livre de distorções. As vantagens incluem ausência de problemas com o emaranhado da malha e advecção livre de erros das propriedades do material por meio do movimento dos pontos materiais. Outra vantagem é que a interação fluido-estrutura pode ser tratada de forma direta, porque o contato é próprio do método, ou seja, aparece naturalmente sem necessidade de busca por contato.

A figura 5 (Fernandéz et al., 2019) mostra de forma simples os principais passos de cálculo: a) Computa massas da partícula e forças; b) Atualiza massas nodais e calcula velocidades nodais via equações de movimento; c) Computa incrementos de deformação nos nós e pontos materiais; d) Atualiza posições dos pontos materiais e retorna os nós aos pontos iniciais.
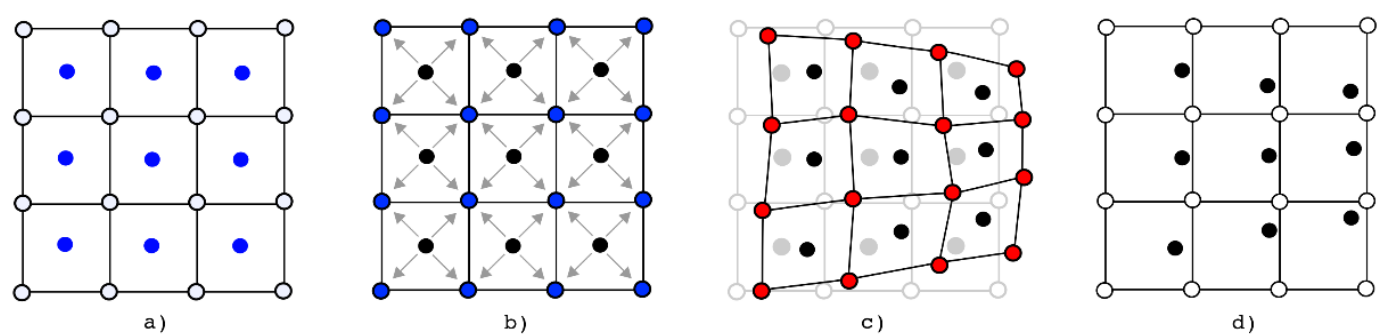

d)

Figura 5 - Ciclo Computacional do Método do Ponto Material (Fernandéz et al., 2019)

\section{3}

\section{Formulação simplificada}

O MPM utiliza uma formulação como em elementos finitos e sua equação diferencial geral da conservação de energia pode ser observada na equação (3.1) como sendo coincidente com a primeira Lei de Newton, o somatório das forças, externas e internas, igual à massa vezes aceleração. 
3.

$$
\begin{aligned}
\int_{\Omega} \rho . \delta u_{i} a_{i} d \Omega+\int_{\Omega} \rho \frac{d \delta u_{i}}{d x_{j}} \sigma_{i j}^{B} d \Omega \\
=\int_{\Omega} \rho . \delta u_{i} b_{i} d \Omega+\int_{\Gamma_{t}} \rho . \delta u_{i} t_{i} d \Gamma
\end{aligned}
$$

Sendo:

$\boldsymbol{\rho}$ - massa específica;

$\mathbf{u}_{\mathbf{i}}$ - deformação;

$\mathbf{a i}_{\mathbf{i}}$ - aceleração;

$\boldsymbol{\Omega}$ - volume do corpo;

$\boldsymbol{\sigma}_{\mathbf{i j}}{ }^{\mathbf{B}}$ - tensão específica do corpo por unidade de massa específica;

bi - forças de campo;

$\mathbf{t}_{\mathbf{i}}$ - forças de superfícies;

$\Gamma$ - superfície do corpo.

O domínio total do material é descrito como um conjunto de pontos materiais, estando a massa de cada um deles concentrada no ponto material, o que significa que o campo de densidade de massa é expresso por:

$$
\rho(x, t)=\sum_{p=1}^{n_{p}} M_{p} \delta\left(x-x_{p}\right)
$$

Sendo $\boldsymbol{\delta}$ a função delta Dirac com dimensão igual ao inverso do volume.

Substituindo (3.2) em (3.1):

$$
\begin{aligned}
& \sum_{p=1}^{n_{p}} M_{p} \cdot \delta u_{i}\left(x_{p}\right) \cdot a_{i}\left(x_{p}\right) \cdot+\sum_{p=1}^{n_{p}} M_{p} \frac{d \delta u_{i}}{d x_{j}} \sigma_{i j}^{B}\left(x_{p}\right) \\
= & \sum_{p=1}^{n_{p}} M_{p} \delta u_{i}\left(x_{p}\right) b_{i}\left(x_{p}\right)+\sum_{p=1}^{n_{p}} M_{p} \delta u_{i}\left(x_{p}\right) t_{i}\left(x_{p}\right)
\end{aligned}
$$

A integração é resolvida nos pontos materiais, até então, o MPM é idêntico ao FEM, considerando que a integração no FEM não é resolvida na mesma posição relativa. O grid no fundo serve como uma malha de elementos finitos com funções 
3.

de interpolação $\mathbf{N}_{\mathbf{I}}$. Com o uso do grid, a avaliação de funções de forma e derivadas é padrão, sem a necessidade de busca por partículas como em métodos discretos.

A posição e deslocamentos de uma partícula são descritas por:

$$
\begin{aligned}
& x_{i}\left(x_{p}\right)=\sum_{I=1}^{n_{n}} N_{I}\left(x_{p}\right) x_{i I} \\
& u_{i}\left(x_{p}\right)=\sum_{I=1}^{n_{n}} N_{I}\left(x_{p}\right) u_{i I}
\end{aligned}
$$

Sendo $\mathbf{x}_{\mathbf{I I}}$ a componente i do vetor de posição no nó I, exemplo 3D: $\mathbf{x}_{\mathbf{I}}=\left(\mathbf{x}_{11}\right.$, X2I, $\mathbf{x 3 I}$ ), e uil a componente i de deslocamento no nó I.

Os campos de velocidade e aceleração são:

$$
\begin{aligned}
& v_{i}\left(x_{p}\right)=\sum_{I=1}^{n_{n}} N_{I}\left(x_{p}\right) v_{i I} \\
& a_{i}\left(x_{p}\right)=\sum_{I=1}^{n_{n}} N_{I}\left(x_{p}\right) a_{i I}
\end{aligned}
$$

Usando o método de Bubnov-Galerkin, o campo de deslocamento virtual é aproximadamente:

$$
\frac{d \delta u_{i}}{d x_{j}}=\sum_{I=1}^{n_{n}}\left(\frac{d N_{I}}{d x_{j}}\right) \cdot \delta u_{i}
$$

Substituindo em (3.3) e sabendo que $\delta u_{i}$ é arbitrário, podemos considerá-lo unitário. Com isso, teremos:

$$
\begin{gathered}
\sum_{p=1}^{n_{p}} M_{p} N_{I}\left(x_{p}\right) \sum_{J=1}^{n_{n}}\left(N_{J}\left(x_{p}\right) a_{i J}\right)-\sum_{p=1}^{n_{p}} M_{p} \frac{d N_{I}}{d x_{j}} \sigma_{i j}^{B}\left(x_{p}\right) \\
=\sum_{p=1}^{n_{p}} M_{p} N_{I}\left(x_{p}\right) b_{i}\left(x_{p}\right)+\sum_{p=1}^{n_{p}} M_{p} N_{I}\left(x_{p}\right) t_{i}\left(x_{p}\right)
\end{gathered}
$$


3.

Na sua forma compactada, tal fórmula é dada por:

$$
m_{I J} a_{I}=f_{I}^{e x t}+f_{I}^{i n t}
$$

sendo,

$\mathbf{m}_{\mathrm{IJ}}=$ matriz de massa consistente

$\mathbf{f}_{\mathbf{I}}{ }^{\text {ext }}, \mathbf{f}_{\mathbf{I}}{ }^{\text {int }}=$ vetor de forças internas e externas

onde:

$$
m_{I J}=\sum_{p=1}^{n_{p}} M_{p} N_{I}\left(x_{p}\right) N_{J}\left(x_{p}\right)
$$

Note que a matriz de massa não é constante, mas muda no tempo porque os pontos materiais movem enquanto o grid é fixo. A integração explícita é usualmente aplicada em MPM com o uso da matriz de massa diagonal agrupada, sendo ela a matriz de soma em linha padrão, na qual os termos da diagonal são dados por:

$$
m_{I}=\sum_{I=1}^{n_{n}} m_{I J}=\sum_{J=1}^{n_{n}} \sum_{p=1}^{n_{p}} M_{p} N_{I}\left(x_{p}\right) N_{J}\left(x_{p}\right)
$$

Sabendo que o somatório das funções de forma é igual a um:

$$
m_{I}=\sum_{p=1}^{n_{p}} M_{p} N_{I}\left(x_{p}\right)
$$

O vetor de forças externas é dado por:

$$
\boldsymbol{f}_{I}^{e x t}=\sum_{p=1}^{n_{p}} M_{p} N_{I}\left(x_{p}\right) b_{i}\left(x_{p}\right)+\sum_{p=1}^{n_{p}} M_{p} N_{I}\left(x_{p}\right) t_{i}\left(x_{p}\right)
$$

O vetor de forças internas: 
3.

$$
\boldsymbol{f}_{I}^{\text {int }}=-\sum_{p=1}^{n_{p}} \frac{M_{p}}{\rho_{p}} \sigma \frac{d N_{I}}{d x_{j}}=-\sum_{p=1}^{n_{p}} V_{p} \cdot \sigma \cdot \nabla N_{I}
$$

Onde $\nabla \mathbf{N}_{\mathrm{I}}=\left(\frac{\mathbf{d N}_{\mathrm{I}}}{\mathbf{d x}_{\mathbf{1}}}, \frac{\mathbf{d N}_{\mathrm{I}}}{\mathbf{d x}_{\mathbf{2}}}, \frac{\mathbf{d N}_{\mathrm{I}}}{\mathbf{d x}_{3}}\right)^{T}$ indica o gradiente da função de forma.

É importante notar que $\boldsymbol{\sigma}$, em 3D é uma matriz $3 \times 3$.

Considerando conhecidas as forças que atuam no corpo e a massa considerada, resolve-se equação (3.10) para encontrar as acelerações nodais e velocidades que são mapeadas para os pontos materiais. Com a velocidade do ponto material, calcula-se as posições no tempo seguinte.

\section{4}

\section{Integração explícita no tempo}

De posse da equação (3.10), quando considerada a soma das forças no tempo e multiplicada por $\Delta \mathbf{t}$, tem-se:

$$
m_{I J}\left(v_{I}^{t+\Delta t}-v_{I}^{t}\right)=f_{I}^{t} \Delta t
$$

Pode-se calcular o momentum nodal atualizado $(\mathbf{m v})_{\mathbf{I}^{+}}^{\mathbf{t} \Delta \mathbf{t}}$. As condições de contorno já devem ter sido aplicadas antes dessa fase de cálculo.

A velocidade e posição das partículas são atualizadas por:

$$
\begin{gathered}
v_{p}^{t+\Delta t}=v_{p}^{t}+\Delta t \sum_{I} N_{I}\left(x_{p}\right) f_{I}^{t} / m_{I}^{t} \\
x_{p}^{t+\Delta t}=x_{p}^{t}+\Delta t \sum_{I} N_{I}\left(x_{p}\right)(m v)_{I}^{t+\Delta t} / m_{I}^{t}
\end{gathered}
$$

Nessa formulação, o momentum é usado ao invés da velocidade tanto quanto possível, evitando divisões por potenciais massas nodais muito pequenas. Como a velocidade é um valor único, a interpenetração do material é impedida. Deve-se enfatizar que essa é uma formulação lagrangiana atualizada, já que os nós do grid se movem para novas posições $\mathbf{x}_{\mathbf{I}}{ }^{\mathbf{t}+\Delta \mathbf{t}}=\mathbf{v}_{\mathbf{I}}{ }^{\mathbf{t}}+\Delta \mathbf{t}_{\mathbf{t}} \mathbf{v}_{\mathbf{I}}{ }^{\mathbf{t}+\Delta \mathbf{t}}$. No entanto, eles não são explicitamente movidos, visto que serão descartados de qualquer forma. 
3.

Depois disso, é preciso computar o gradiente das velocidades das partículas usando velocidades nodais $\mathbf{v}_{\mathbf{I}}{ }^{\mathbf{t}+\Delta \mathbf{t}}$. Pode-se mapear a velocidade da partícula através das velocidades nodais, conforme:

$$
(m v)_{I}^{t+\Delta t}=\sum_{p} N_{I}\left(x_{p}\right)(M v)_{p}^{t+\Delta t}
$$

Por isso:

$$
\boldsymbol{v}_{I}^{t+\Delta t}=\frac{(m v)_{I}^{t+\Delta t}}{m_{I}^{t}}=\frac{\sum_{p} N_{I}\left(x_{p}\right)(M v)_{p}^{t+\Delta t}}{\sum_{p} N_{I}\left(x_{p}\right) M_{p}}
$$

O gradiente de velocidade da partícula é computado mediante o gradiente das funções de interpolação na posição de cada partícula.

$$
L_{p}^{t+\Delta t} \equiv \nabla v_{p}^{t+\Delta t}=\sum_{I} \nabla N_{I}\left(x_{p}\right) v_{I}^{t+\Delta t}
$$

O cálculo das forças internas na eq. (3.15) requer o tensor de tensões atualizado no tempo atual.

$$
\sigma_{p}^{t+\Delta t}=\sigma_{p}^{t}+\Delta \sigma_{p}
$$

Onde o incremento de tensão da partícula $\Delta \boldsymbol{\sigma}_{\mathbf{p}}$ é obtido utilizando o incremento de deformação da partícula.

$$
\Delta e=\frac{1}{2}\left(\nabla N_{I} \cdot v_{I}^{t+\Delta t}+\left(\nabla N_{I} \cdot v_{I}^{t+\Delta t}\right)^{T}\right) \cdot \Delta t
$$

É necessária também uma relação constitutiva incremental objetiva, em que a resposta do material não dependa da estrutura de referência. $O$ tensor de tensões de Cauchy não é objetivo, se considerarmos um objeto girando e as tensões aplicadas em um eixo, nenhuma deformação foi imposta e o tensor de tensões muda conforme o as tensões giram. O tensor de tensões de Jaumann ou taxa de Jaumann 
3.

considera um tensor co-rotacional de Cauchy e é usado para garantir que toda variação no tensor de tensões seja dada por uma variação de deformações (Zhang et al., 2017).

O código utilizado para modelagem nesse trabalho foi o MPM-PUCRio que está em contínuo desenvolvimento pelo Grupo de GeoAnlise, do departamento de Engenharia Civil da Pontifícia Universidade Católica do Rio de Janeiro. A teoria apresentada até então é uma simplificação das etapas de cálculo efetuadas no programa. Além do modelo constitutivo de Drucker-Prager, outros materiais podem ser modelados, com diferentes estruturas e geometrias.

\section{5}

\section{Critério de Drucker-Prager}

Drucker e Prager (1952) admitiram que uma função de plasticidade pode ser generalizada por:

$$
f=\alpha J_{1}+J_{2}^{1 / 2}=k
$$

Sendo $\alpha$ e k parâmetros que podem ser determinados experimentalmente ou descritos pelos parâmetros c e $\boldsymbol{\varphi}$ do modelo de Mohr-Coulomb, igualando as superfícies de ruptura, e $\mathbf{J}_{1}$ e $\mathbf{J}_{2}$ o primeiro e o segundo invariantes de tensões. O modelo de Drucker-Prager descreve um cone ou círculo no plano $\pi$, conforme a Figura 6, e pode ser aproximado ao hexágono irregular que forma o critério de Mohr-Coulomb, segundo as fórmulas:

$$
\alpha=\frac{6 \operatorname{sen} \varphi}{\sqrt{3}(3 \pm \operatorname{sen} \varphi)} \quad k=\frac{6 c \cos \varphi}{\sqrt{3}(3 \pm \operatorname{sen} \varphi)}
$$

Os sinais de positivo e negativo se devem ao círculo que se quer aproximar: os sinais de mais se referem ao círculo interno e os sinais de menos, ao círculo externo. 
3.

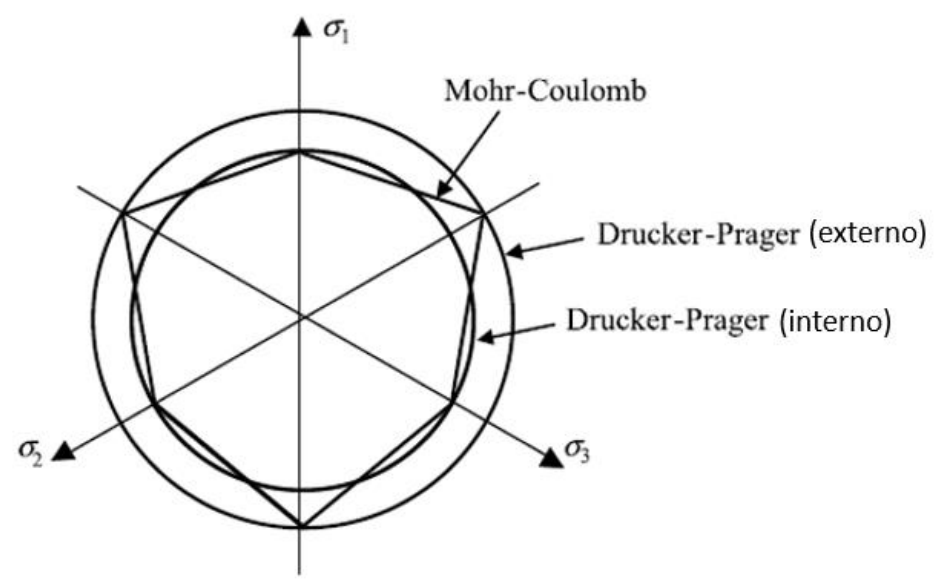

Figura 6 - Superfícies de ruptura de Mohr-Coulomb e Drucker-Prager, Modificado de Zhang et. al (2017)

Um terceiro círculo, que está localizado a uma distância intermediária das superfícies de ruptura no plano $\pi$ descritas, pode ser ajustado, gerando os seguintes coeficientes:

$$
\alpha=\frac{3 \tan \varphi}{\sqrt{9+12 \tan ^{2} \varphi}} \quad k=\frac{3 c}{\sqrt{9+12 \tan ^{2} \varphi}}
$$

Com o objetivo de incorporar o efeito da poropressão na análise, a superfície de ruptura do modelo constitutivo é modificada como segue:

$$
f=\alpha\left(J_{1}-3 u_{w}\right)+J_{2}^{1 / 2}=k
$$

Onde $\mathbf{u}_{w}$ é a pressão da água nos poros do solo.

\section{6}

\section{Fator de redução}

O fator de segurança é o método mais usado para quantificar estabilidade em engenharia civil e geotecnia. Esse fator geralmente é calculado como tensão ou forças resistentes divididas por tensões ou forças atuantes. Em métodos numéricos, é frequentemente representado como um fator de redução dos parâmetros de resistência até que o material esteja na iminência de ruptura.

Considerando o critério de ruptura de Mohr-Coulomb, os parâmetros de resistência reduzidos são: 
3.

$$
\begin{gathered}
c_{r}=\frac{c}{F R} \\
\operatorname{tg} \varphi_{r}=\frac{\operatorname{tg} \varphi}{F R}
\end{gathered}
$$

Para o Método dos Elementos Finitos, o fator de redução que corresponde ao fator de segurança é encontrado quando a solução não converge, indicando que não há equilíbrio. Como o Método do Ponto Material calcula grandes deformações e consegue acompanhar a trajetória das partículas mesmo após a ruptura, o fator de redução que corresponde ao fator de segurança deve ser interpretado de acordo com as deformações evidenciadas. Quando o material apresenta grandes deformações, caracterizando uma mudança de comportamento, tem-se evidenciada a ruptura. Então, o fator de segurança é o valor do fator de redução que indicaria onde ainda não há ruptura, ou onde haja iminência de ruptura.

\section{7 \\ Força de impacto}

Como descrito no capítulo 2, novas implementações têm sido responsáveis por melhoria nos cálculos e modelagem em MPM, sendo o algoritmo de contato desenvolvido por Bardenhagen et al (2000) uma delas. O contato entre dois corpos é caracterizado com maior precisão e descreve forças normais e tangenciais. No entanto, o código usado neste trabalho não apresenta a implementação do algoritmo de contato. Porém o MPM reconhece o contato naturalmente na sua estrutura e o desenvolvimento de deformações no corpo é capaz de calcular as forças considerando a lei de Hooke (1678).

$$
F=-k \cdot x
$$

Ele descreve o comportamento elástico em uma direção, na qual o deslocamento de um corpo é proporcional à força aplicada, sendo ele dependente do material, então chamamos $\mathbf{k}$ de constante elástica. É comum descrever essa equação em função de tensões e deformação e considerar a constante elástica como módulo de elasticidade. 
3.

$$
\sigma=E . \varepsilon
$$

Em mais de uma direção a equação (3.31) é formada por matrizes, e o módulo de elasticidade pode variar para cada direção. Para que seja mais fácil calcular a força de impacto, indica-se a estruturação de um objeto simples. Por isso, é especificado um objeto elástico e uniforme.

Considerando que o MPM calcula a deformação nos pontos materiais, podese calcular a tensão e, então, a força, que, por definição, é:

$$
F=\sigma \cdot A
$$

A força descrita pela equação (3.32) considera compressão simples. Sendo assim, serão tomadas precauções no modelo para que não haja flexão do corpo em que se deseja calcular a força. 


\section{4. \\ Resultados e Discussão}

\section{1}

\section{Talude infinito 2D}

A geometria de um talude infinito e o cálculo do fator de segurança usando o método do equilíbrio limite de Lambe e Whitman (1969) é largamente conhecida no meio geotécnico. Outros métodos, que garantem maior precisão, têm sido investigados para avaliação de ruptura.

O MPM assim como o FEM pode ser usado para cálculo do fator de segurança de acordo com a variação do fator de redução definido no tópico 3.6. Esse método não é o mais eficiente devido ao tempo de processamento que este necessita. $\mathrm{O}$ cálculo do fator de segurança nesse presente trabalho visa apenas validar o cálculo utilizando este método.

Considerando um talude infinito, conforme proposto por Camargo (2015), como se pode observar na Figura 7 para efeito de comparação, com parâmetros de resistência em termos de tensão efetiva e peso específico único para solo saturado e não saturado, observa-se que a diferença de volume de água entre saturação e não saturação é pequena (visto que o solo pode estar não saturado com alto de grau de saturação), conforme a Tabela 2. Camargo utiliza o método da análise limite, mais eficiente nesse caso devido à velocidade do seu processamento.

Para modelagem em MPM embaixo do talude foi disposta uma rocha caracterizada com alta resistência e rigidez, sendo ela necessária porque nesse código do MPM o volume de controle deve ser retangular. A base da rocha e todos os nós no limite do volume considerado são, então, fixados. O modelo apresenta 15486 pontos materiais sendo metade de solo e a outra metade simula a rocha na base. 
4.

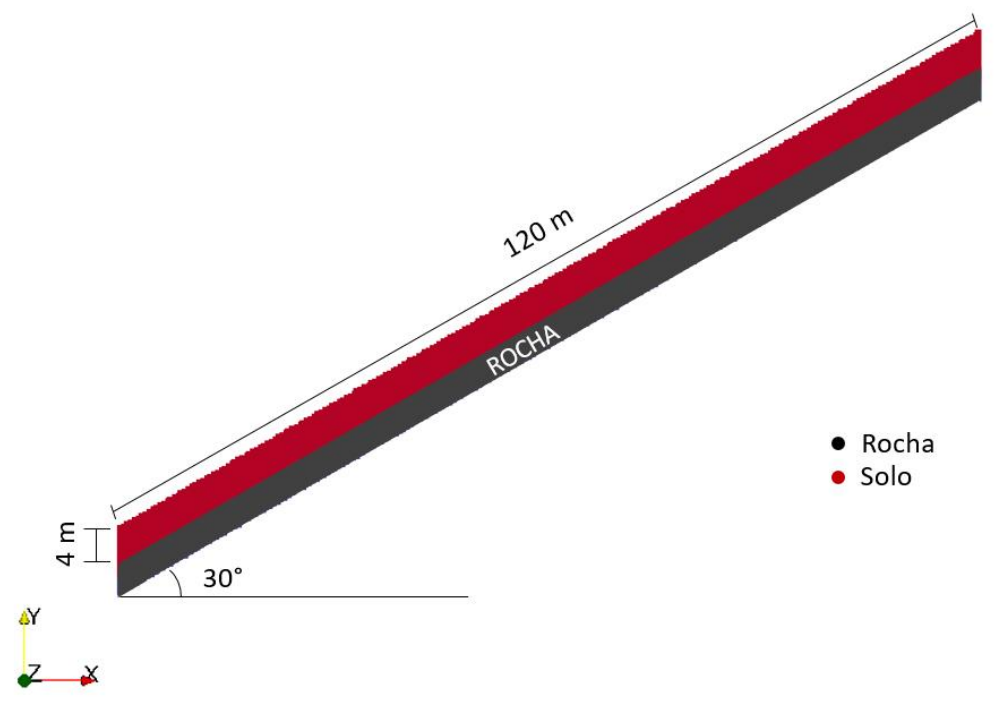

Figura 7 - Talude infinito considerado

Tabela 2 - Parâmetros do Solo

\begin{tabular}{|c|c|c|}
\hline Coesão & Ângulo de atrito & Peso Específico \\
\hline$c^{\prime}=5 \mathrm{kPa}$ & $\varphi^{\prime}=23,5^{\circ}$ & $\gamma=18 \mathrm{kN} / \mathrm{m}^{3}$ \\
\hline
\end{tabular}

Serão analisados quatro cenários para o cálculo do fator de segurança considerando as circunstâncias nas quais o talude pode estar inserido. No primeiro cenário, conforme visto na Figura 8, não há chuva e o talude encontra-se não saturado, é simulado um aumento da coesão aparente devido à sucção de um talude com umidade natural. Essa sucção é considerada 4 kPa nos casos em que não houve saturação.

O segundo cenário, Figura 9, apresenta a metade superior do talude saturada, tendo em vista o início da chuva, momento no qual a água infiltra e satura a superfície do solo. Neste cenário, a parte inferior é tratada como não saturada, ou seja, inclui coesão aparente de $4 \mathrm{kPa}$ e a parte superior saturada sofre decréscimo de resistência devido ao efeito de poropressão como indicado pela equação 3.27.

No terceiro cenário, de acordo com o exposto na Figura 10, a continuidade da chuva gera saturação em toda profundidade do talude. Por fim, o quarto cenário, apresentado na Figura 11, simula a situação após o fim da chuva em que a água escoa e o talude volta a se tornar parcialmente saturado. Ou seja, apresenta arranjo contrário do segundo cenário. As figuras apresentam os casos considerados, com a variação de poropressão nos pontos materiais. As poropressões foram impostas nos pontos materiais como dado de entrada e não variam com o tempo ou posição da 
4.

partícula, essa simplificação só pode ser usada quando a posição relativa da partícula não varia excessivamente.

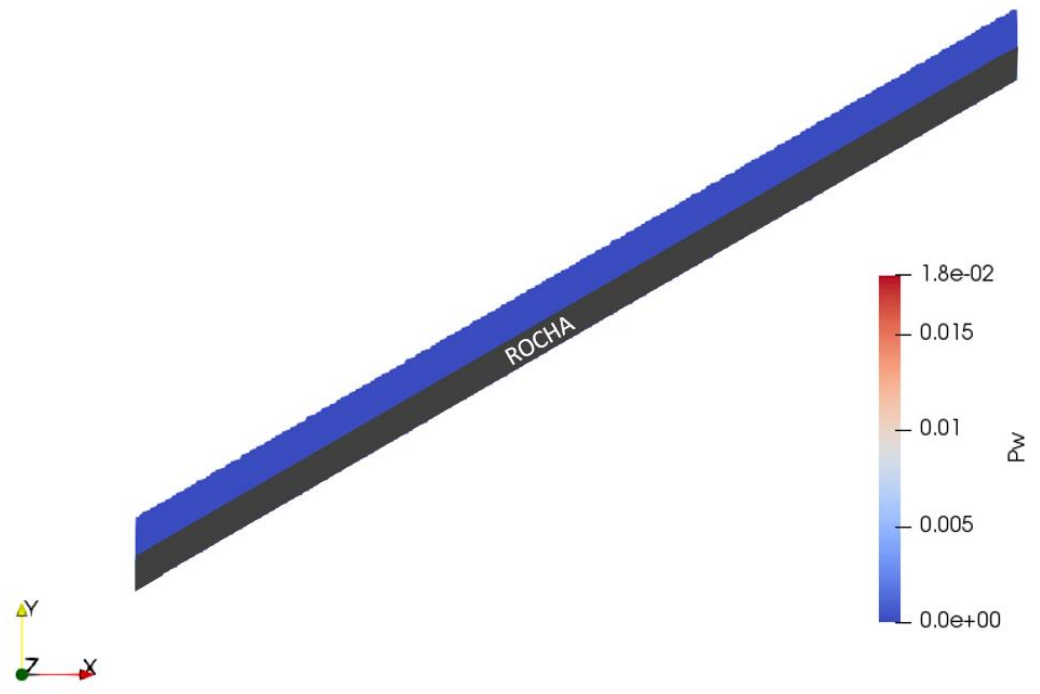

Figura 8 - Talude infinito não saturado

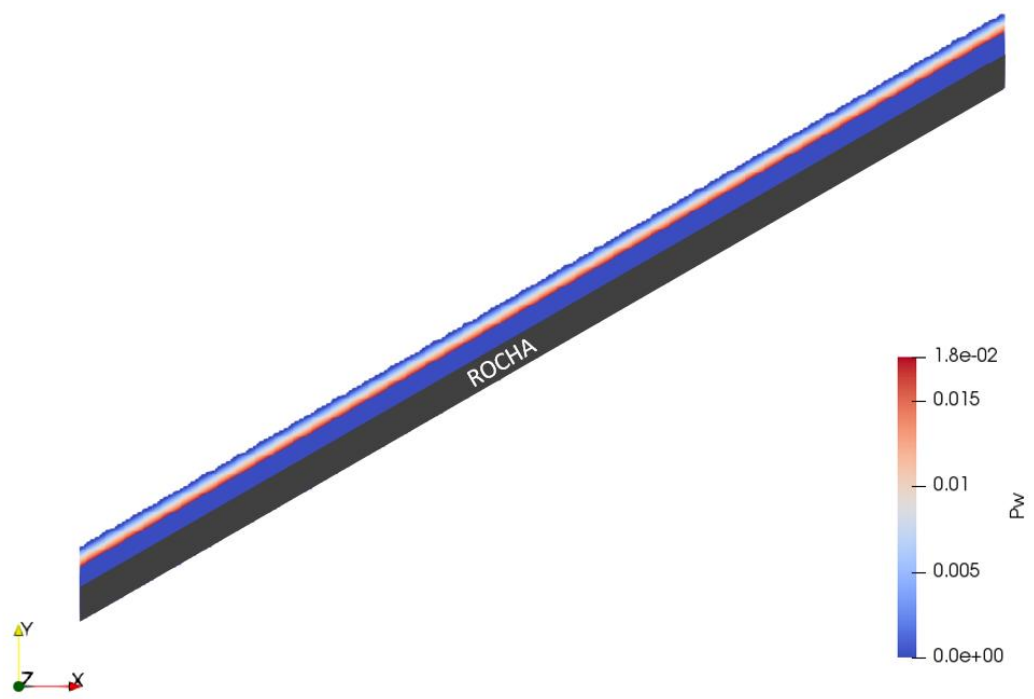

Figura 9 - Talude infinito metade superior saturada 
4.

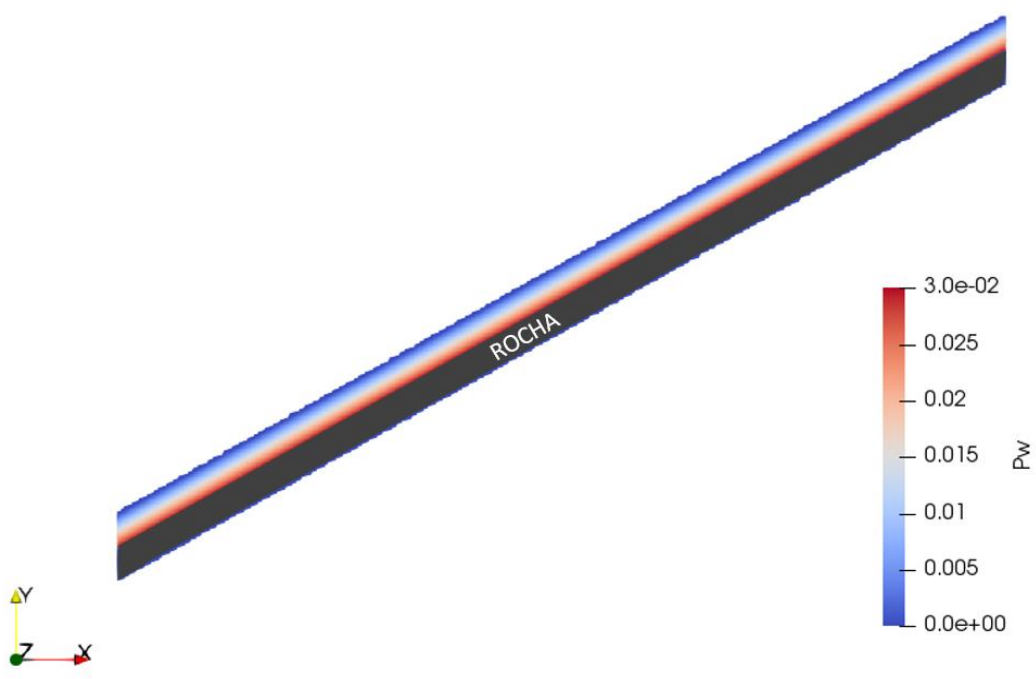

Figura 10 - Talude infinito todo saturado

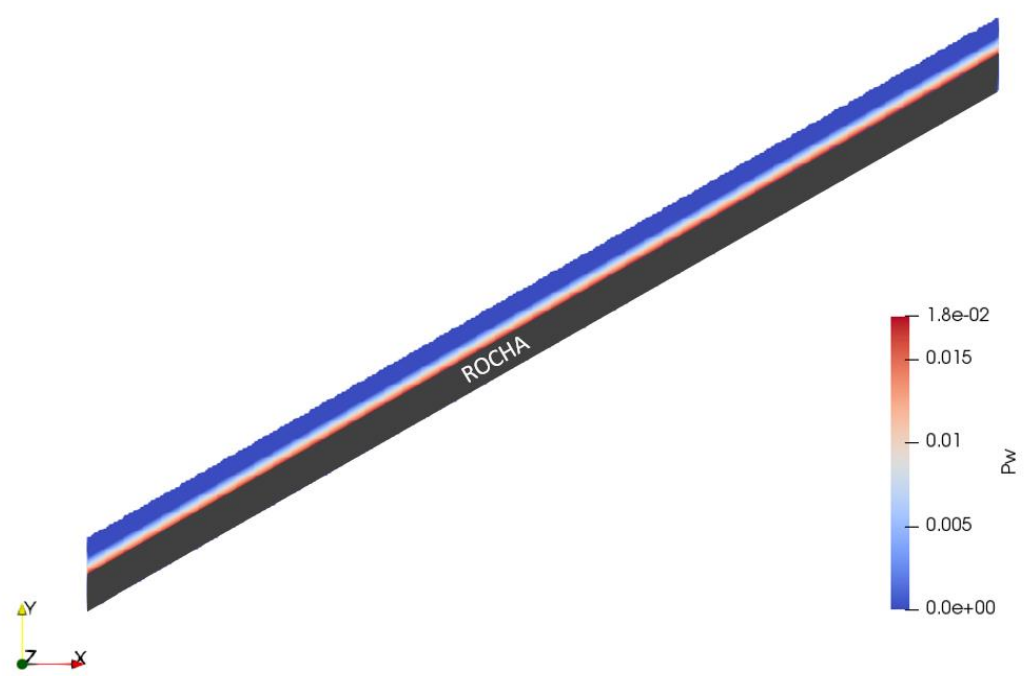

Figura 11 - Talude infinito metade inferior saturada

Ao calcular as deformações para diferentes fatores de redução pode-se calcular o fator de segurança. Os gráficos "Deformação x SRF" e "Taxa de Deformação x SRF" são apresentados na Figura 12, na qual a deformação está normalizada a fim de apresentar valores adimensionais (Griffiths; Marquez, 2007).

$$
\delta^{\prime}=\frac{\delta_{M A X} E}{\gamma H^{2}}
$$

Onde:

$\delta^{\prime}$ : deformação normalizada

$\delta$ : deformação

E: módulo de elasticidade

$\gamma$ : peso específico

H: altura da camada de solo 
4.

A taxa de deformação é definida como a variação da deformação entre um fator de redução e o anterior. Dessa forma pode-se visualizar com ainda mais clareza onde houve maior variação.

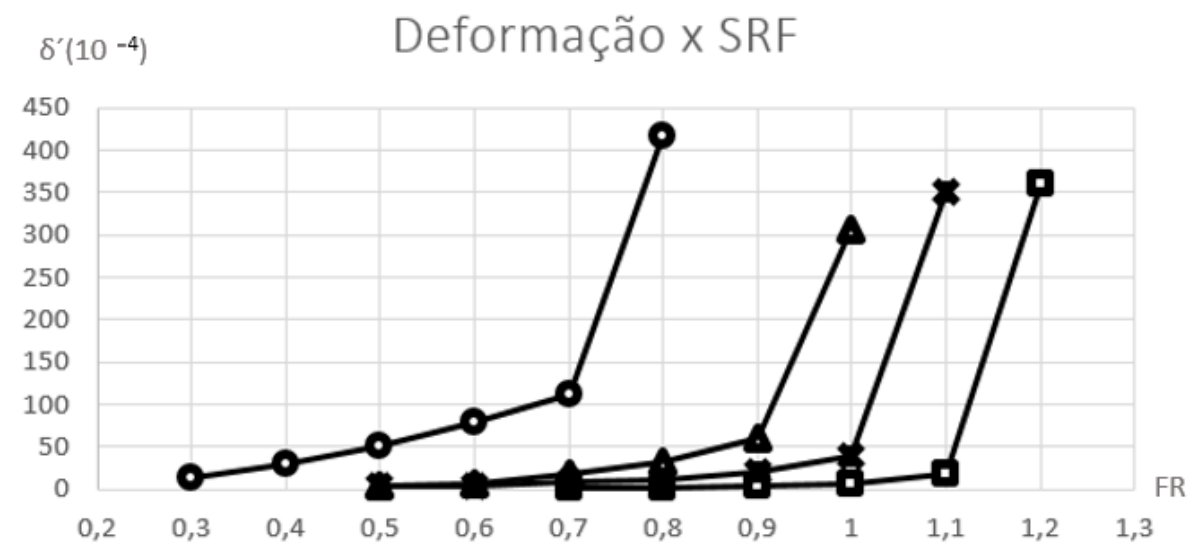

\section{$\left(\delta^{\prime}-\varepsilon_{i=1}^{\prime}\right) \quad$ Taxa de Deformação x SRF \\ $\left(\mathrm{FR}_{\mathrm{i}}-\mathrm{FR}_{\mathrm{i}-1}\right)$}

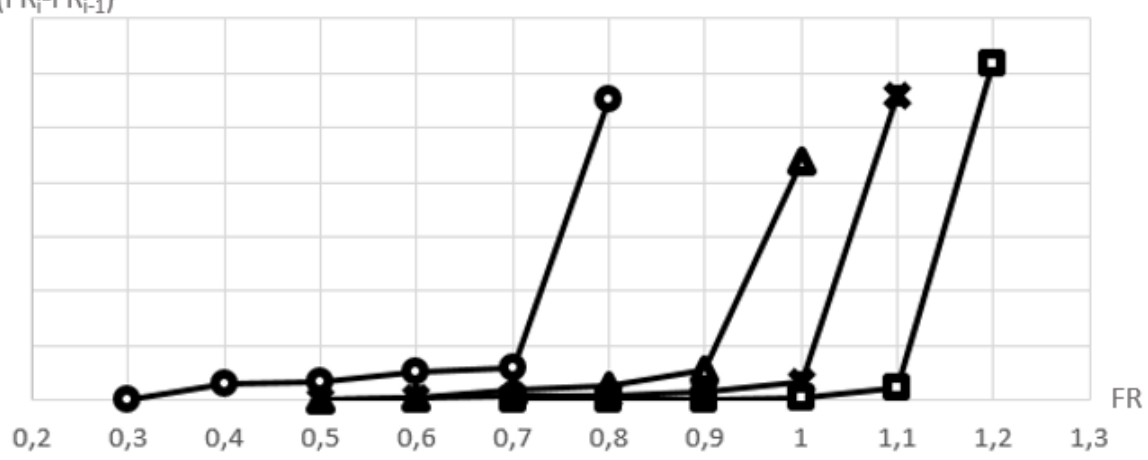

- Não Saturado

Figura 12 - Gráficos de Deformação e Taxa de Deformação pelo fator de redução

O fator de segurança é, então, definido, apontando o local de mudança no comportamento do material. Esse passo requer interpretação do autor, por isso pode ser considerado subjetivo. Cada caso deverá contar com uma análise específica e crítica do que será considerado como mudança de comportamento.

A Figura 13 apresenta os fatores de segurança encontrados e comparados àqueles calculados por Camargo (2015), com equilíbrio limite e análise limite. A avaliação pelo MPM indica fatores de segurança maiores que pelos métodos do equilíbrio limite e análise limite. Isso pode ser coerente considerando os seguintes aspectos. O método do equilíbrio limite, por ser mais simples em sua formulação, faz-se mais conservador e resulta fatores de segurança mais baixos. Além disso, os métodos numéricos, por utilizarem malha, apresentam resultados que têm grande 
4.

relação com o espaçamento da malha. Os valores elevados do fator de segurança estão relacionados à uma aproximação rígida da malha. O refinamento da malha torna o procedimento mais demorado e, por consequência, inviável. Como já explicitado, o MPM não é o recurso mais indicado para cálculo do fator de segurança devido à demanda computacional.

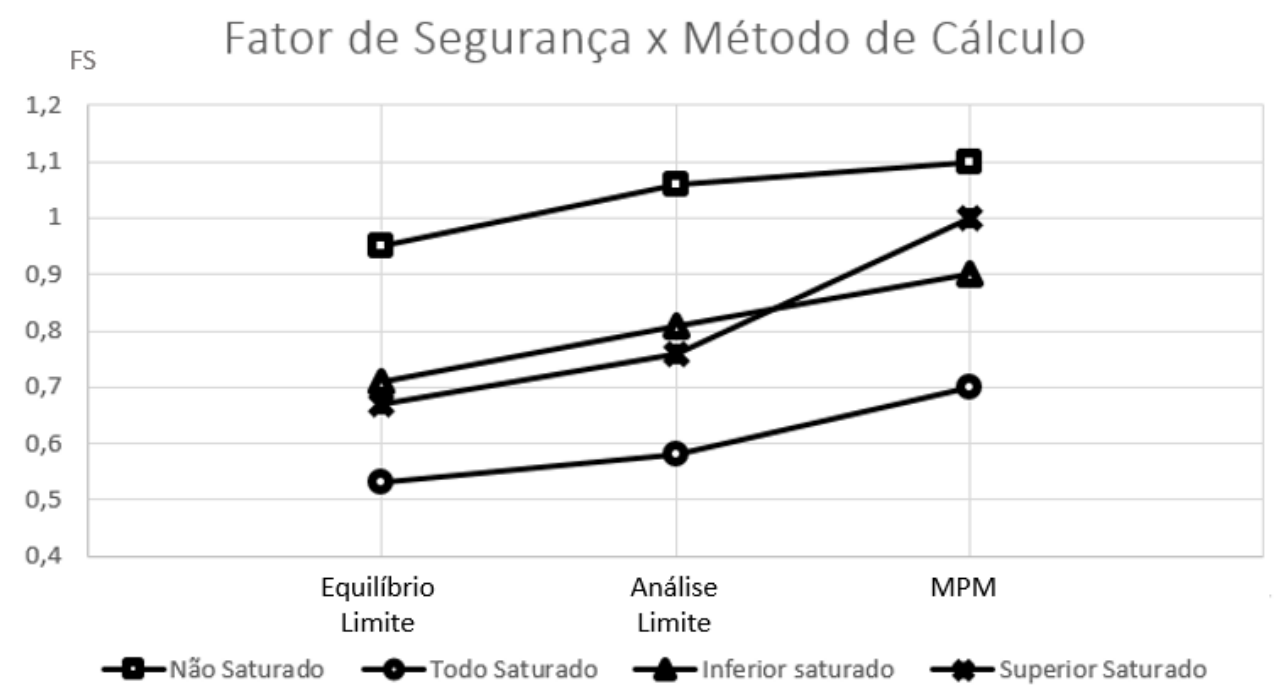

Figura 13 - Gráfico comparativo entre os Fatores de segurança

Pelos dados de deslocamento, é possível encontrar a superfície de ruptura no talude. A Figura 14 apresenta a parte central do talude, lembrando que a premissa de talude infinito deve desconsiderar as influências e os efeitos das bordas. A escala de cores indica onde ocorreram deformações plásticas, ou seja, local onde houve ruptura do talude. Como esperado, o solo rompe na parte inferior do talude quando não há saturação (14a), devido às tensões efetivas mais altas, e também quando há saturação na parte inferior (14d) e em todo o talude (14c), tanto pelas tensões efetivas quanto redução na resistência devido ao aumento da poropressão. Quando a saturação está presente apenas na parte superior (10b), a superfície de ruptura sobe, acontecendo principalmente na parte saturada. Apesar da tensão efetiva ser maior na base, a saturação diminui a coesão aparente imposta pela sucção e há redução da resistência quando há saturação pelo modelo constitutivo empregado.

Pode-se observar deformações em uma pequena parcela da faixa não saturada em 14(b), isso acontece devido ao método de cálculo de deslocamento dos nos que garante a continuidade do material, como no Método dos Elementos Finitos. Esse comportamento não é observado na rocha porque esse material foi definido como elástico, e não apresenta deformações plásticas. A implementação de um algoritmo 
4.

de contato é capaz de ajustar melhor as diferenças de deslocamentos e tensões nos contatos entre dois materiais, diferenciando tensões normais e cisalhantes.
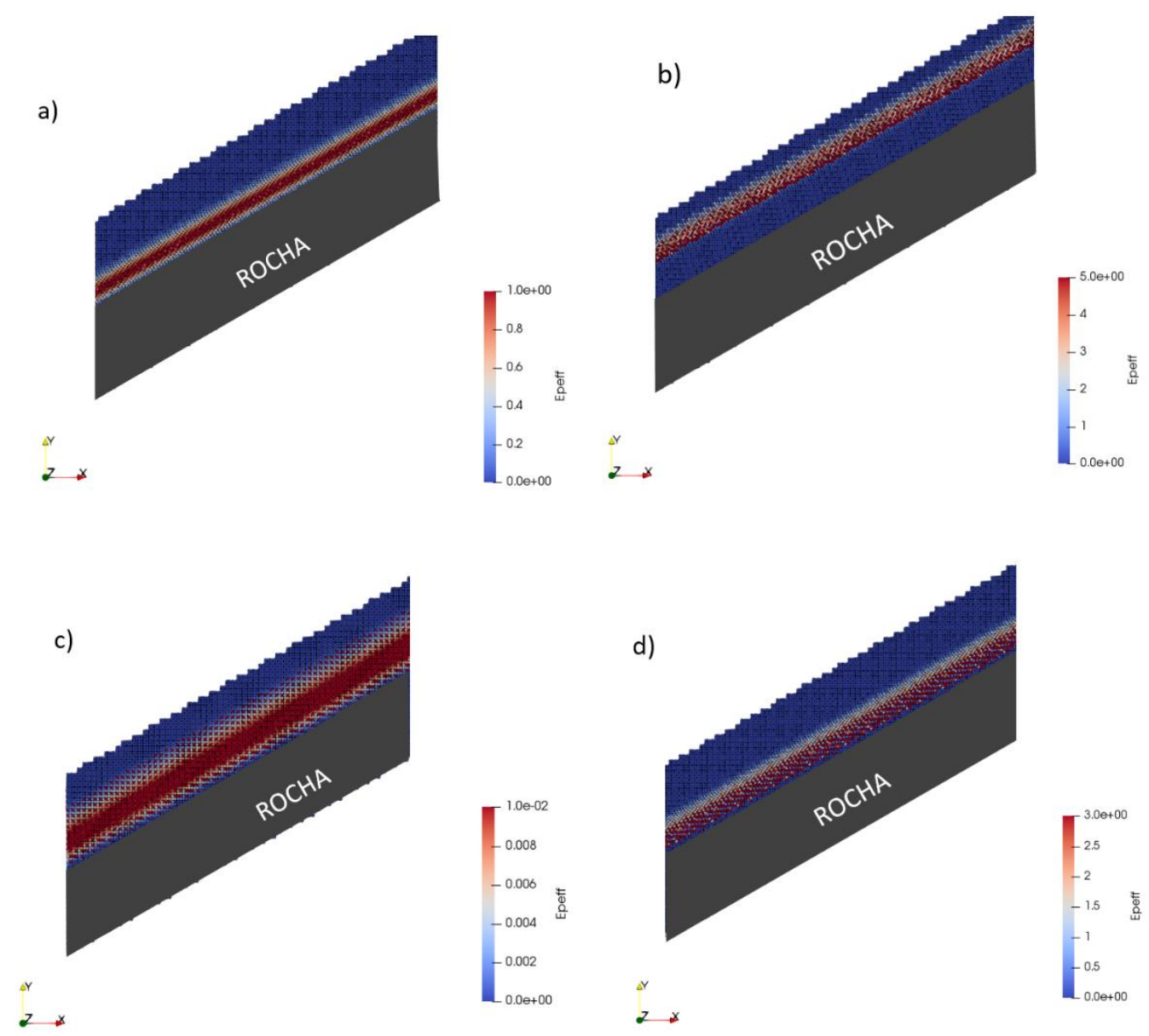

Figura 14 - Deformações plásticas talude (a) não saturado, (b) superior saturado, (c) todo saturado e (d) inferior saturado

\section{2}

\section{Bloco em queda livre}

Para avaliação da força de impacto pelo MPM foi criado um modelo de dois blocos em 2D com um exemplo de queda livre, para que se possa avaliar os resultados de um caso simples do qual se conheça as premissas. A Figura 15 apresenta dois blocos, sendo o bloco inferior é impactado funcionando como célula de carga na qual são mensuradas deformações. A Tabela 3 apresenta as especificações de cada um dos blocos com propriedades genéricas para análise. 
4.

Figura 15 - Bloco superior em queda livre e bloco inferior atuando como célula de carga Tabela 3 - Especificações dos blocos

\begin{tabular}{|l|l|l|}
\hline Propriedades & Bloco em queda livre & Bloco impactado \\
\hline Grid $(\mathrm{m})$ & 0,2 & 0,2 \\
\hline Altura $(\mathrm{m})$ & 3,0 & 0,0 \\
\hline Dimensões $(\mathrm{m})$ & $1 \times 1$ & $1 \times 1$ \\
\hline Massa específica $\left(\mathrm{kg} / \mathrm{m}^{2}\right)$ & $1.000,0$ & 100,0 \\
\hline Módulo de Elasticidade $(\mathrm{MPa})$ & 100,0 & 100,0 \\
\hline Coeficiente de Poisson & 0,25 & 0,25 \\
\hline
\end{tabular}

A massa do bloco impactado é definida como dez vezes menor que o outro para que as deformações relativas ao peso próprio sejam muito pequenas e não influenciem no cálculo da força e peso do bloco em queda livre. Sabe-se que o peso do bloco é 9,8 kN; então, após o impacto, espera-se que a força calculada seja de $9,8 \mathrm{kN}$.

Para interpretação dos resultados serão avaliadas as condições de variação dos seguintes parâmetros: discretização da malha, altura do bloco em queda livre e geometria do bloco impactado. 
4.

\subsubsection{Discretização da malha}

Para a primeira condição foram impostas discretização de 1,0 m, 0,5 m, 0,2 m e $0,1 \mathrm{~m}$. Dentro de cada célula são incluídos quatro pontos materiais dispostos uniformemente, no primeiro caso, cada bloco tem apenas uma célula, no segundo caso, cada bloco tem quatro células, e assim por diante. A Figura 16 evidencia como ficam representados os modelos de acordo com sua discretização.
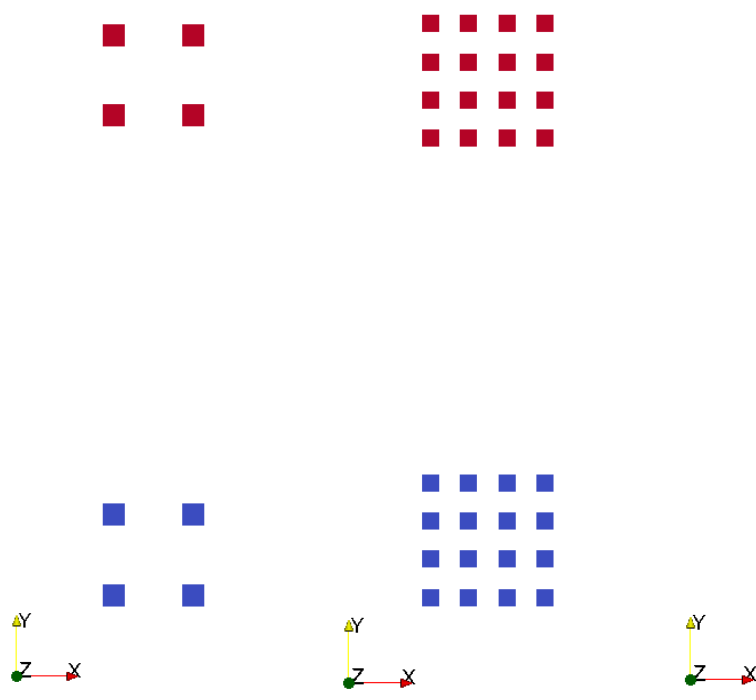
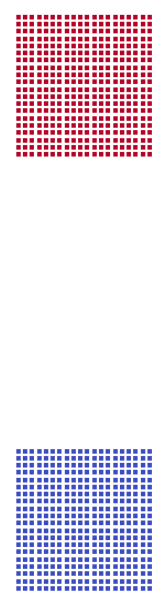

$\Delta$

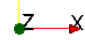

Figura 16 - Apresentação da discretização para primeira análise, da esquerda para direita: $1,0 \mathrm{~m}, 0,5 \mathrm{~m}, 0,2 \mathrm{~m}$ e $0,1 \mathrm{~m}$

Sabe-se que para modelo contínuo quanto maior a discretização, mais liberdade a malha tem para se movimentar. Como o cálculo da força depende diretamente da deformação, esse dado é crucial para uma representação realista da força de impacto. A Figura 17 apresenta as forças calculadas no tempo. 
a.
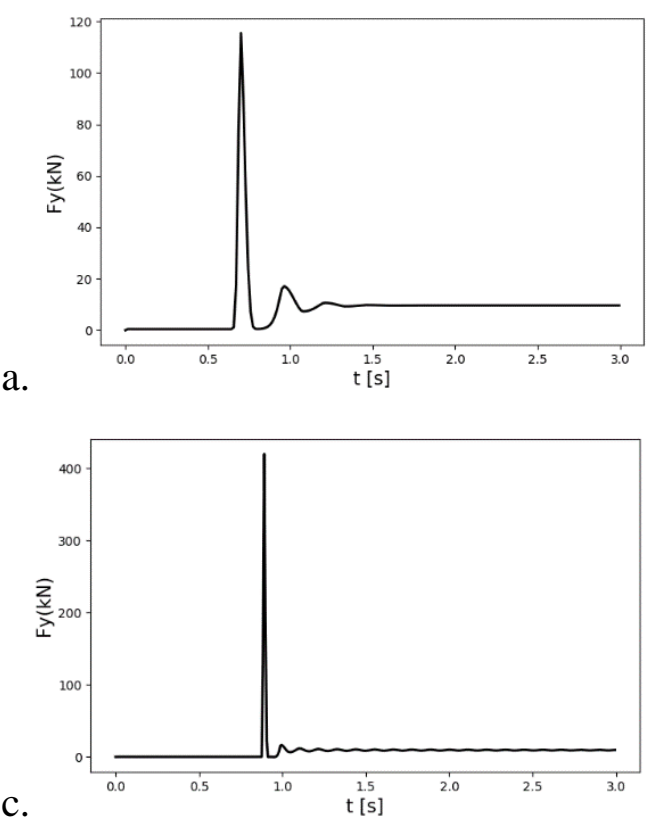

b.

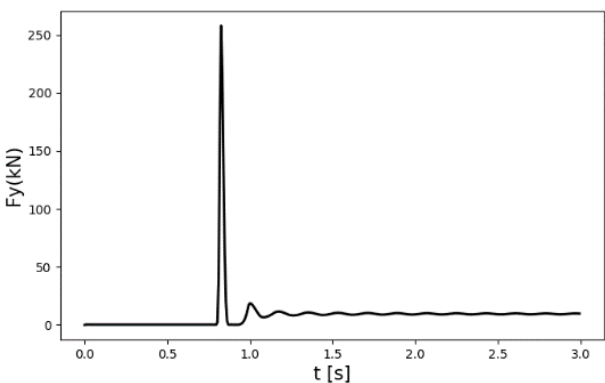

d.

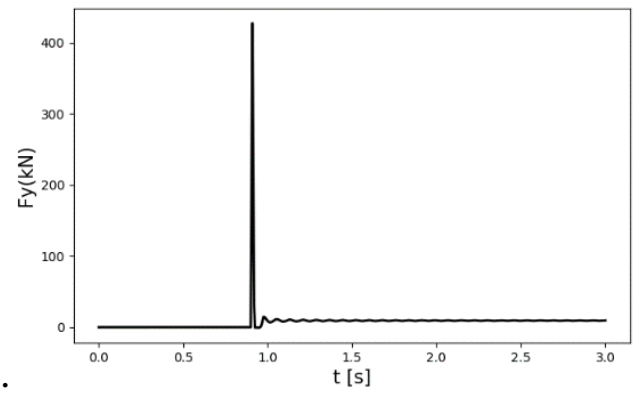

Figura 17 - Força no tempo para bloco caindo em queda livre variando a discretização da malha: a. $1,0 \mathrm{~m}$ b. $0,5 \mathrm{~m}$ c. $0,2 \mathrm{~m}$ e d. $0,1 \mathrm{~m}$

Analisando os gráficos, percebe-se que quando há estabilidade todos os casos tendem para, aproximadamente, $10 \mathrm{kN}$, o que confirma a medida do peso do bloco superior esperado. Já a força devido ao peso próprio do bloco usado como célula de carga, próximo a $1 \mathrm{kN}$, aparece imperceptível devido à grandeza das demais medidas. A força de impacto que se deseja calcular, contudo, varia largamente. A Figura 18 apresenta o gráfico das forças de pico pelo inverso do espaçamento da malha.

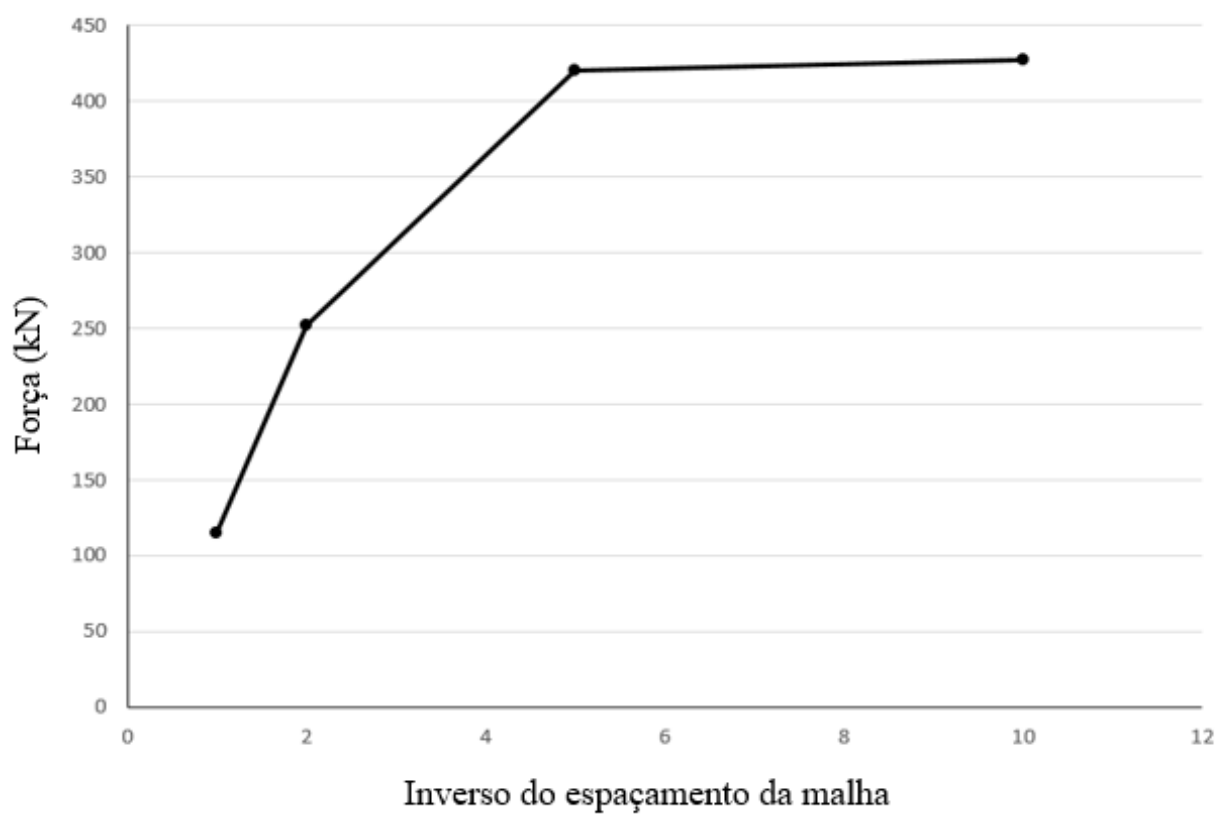

Figura 18 - Gráfico da força de impacto x Inverso do espaçamento da malha 
4.

Pode-se inferir, pelo gráfico que uma pequena discretização reduz a capacidade de deslocamento dos nós e, por isso, gera uma menor força. Quando se aumenta a discretização, os resultados tendem para uma assíntota que apresenta o resultado do problema.

Quanto menor o espaçamento da malha, ou seja, quanto maior o número de nós e pontos materiais, maior será o custo computacional modelo. Tendo em vista a ordem de grandeza necessária para o resultado de cada caso, deve-se escolher a escala adequada. Nesse exemplo, continuar-se-á os testes com o espaçamento 0,2 $\mathrm{m}$, considerando esses resultados adequados e visando aceleração do processo de cálculo.

\subsubsection{Altura do bloco em queda livre}

No segundo caso, foram impostas diferentes alturas para verificar o tempo de queda de cada bloco, o aumento da velocidade e, consequentemente, o aumento do impacto no bloco inferior. A Figura 19 apresenta a disposição dos blocos em queda livre.
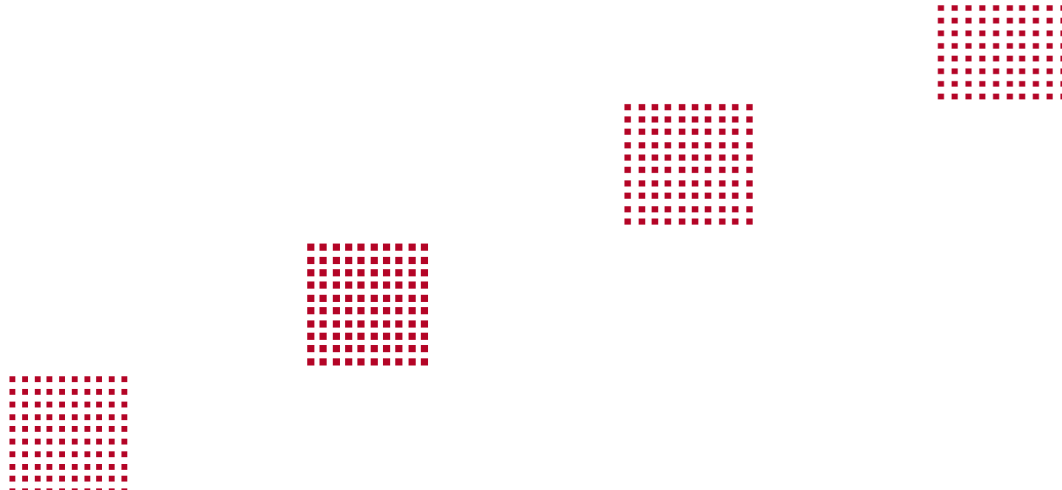

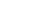


4.

O aumento da altura deve refletir no aumento da força de impacto e no instante em que essa é observada. Cada instante deve ser maior e a diferença entre eles deve diminuir, dado que a velocidade aumenta. Já a força deve crescer linearmente com a altura, uma vez que a aceleração é constante. A Figura 20 apresenta os resultados obtidos, mostrando que, em todos eles, a estabilidade é atingida em $10 \mathrm{kN}$, o que corresponde ao peso do bloco.

a.

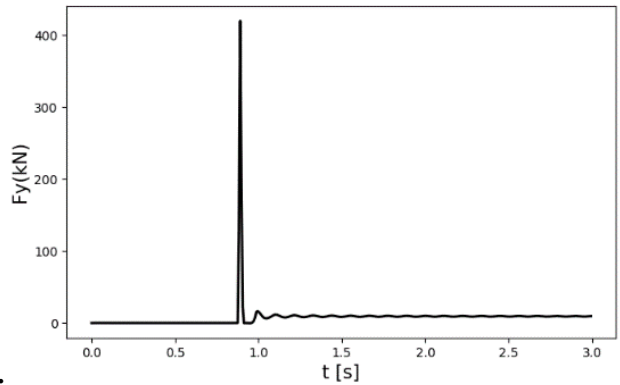

c.

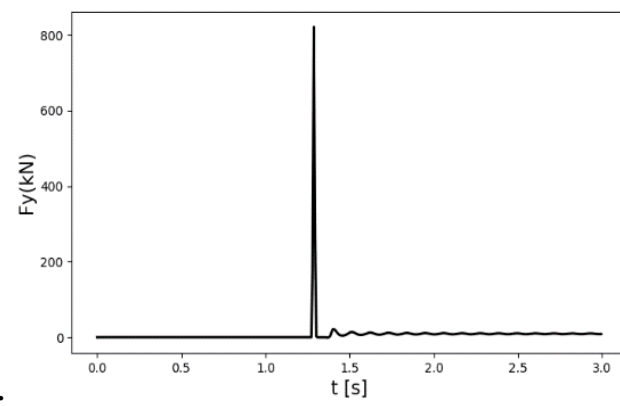

b.

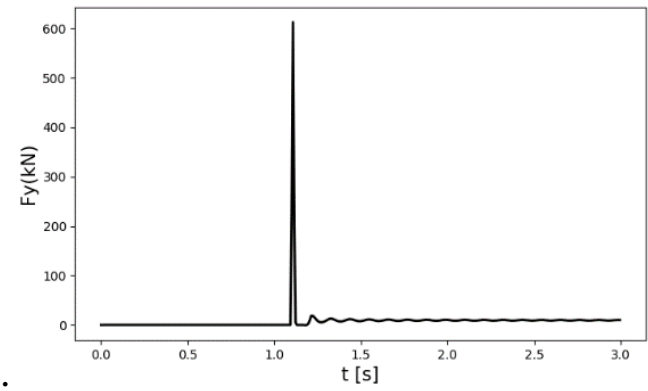

d.

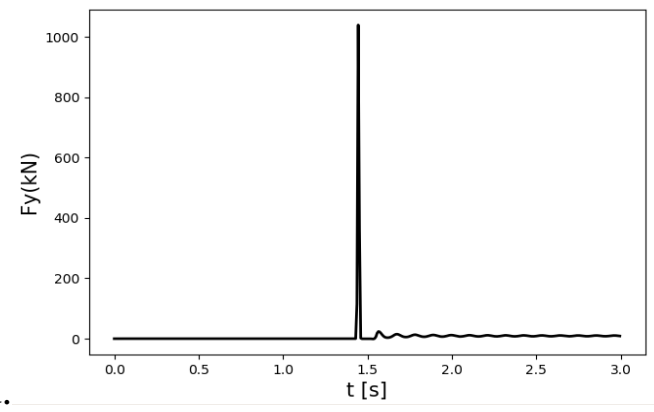

Figura 20 - Força no tempo para bloco caindo em queda livre variando a altura: a. $3,0 \mathrm{~m}$ b. $4,0 \mathrm{~m}$ c. $5,0 \mathrm{~m}$ e d. $6,0 \mathrm{~m}$

A Tabela 4 e a Figura 21 pontuam os resultados que se pretende analisar. A segunda coluna da tabela apresenta os dados de força, que podem ser evidenciados como lineares pela figura, conforme esperado. A terceira coluna apresenta os momentos em que o pico foi atingido. Observa-se que quanto maior a altura, mais tempo é necessário para que o bloco em queda atinja o bloco inferior. Porém, essa diferença de tempo deve ser cada vez menor, visto que a velocidade aumenta devido ao aumento de energia. Essa inferência também pode ser observada, como apresentado na quarta coluna. 
4.

Tabela 4 - Tabela de resultados de força e momento do impacto pela altura do bloco

\begin{tabular}{|c|c|c|c|}
\hline Altura (m) & $\begin{array}{c}\text { Força de Impacto } \\
(\mathrm{kN})\end{array}$ & $\begin{array}{c}\text { Momento de } \\
\text { impacto (s) }\end{array}$ & $\begin{array}{c}\text { Diferença entre } \\
\text { instantes (s) }\end{array}$ \\
\hline 3,0 & 420 & 0,89 & - \\
\hline 4,0 & 613 & 1,11 & 0,22 \\
\hline 5,0 & 822 & 1,29 & 0,18 \\
\hline 6,0 & 1040 & 1,45 & 0,16 \\
\hline
\end{tabular}

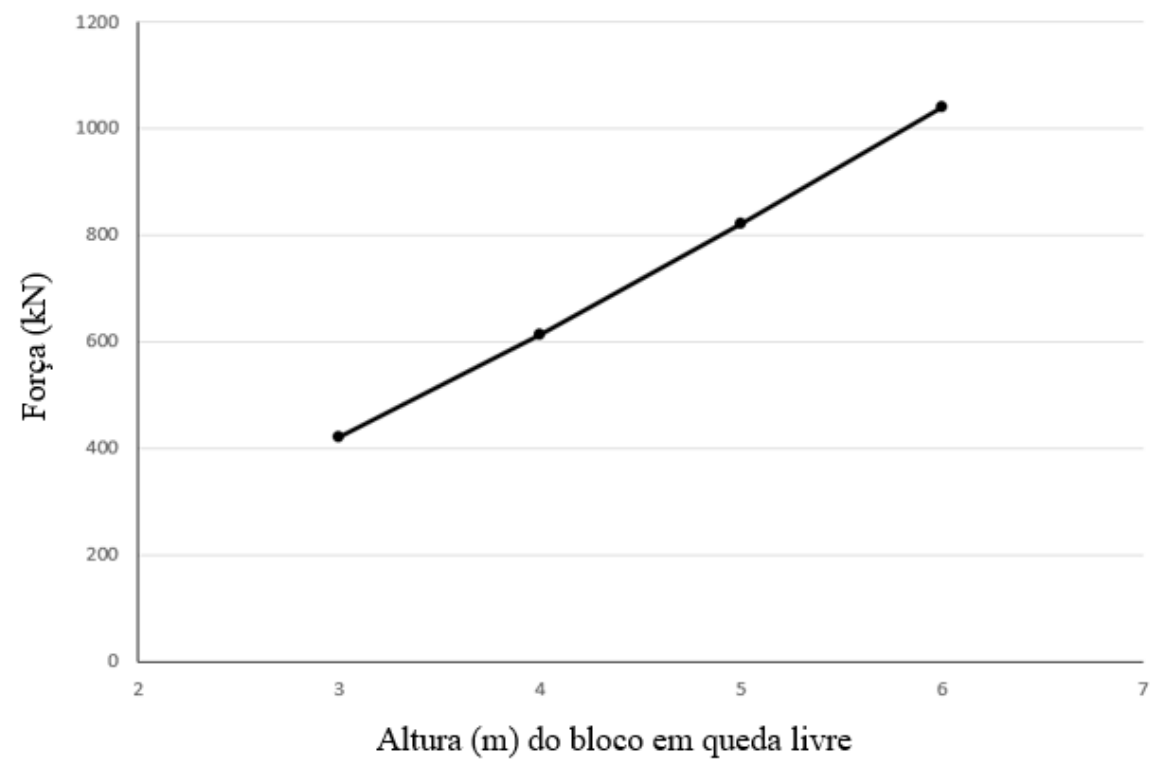

Figura 21- Gráfico da Força de impacto x Altura do bloco em queda livre

Na próxima seção, será descrito o caso em que o bloco cai da altura de três metros, ainda considerando o espaçamento de $0,2 \mathrm{~m}$, apenas para manter a padronização da análise.

\subsubsection{Geometria do bloco impactado}

O impacto deve depender apenas das caraterísticas do bloco em queda livre. Com isso, variando o bloco inferior (ou a célula de carga), não é esperada qualquer alteração na força ou no instante de impacto. A Figura 22 apresenta diferentes blocos cujas as deformações foram medidas. Como nos casos anteriores, espera-se que os modelos tendam para estabilidade em $10 \mathrm{kN}$, de acordo com o peso do bloco. 
4.
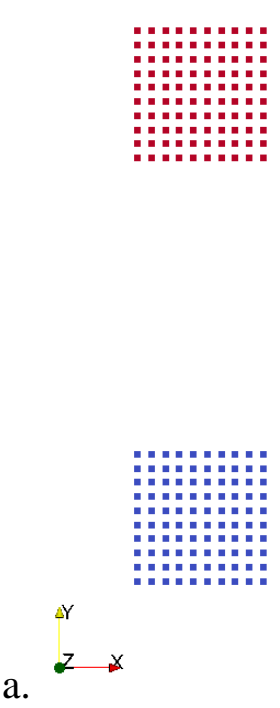

b.
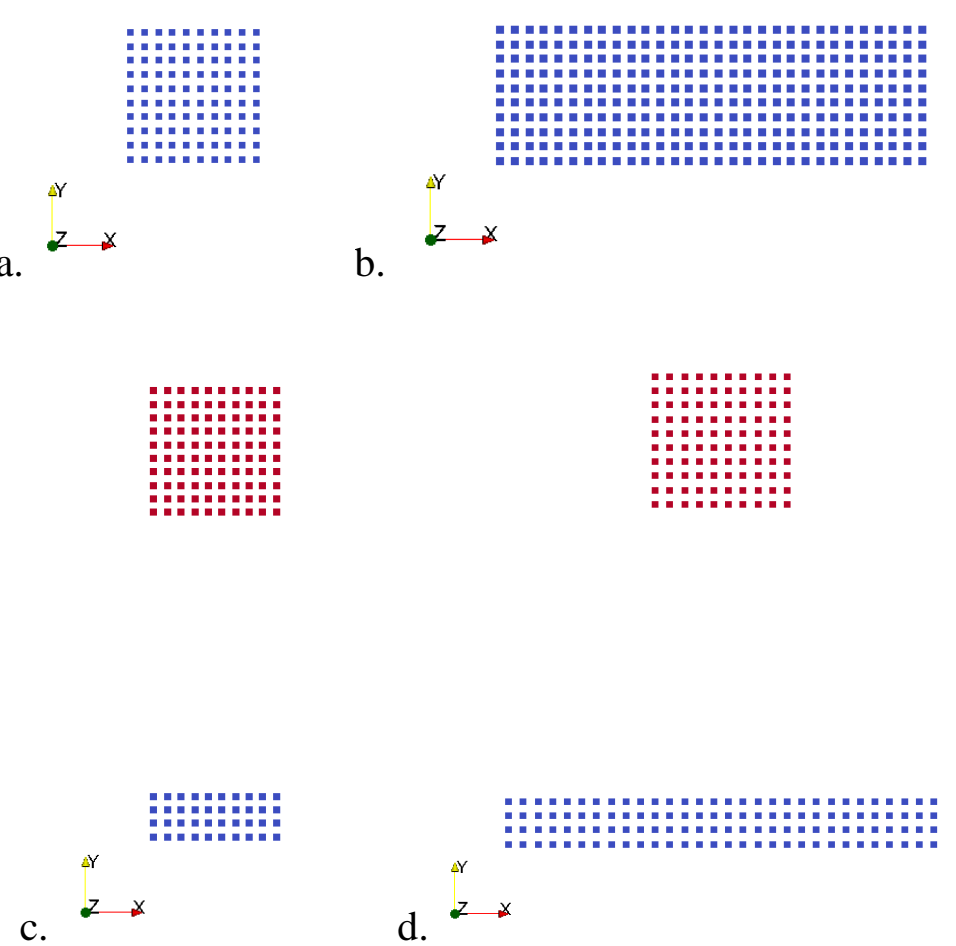

Figura 22 - Apresentação da geometria dos blocos inferiores para terceira análise: a. $1 \times 1$ b. $3 \times 1$ c. $1 \times 0,3$ e d. $3 \times 0,3$

A Figura 23 mostra que o impacto ocorreu no mesmo instante para todas as configurações de geometria, mostrando pequenas alterações na força de impacto. Além disso, a estabilização acompanhou o mesmo padrão nas diferentes geometrias. A Tabela 5 apresenta os dados do impacto para maior facilidade de comparação. 
a.

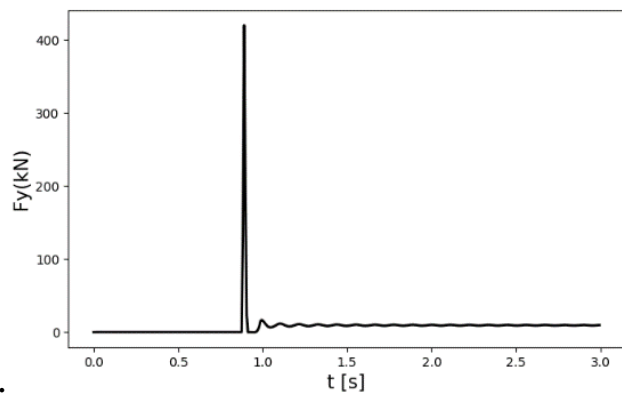

c.

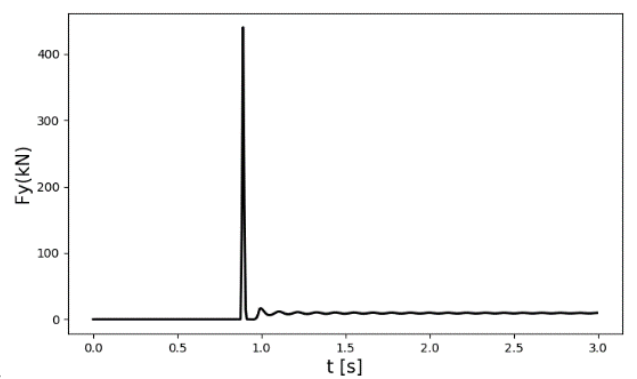

b.

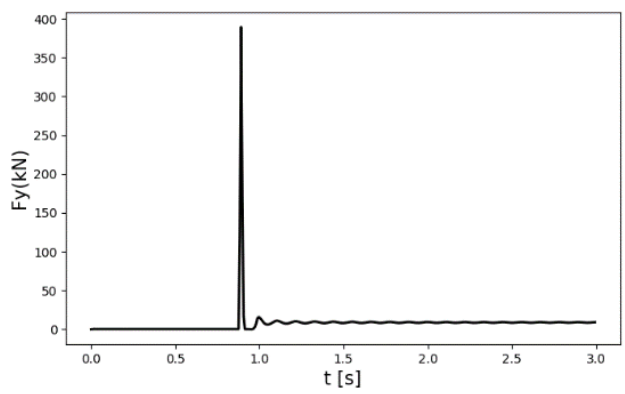

d.

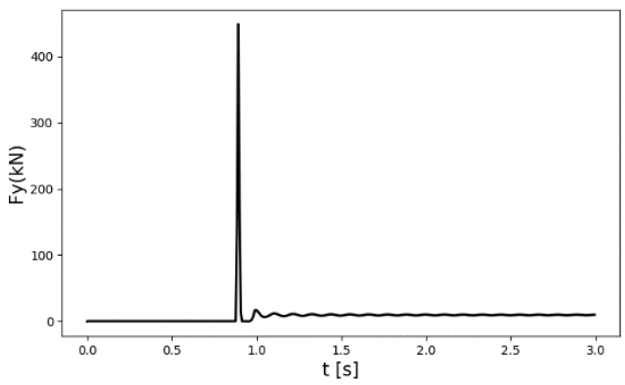

Figura 23 - Força no tempo para bloco caindo em queda livre variando a geometria do bloco impactado: a. $1 \times 1$ b. $3 \times 1$ c. $1 \times 0,3$ e d. $3 \times 0,3$

Tabela 5 - Tabela de resultados de força e momento do impacto pela geometria do bloco impactado

\begin{tabular}{|c|c|c|}
\hline Geometria & Força de Impacto $(\mathrm{kN})$ & Instante de impacto $(\mathrm{s})$ \\
\hline $1 \times 1$ & 420 & 0,89 \\
\hline $3 \times 1$ & 389 & 0,89 \\
\hline $1 \times 0,3$ & 440 & 0,89 \\
\hline $3 \times 0,3$ & 447 & 0,89 \\
\hline
\end{tabular}

Para entender melhor a variação nos resultados de força de impacto, deve-se recorrer à estatística. O desvio padrão é uma medida de dispersão em torno da média de uma variável. A média da força de impacto é 424,0 e o desvio padrão é 22,5 . O desvio encontrado é de, aproximadamente, $5 \%$ do valor médio da força. Ou seja, uma variação pequena que pode ocorrer devido às condições de cálculo numérico empregadas.

O estudo desse caso demonstra que a resposta do cálculo da força é semelhante independente da geometria do bloco impactado. Essa avaliação é muito importante porque nos casos $3 \times 1$ e $3 \times 0,3$ não temos um caso real de compressão simples, porém a aproximação é válida sem grande prejuízo para a solução. Com isso, pode-se garantir validade do próximo exemplo, um modelo que assume a mesma premissa. 
4.

\section{3}

\section{Areia em plano inclinado 2D}

Um experimento para calcular a força de impacto foi executado por Moriguchi et al. (2009). Ele consistia em uma caixa de areia sobre um plano inclinado, na base do plano foi colocada uma célula de carga onde foram aferidas as forças. As Figura 24, Figura 25 e Figura 26, mostram o experimento e o seu esquema, a caixa de areia e seu esquema e a célula de carga e seu esquema, respectivamente.
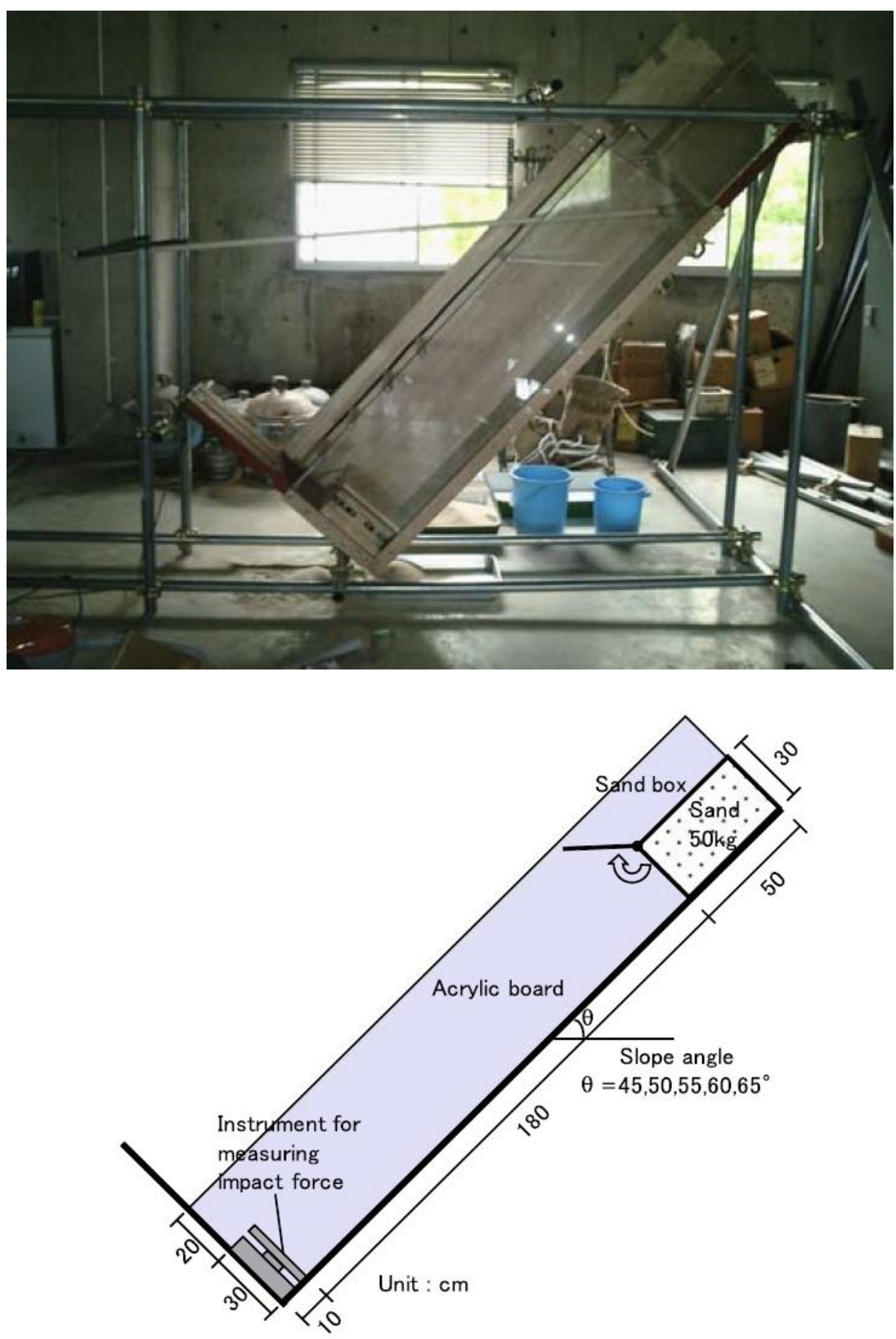

Figura 24 - Foto do experimento e esquema (Moriguchi et al., 2009) 
4.
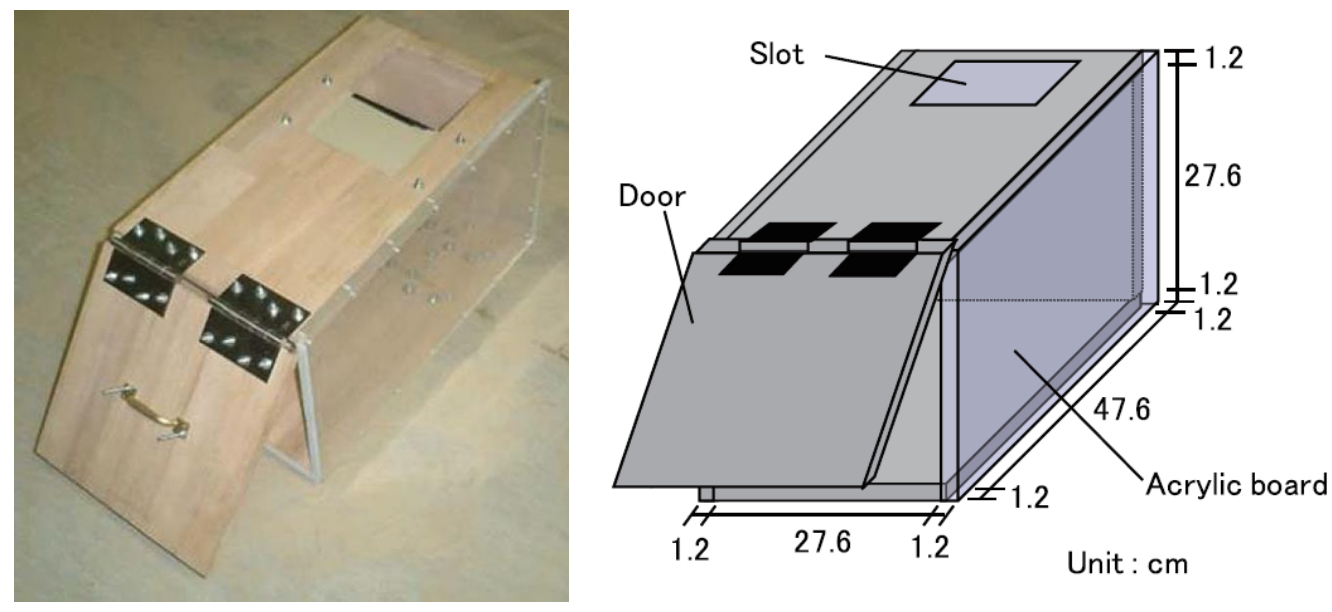

Figura 25 - Foto da caixa de areia e esquema (Moriguchi et al., 2009)
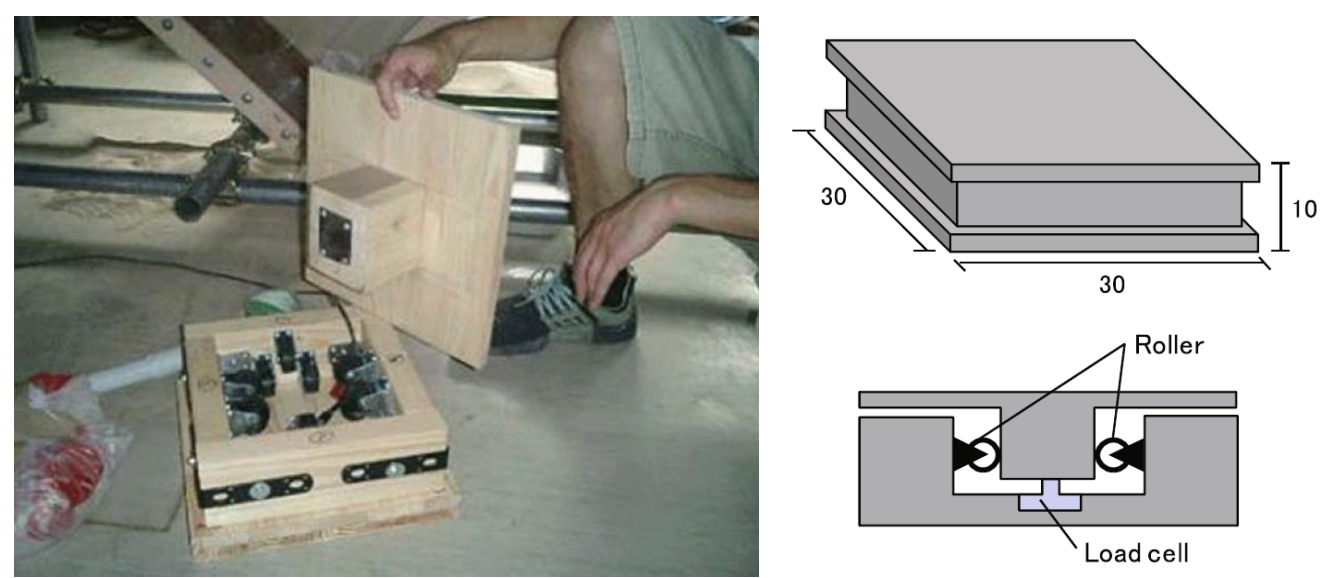

Figura 26 - Foto da célula de carga e esquema (Moriguchi et al., 2009)

Foram feitos experimentos variando a inclinação da caixa para que esta apresentasse $45^{\circ}, 50^{\circ}, 55^{\circ}, 60^{\circ}$ e $65^{\circ}$ com a horizontal. Para cada inclinação, foram feitos cinco testes, conforme a Tabela 6 , então, foram calculadas as médias e o desvio padrão para melhor identificar a tendência das curvas.

Tabela 6 - Medidas de força de impacto máxina (em Newtons) em função da inclinação da calha (Moriguchi et al., 2009)

\begin{tabular}{|c|c|c|c|c|c|}
\hline Inclinação & $45^{\circ}$ & $50^{\circ}$ & $55^{\circ}$ & $60^{\circ}$ & $65^{\circ}$ \\
\hline Teste 1 & 168,9 & 212,7 & 269,0 & 394,1 & 500,4 \\
\hline Teste 2 & 200,2 & 193,9 & 262,7 & 369,1 & 487,8 \\
\hline Teste 3 & 187,7 & 200,4 & 265,5 & 406,6 & 512,9 \\
\hline Teste 4 & 193,9 & 200,2 & 294,0 & 444,1 & 469,1 \\
\hline Teste 5 & 212,7 & 206,4 & 300,2 & 337,7 & 512,9 \\
\hline Média & 192,7 & 202,7 & 276,5 & 390,3 & 496,7 \\
\hline Desvio & 14,5 & 6,4 & 17,4 & 35,7 & 16,6 \\
\hline
\end{tabular}


4.

A partir desses dados, foram elaborados gráficos que retratam a força exercida na célula de carga ao longo do tempo. A Figura 27 mostra esses gráficos que servem de base para o nosso estudo em MPM.

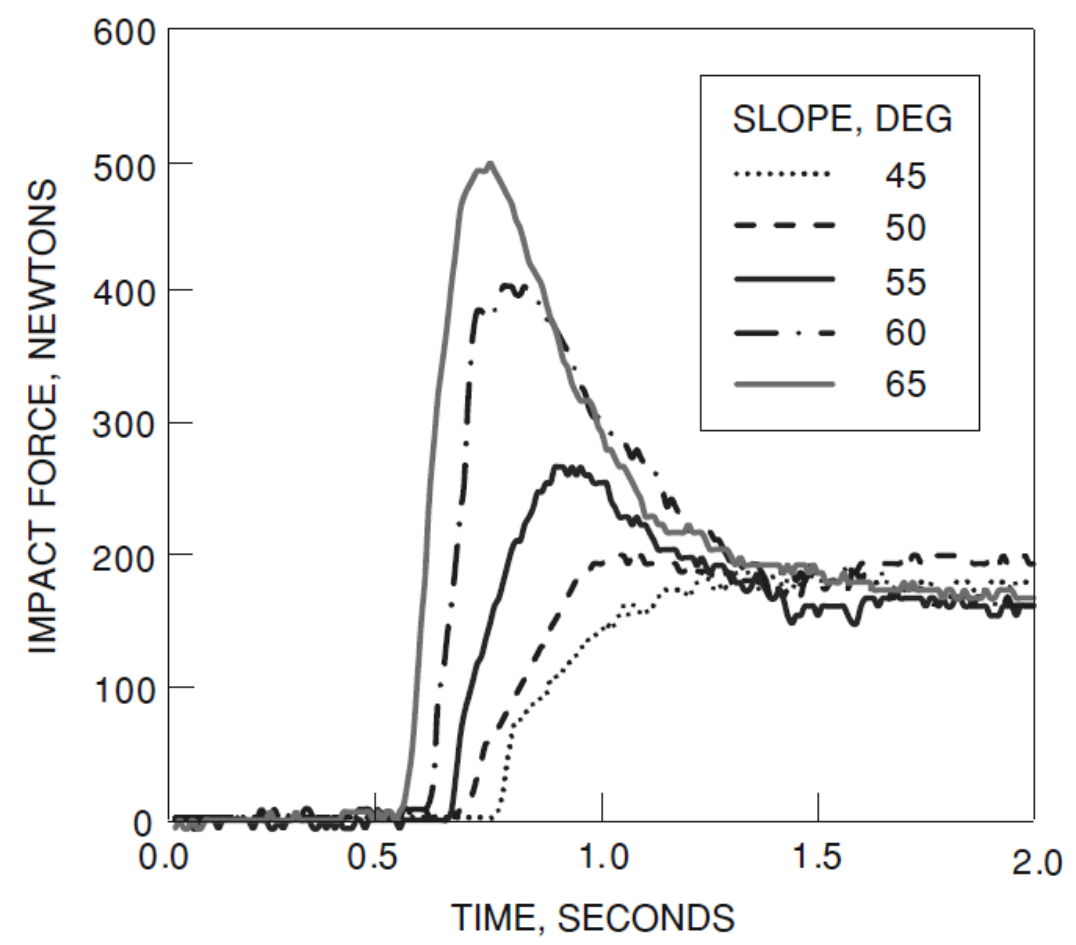

Figura 27 - Medidas de força de impacto no tempo para diferentes inclinações de rampa

(Moriguchi et al., 2009)

Para o modelo em MPM será usado o modelo constitutivo de Drucker e Prager (1952) indicado para areias. Seus dados, conforme indicação no artigo, serão: massa específica $1,379 \mathrm{~kg} / \mathrm{m}^{3}$, ângulo de atrito $35^{\circ}$ e esquema, como indicado na Figura 28. O modelo é concebido com a rampa na horizontal (direção x) e a gravidade é imposta considerando suas componentes em x e y, a fim de que se possa determinar a declividade. 
4.

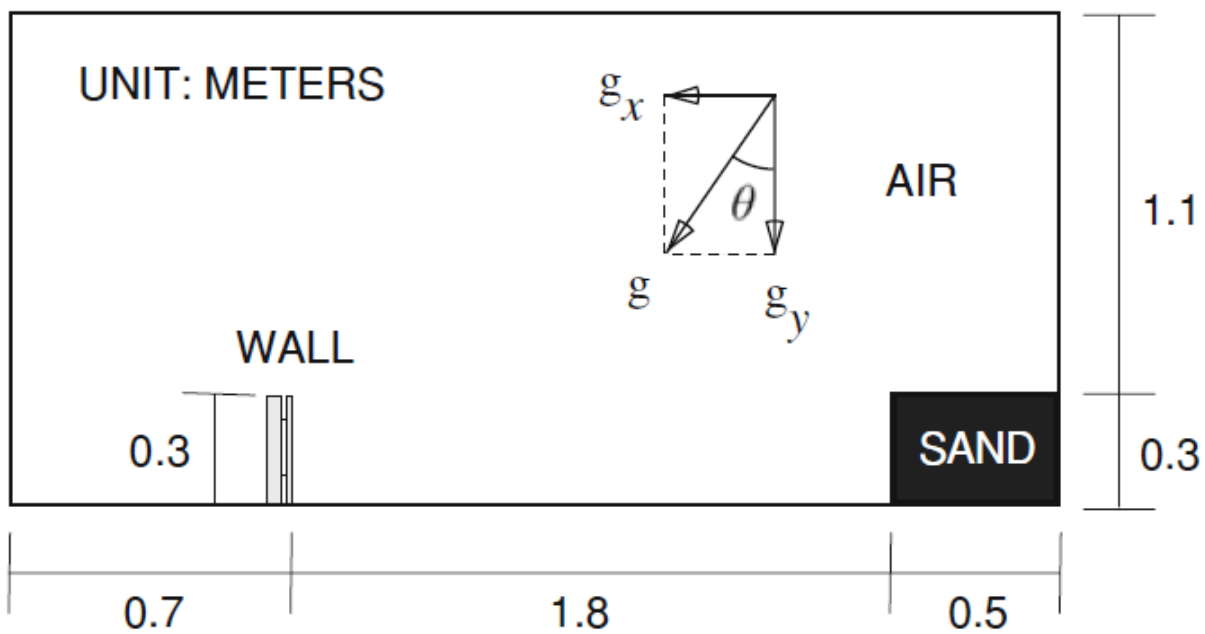

Figura 28 - Representação esquemática do modelo para simulações numéricas

(Moriguchi et al., 2009)

Em primeiro lugar, é fundamental a verificação da influência da malha escolhida nos resultados. Para isso, foram considerados modelos com grid de 0,1 $\mathrm{m}, 0,05 \mathrm{~m}$ e $0,025 \mathrm{~m}$. O maior desafio, no entanto, é modelar adequadamente o contorno, já que o MPM não permite especificação de atrito entre a base e o material. Por isso, foram especificados testes de modelos com o contorno livre e fixo na direção x. Ou seja, os nós da base da areia podem se deslocar em x quando livres, porém terão deslocamento imposto igual a zero quando fixos.

\subsubsection{Contorno livre em x com malha de $0,1 \mathrm{~m}$}

A Figura 29 apresenta a concepção do modelo em MPM, com escala de cor por material. No material 1 (azul), definido como elástico, foram medidas as deformações para cálculo da força. O material 2 (verde) é um bloco fixo, sendo ele necessário para que o material 1 não sofra flexão, ele permite que o cálculo seja executado considerando compressão simples. Já o material 3 (vermelho) representa a areia com o modelo constitutivo de Ducker e Prager (1952). 
4.

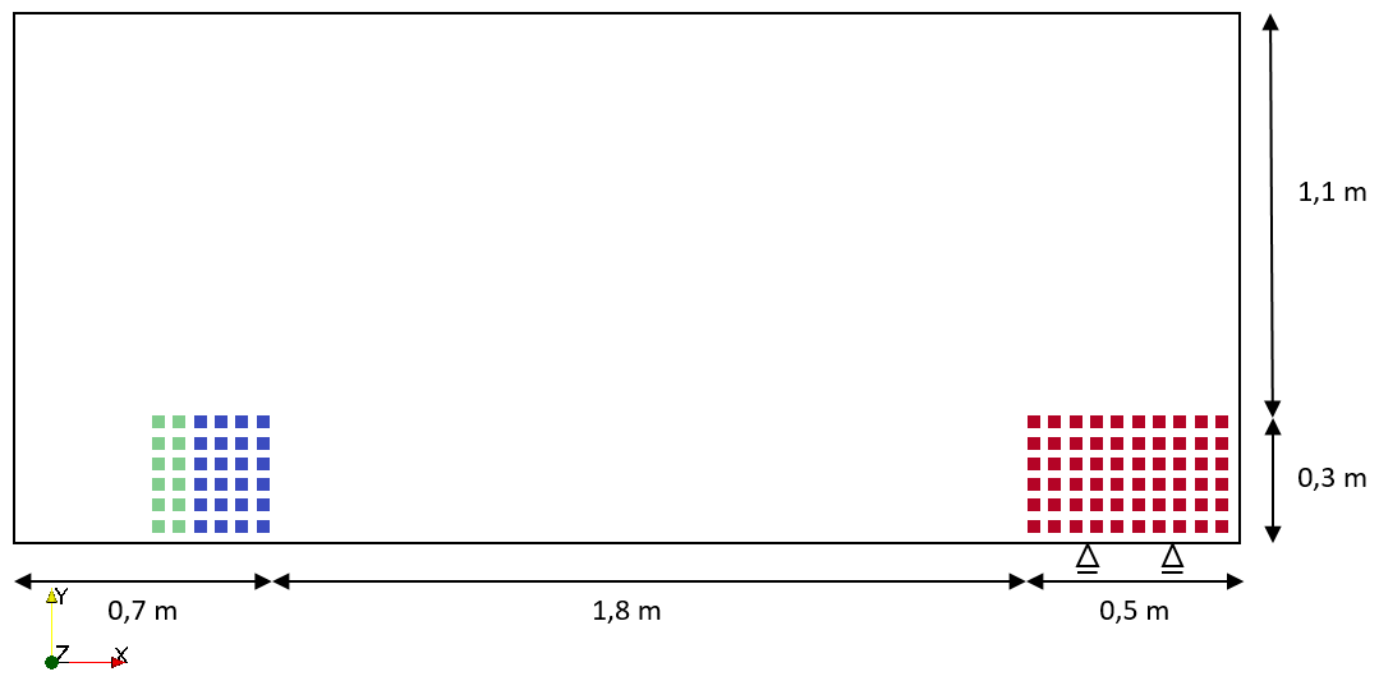

Figura 29 - Representação do modelo MPM (grid 0,1 m) com escala de cores por material

A malha de 0,1 m é a mais grossa que se irá apresentar, e o aumento do refinamento deve apresentar um aumento de precisão nos resultados. Cada célula do grid tem quato pontos materiais inseridos uniformemente. Para essa malha, a areia apresenta 60 pontos materiais.

Os resultados de força foram encontrados de acordo com a descrição no item 3.7. Como o sinal obtido no MPM mostra alto nível de ruído, foi utilizado o filtro de Savitsky-Golay para facilitar interpretação dos dados. A Figura 30 apresenta os resultados obtidos no MPM e, logo abaixo, o sinal tratado.
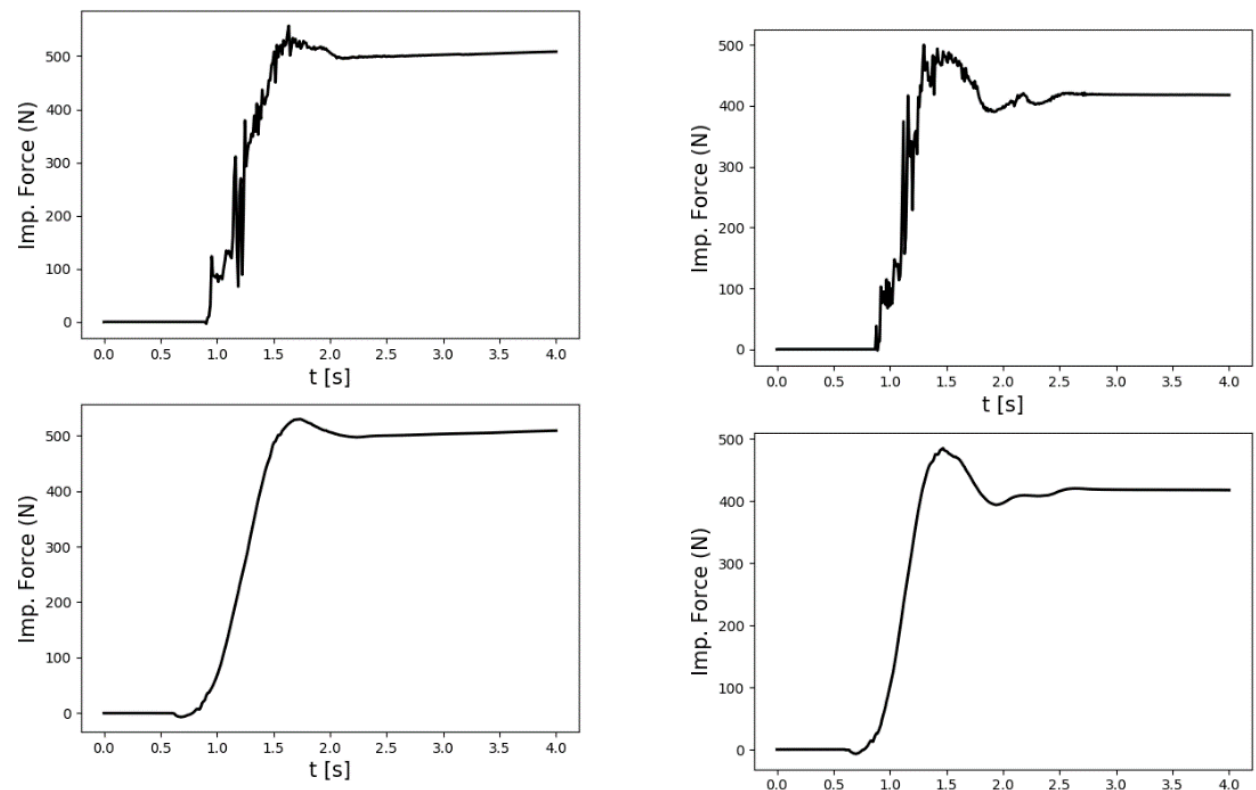

a.

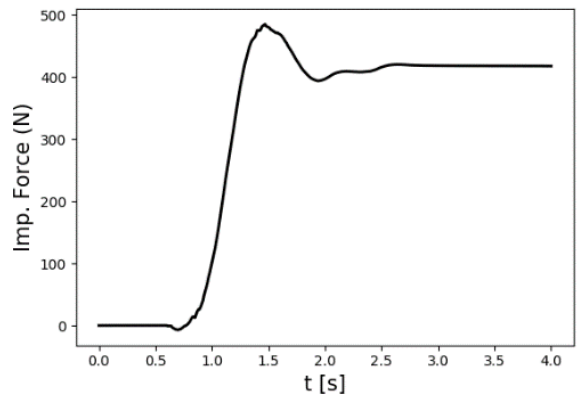

b. 
4.
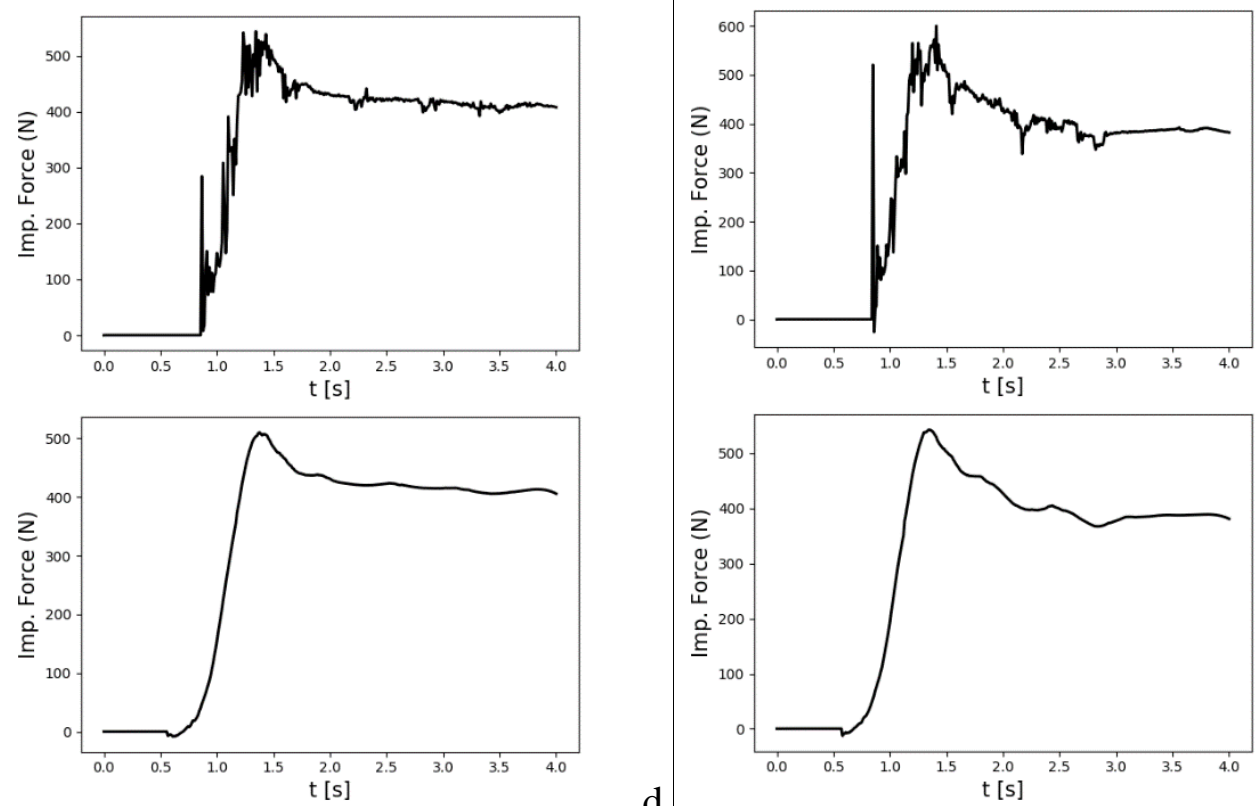

d.
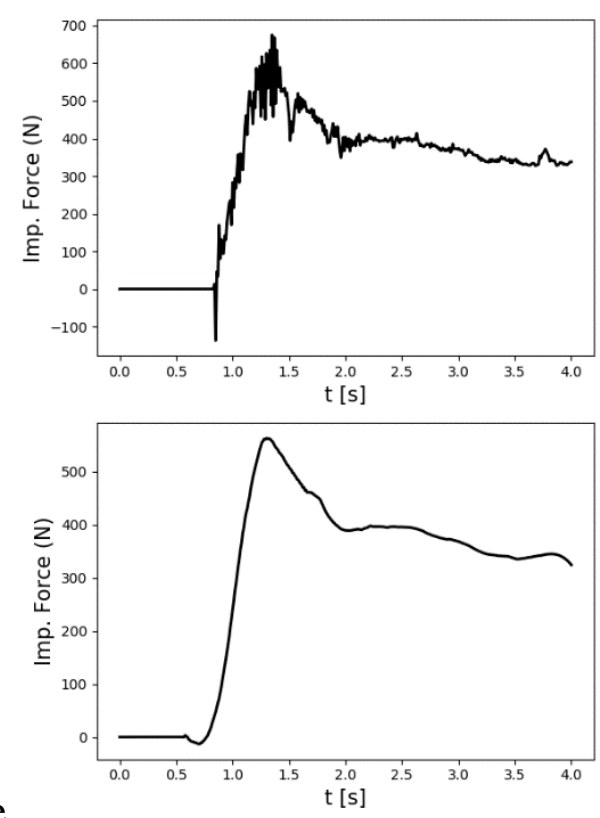

Figura 30 - Força de Impacto (N) no tempo com inclinação de:

a. $45^{\circ}$ b. $50^{\circ}$ c. $.55^{\circ}$ d. $60^{\circ}$ e. $65^{\circ}$

O formato dos gráficos está de acordo com o esperado, com pico crescente conforme o aumento da inclinação. Os valores estão acima dos encontrados em laboratório, porém as análises da malha e do contorno serão necessárias para melhor caracterização dos resultados. Os picos de cada modelo estão descritos na Tabela 7 junto com os resultados das demais malhas para comparação. 
4.

\subsubsection{Contorno livre em x com malha de 0,05 m}

A Figura 31 apresenta a concepção do modelo em MPM com grid de 0,05 m e escala de cor por material, análoga à Figura 29. Novamente, para cada célula foram dispostos quatro pontos materiais distribuídos uniformemente, ou seja, com essa malha a areia apresenta 240 pontos materiais.

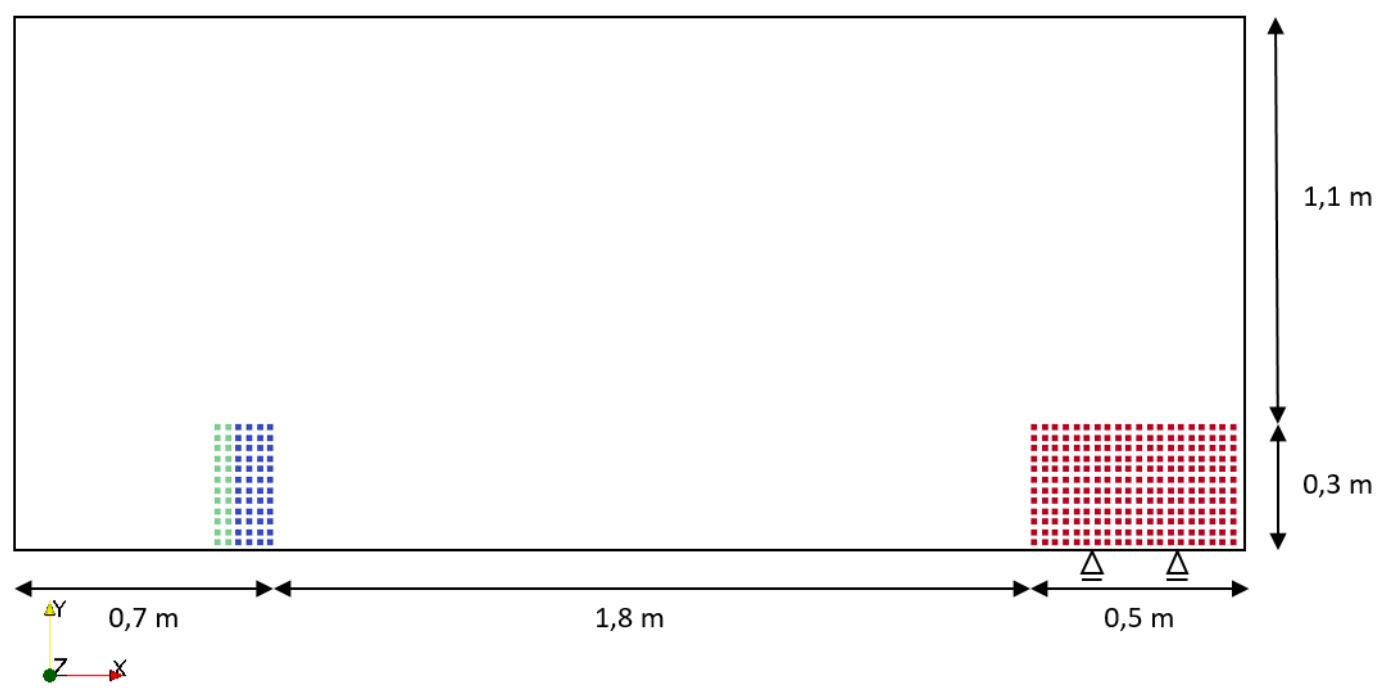

Figura 31 - Representação do modelo MPM (grid 0,05 m) com escala de cores por material

A Figura 32 mostra apenas o resultado dos sinais tratados para simplicidade de demonstração. Pode-se perceber que os resultados foram mais próximos dos experimentais, porém ainda bastante superiores para as menores inclinações.

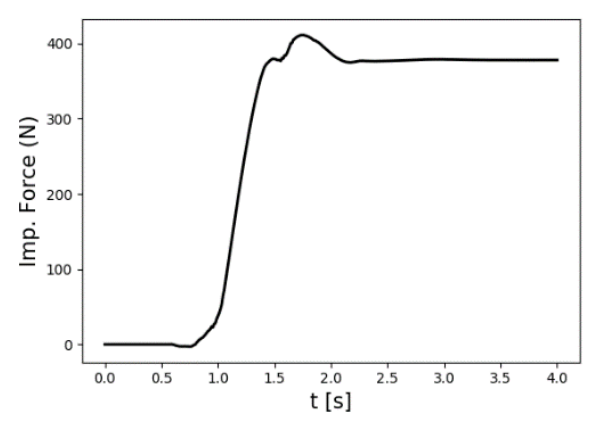

a.

b.

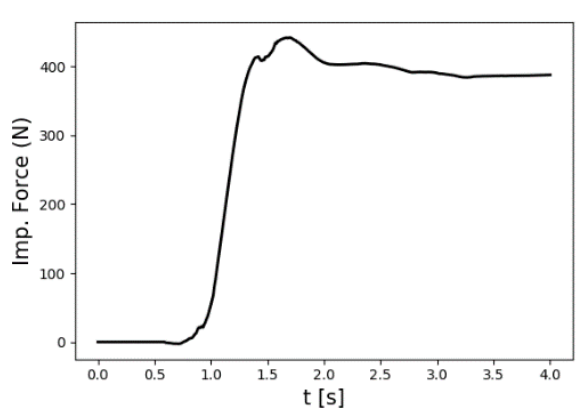


4.

c.
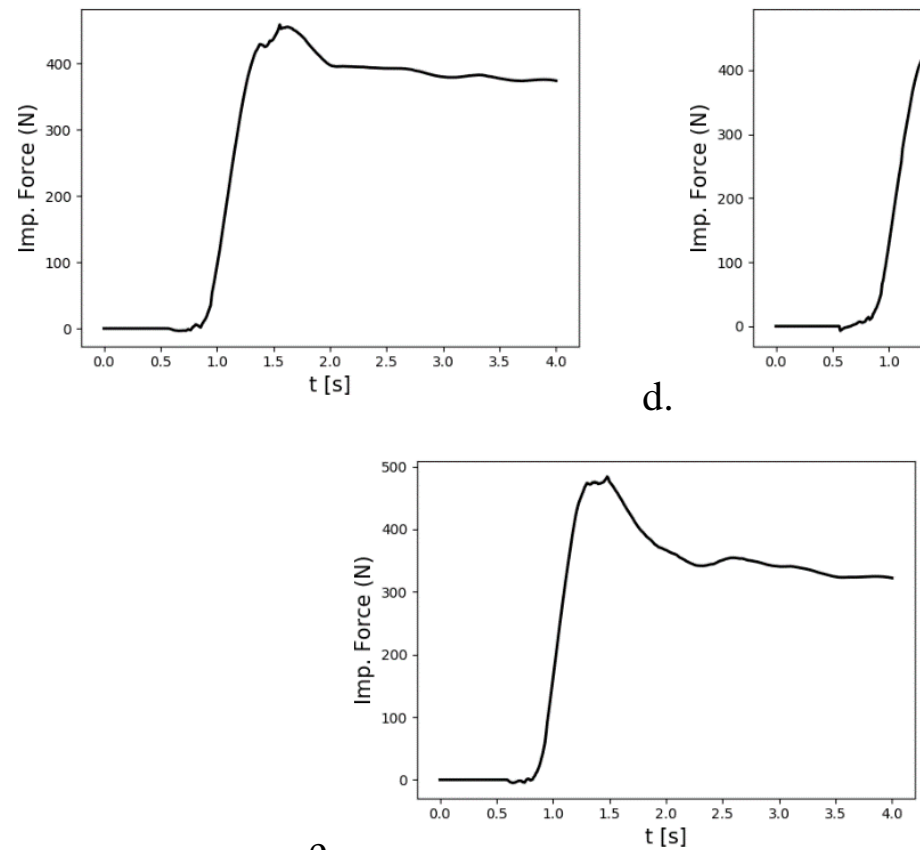

Figura 32 - Força de Impacto (N) no tempo com inclinação de:

a. $45^{\circ}$ b. $50^{\circ}$ c. $55^{\circ}$ d. $60^{\circ}$ e. $65^{\circ}$

\subsubsection{Contorno livre em $x$ com malha de $0,025 \mathrm{~m}$}

A Figura 33 expõe como é o modelo com grid refinado com célula de 0,025 m, que implica em 960 pontos materiais, e a Figura 34 apresenta o resultado apenas dos sinais tratados.

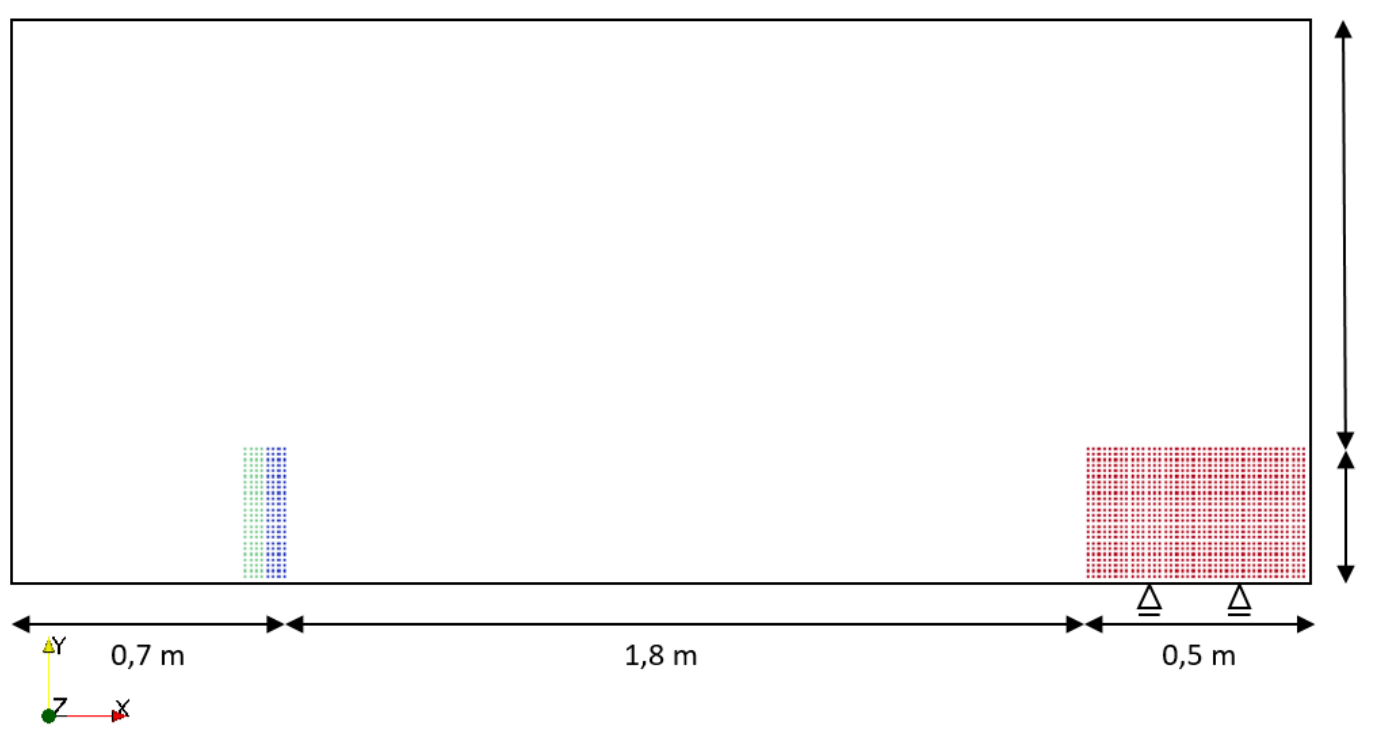

Figura 33 - Representação do modelo MPM (grid 0,025 m) com escala de cores por material 
4.

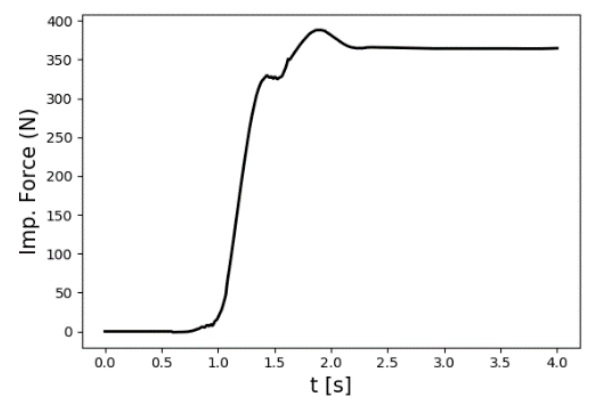

a.
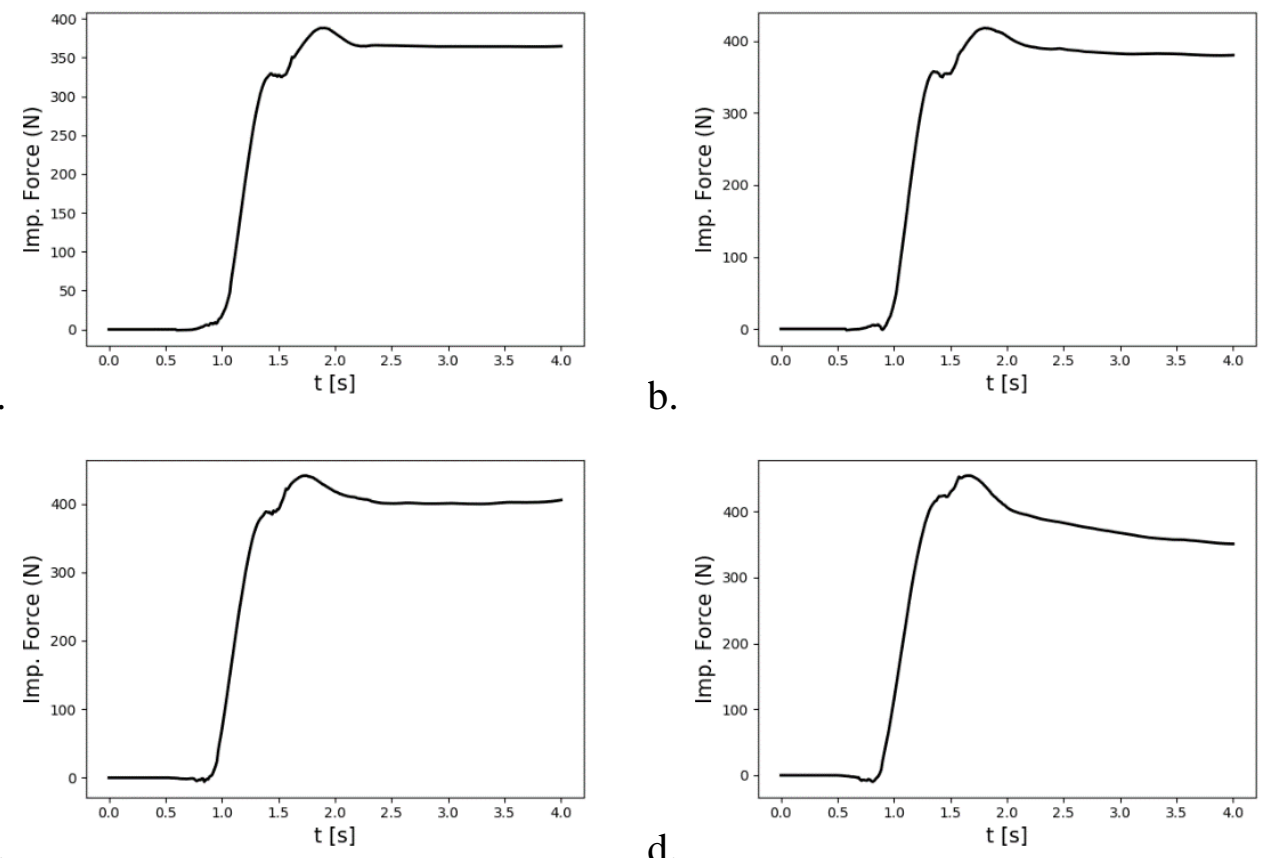

d.

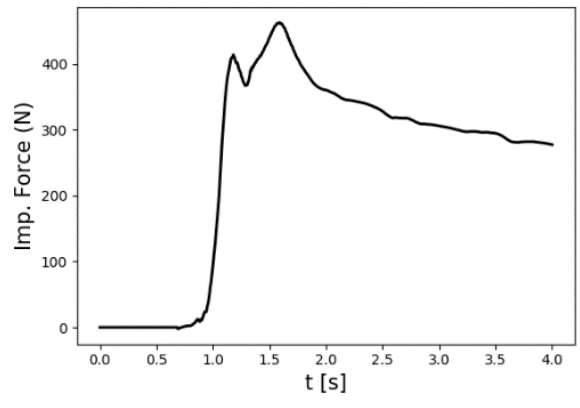

Figura 34- Força de Impacto (N) no tempo com inclinação de:

a. $45^{\circ}$ b. $50^{\circ}$ c. $55^{\circ}$ d. $60^{\circ}$ e. $65^{\circ}$

Percebe-se que os resultados não apresentam grandes divergências, variando a malha se comparados com a Figura 32. A verificação completa será descrita no próximo item.

\subsubsection{Análise do refinamento da malha}

Para garantir que a malha foi escolhida adequadamente, é necessário que os resultados não oscilem com a sua variação, ou seja, uma simulação que indique pequenas diferenças nos resultados. A Figura 35 mostra claramente a tendência dos resultados com o refinamento, enquanto a Tabela 7 apresenta os valores de pico e os desvios em porcentagem entre duas malhas sucessivas. 
4.

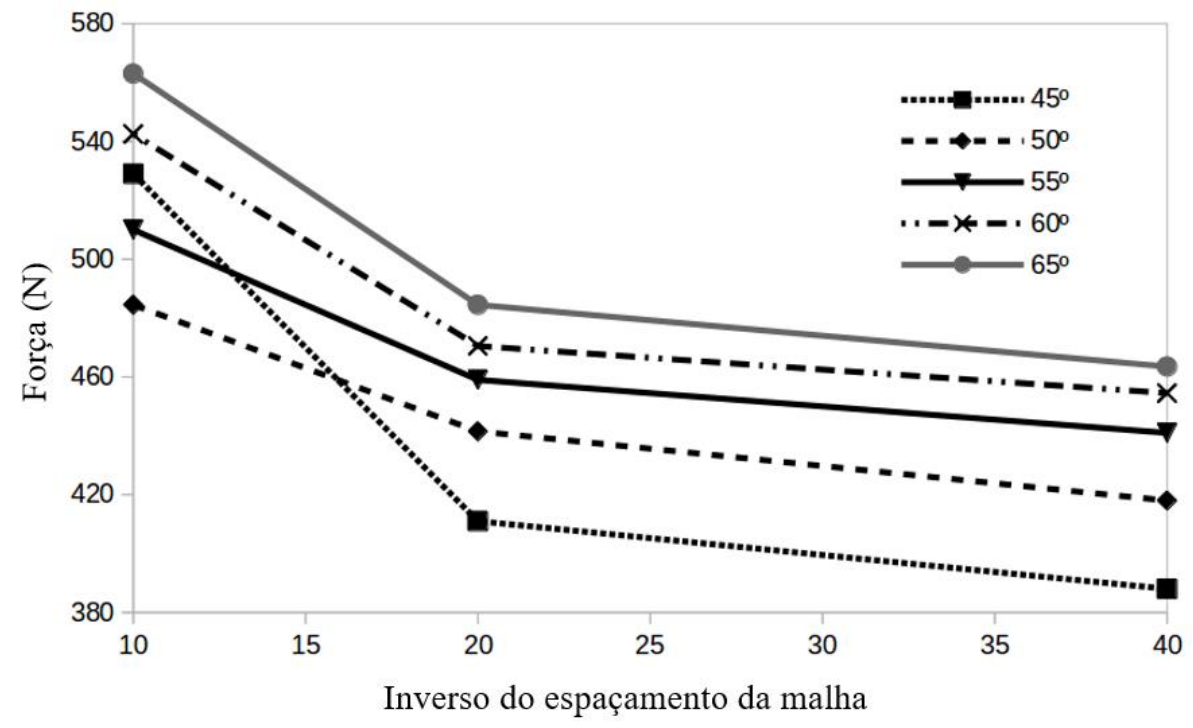

Figura 35 - Análise do refinamento da malha

Força de Impacto x Inverso do espaçamento da malha

Tabela 7 - Análise do refinamento da malha

Força de impacto e desvio entre malhas sucessivas

\begin{tabular}{|c|c|c|c|}
\hline Modelos & MPM $(0,1 \mathrm{~m})$ & MPM $(0,05 \mathrm{~m})$ & MPM $(0,025 \mathrm{~m})$ \\
\hline $45^{\circ}$ & $529,0 \mathrm{~N}$ & $411,0 \mathrm{~N}$ & $388,0 \mathrm{~N}$ \\
\hline Erro (\%) & - & 22,3 & 5,6 \\
\hline $50^{\circ}$ & $484,5 \mathrm{~N}$ & $441,5 \mathrm{~N}$ & $418,0 \mathrm{~N}$ \\
\hline Erro (\%) & - & 8,9 & 5,3 \\
\hline $55^{\circ}$ & $510,0 \mathrm{~N}$ & $459,0 \mathrm{~N}$ & $441,0 \mathrm{~N}$ \\
\hline Erro (\%) & - & 10,0 & 3,9 \\
\hline $60^{\circ}$ & $542,5 \mathrm{~N}$ & $470,5 \mathrm{~N}$ & $454,5 \mathrm{~N}$ \\
\hline Erro (\%) & - & 13,3 & 3,4 \\
\hline $65^{\circ}$ & $563,0 \mathrm{~N}$ & $484,5 \mathrm{~N}$ & $463,5 \mathrm{~N}$ \\
\hline Erro (\%) & - & 13,9 & 4,3 \\
\hline
\end{tabular}

Pode-se perceber que o desvio é maior da malha mais grossa para a média; já o desvio padrão da malha média para a fina é de cerca de 5\%. Com isso, admite-se validade para o grid $0,05 \mathrm{~m}$ que, por ser mais largo, despende menos tempo. Comparativamente, o modelo com grid $0,05 \mathrm{~m}$ leva cinco minutos para ser calculado, enquanto o modelo com grid refinado de $0,025 \mathrm{~m}$ gasta 30 minutos. Por isso, para análise de comparação entre contorno livre e fixo decidiu-se usar o grid de $0,05 \mathrm{~m}$. 
4.

Tabela 8 - Comparação entre a força de impacto em Newtons calculada pelo MPM $(0,05 \mathrm{~m})$ e ensaio de laboratório

\begin{tabular}{|c|c|c|c|c|}
\hline \multirow{2}{*}{ Inclinação } & \multicolumn{4}{|c|}{ Força de impacto N (N) } \\
\cline { 2 - 5 } & Ensaio (N) & MPM (N) & Média (N) & Erro (\%) \\
\hline $45^{\circ}$ & 192,7 & 411,0 & 301,9 & 36,1 \\
\hline $50^{\circ}$ & 202,7 & 441,5 & 322,1 & 37,1 \\
\hline $55^{\circ}$ & 276,5 & 459,0 & 367,8 & 24,8 \\
\hline $60^{\circ}$ & 390,3 & 470,5 & 430,4 & 9,3 \\
\hline $65^{\circ}$ & 496,7 & 484,5 & 490,6 & 1,2 \\
\hline
\end{tabular}

Comparando os resultados do MPM de grid 0,05 m aos experimentais da Figura 27, nota-se que há grande diferença nos resultados com menor inclinação. No entanto, ela diminui conforme a declividade aumenta, de acordo com o desvio padrão na Tabela 8. Como esse modelo foi calculado com o contorno livre, ou seja, sem atrito entre a base e a areia, pode-se perceber, então, que o atrito entre a areia e a base da rampa é de suma importância quando a força normal é maior, ou seja, o atrito é maior. Quando a declividade aumenta, o atrito tem sua significância reduzida. No caso de $60^{\circ}$ o erro encontra-se próximo ao desvio encontrado no experimento (que é de $35,7 \mathrm{~N}$ ), quando a inclinação é $65^{\circ}$ o erro é menor que qualquer desvio do experimento.

\subsubsection{Contorno fixo em $x$ com malha de $0,05 \mathrm{~m}$}

Considerando o tempo consumido pelo grid mais refinado, torna-se mais viável o uso do grid 0,05 m. Com isso, esse caso segue conforme a representação da Figura 31, com alteração da condição de contorno na direção x. O engaste indica que os nós do grid na base da areia não se movimentam. 
4.

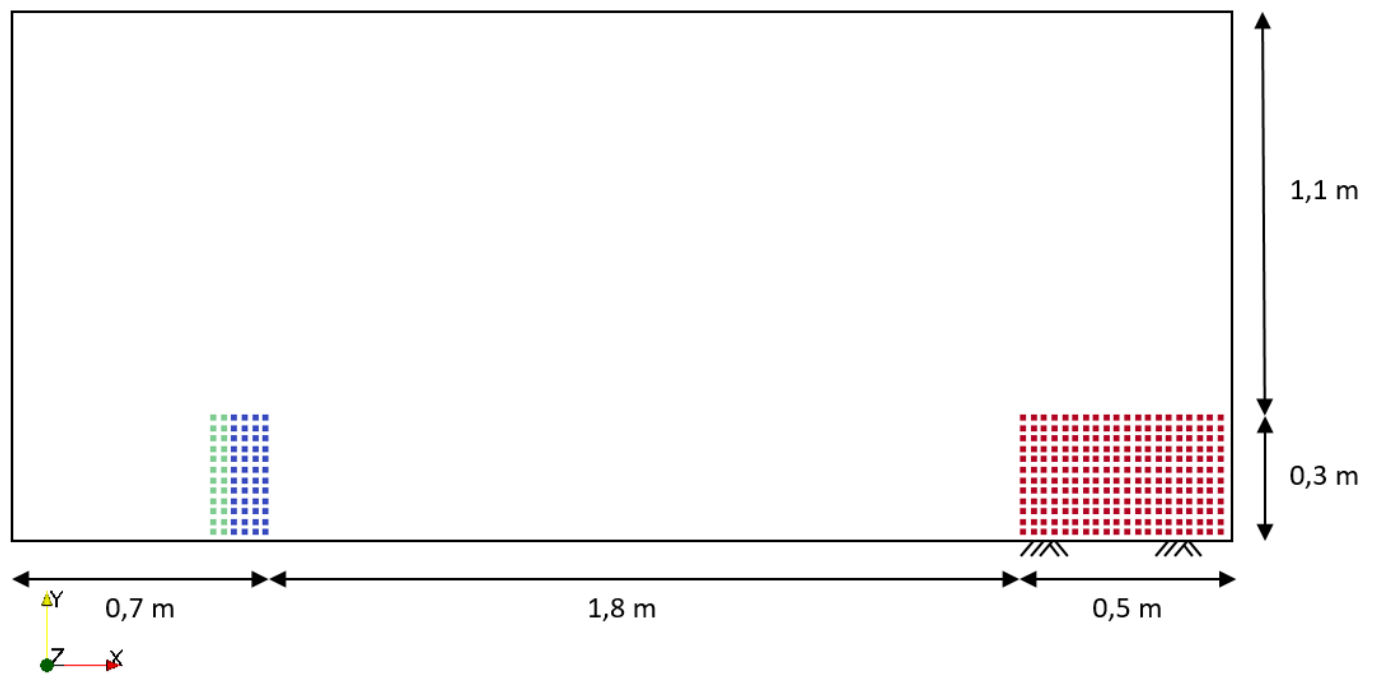

Figura 36 - Representação do modelo MPM (grid 0,05 m) com escala de cores por material

Os resultados na Figura 37, novamente, apresentam apenas o sinal tratado dos resultados. Comparando as forças de impacto com o modelo sem atrito pode-se perceber que elas foram bem menores, conforme o esperado. Comparando as forças de impacto calculadas com as forças de impacto obtidas no ensaio, fica demonstrado que esse método é mais representativo que usando o contorno sem atrito. Importante lembrar que, para um caso de ruptura de talude real, não haverá esse problema de modelagem, dado que a superfície de ruptura é formada naturalmente pelo modelo.

a.
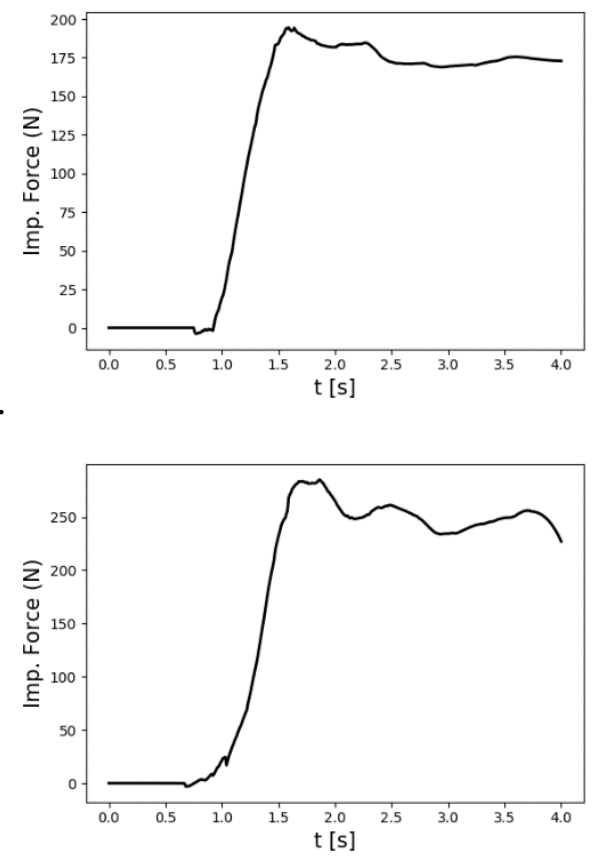

b.
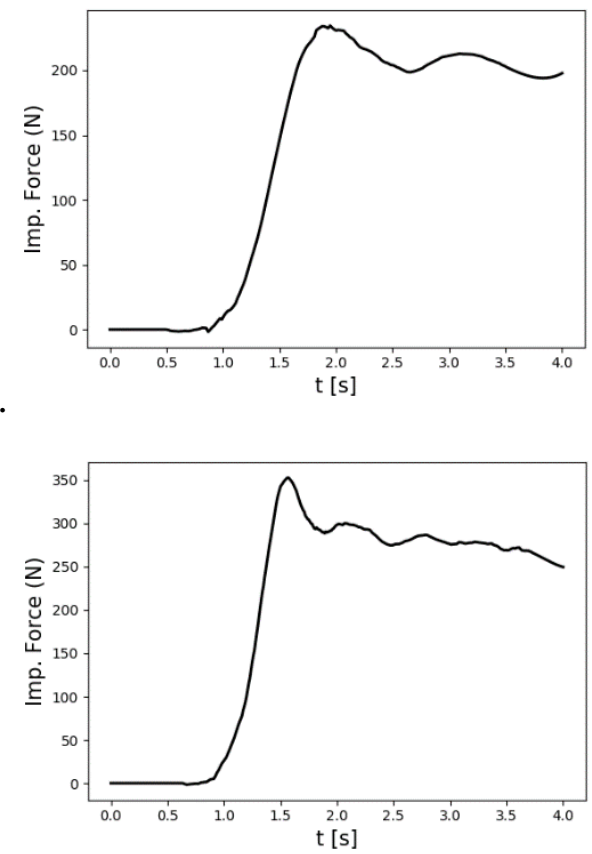

d. 
4.

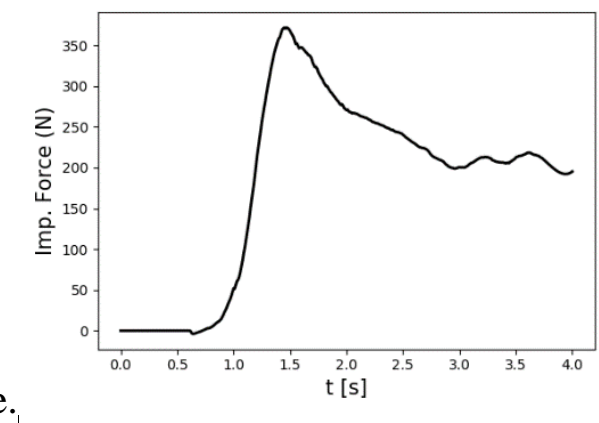

Figura 37 - Força de Impacto (N) no tempo com inclinação de:

a. $45^{\circ}$ b. $50^{\circ}$ c. $55^{\circ}$ d. $60^{\circ}$ e. $65^{\circ}$

O erro na Tabela 9, entretanto, mostra que a acurácia diminui conforme a declividade aumenta. A lógica nesse caso é análoga ao primeiro caso: quando a inclinação é menor, o atrito tem maior influência. Nesse caso a fixação da base da areia contribui impedindo deslocamento das partículas da base. Quando a inclinação aumenta, a redução da força normal no plano x faz com que o atrito diminua chegando mais próximo da condição de contorno livre do que engastado. É importante notar que todos resultados, exceto $65^{\circ}$, apresentaram desvio menor que $7 \%$ o que indica resultados satisfatórios.

Tabela 9 - Comparação entre a força de impacto em Newtons calculada pelo MPM e ensaio de laboratório

\begin{tabular}{|c|c|c|c|c|}
\hline Inclinação & Ensaio (N) & MPM (N) & Média (N) & Erro (\%) \\
\hline $45^{\circ}$ & 192,7 & 194,5 & 193,6 & 0,5 \\
\hline $50^{\circ}$ & 202,7 & 234,0 & 218,4 & 7,1 \\
\hline $55^{\circ}$ & 276,5 & 285,5 & 281,0 & 1,6 \\
\hline $60^{\circ}$ & 390,3 & 352,5 & 371,4 & 5,1 \\
\hline $65^{\circ}$ & 496,7 & 372,5 & 434,6 & 14,3 \\
\hline
\end{tabular}

Para facilidade de comparação, Figura 38 mostra os resultados obtidos pelo MPM e o resultado experimental lado a lado. As curvas de $45^{\circ}, 50^{\circ}, 55^{\circ}$ e $60^{\circ}$ foram obtidas com o modelo considerando o contorno fixo, enquanto a curva de $65^{\circ}$ considerou o contorno livre já que esse representa melhor a realidade.

O pico foi observado em momentos levemente diferentes nos dois casos. Gabrielli e Ceccato (2016) mostraram que o MPM tende a ser mais devagar quando comparado a modelos numéricos discretos, o que indica um comportamento mais demorado, que pode ser devido à etapa lagrangiana no cálculo. 
4.

Após o pico, a força na parede cai, já no MPM, essa força cai com velocidade muito menor do que o registrado no experimento, comportamento pode estar relacionado à interação solo estrutura calculada pelo MPM de forma contínua. Isso porque o algoritmo de contato calcula velocidades diferentes para pontos materiais de diferentes corpos, sendo, por isso indicado para estudos de força.
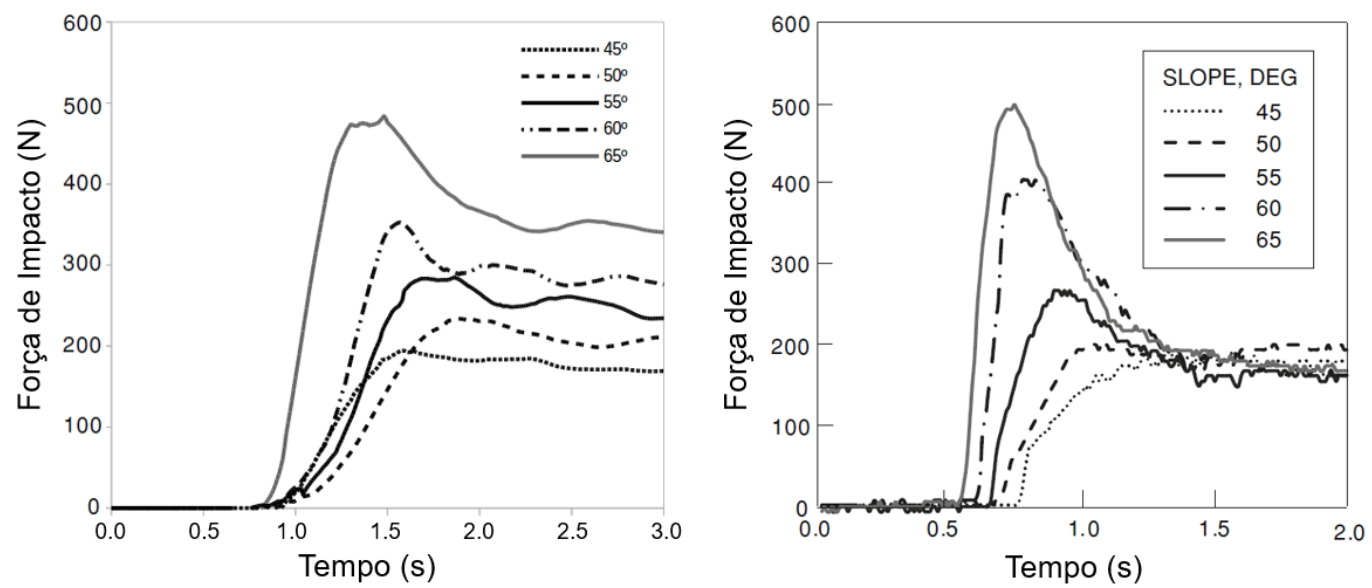

Figura 38 - Resultados com cálculo pelo MPM (esquerda) e experimental (direita)

Para construção otimizada de um muro de contenção, a força de pico deve ser considerada como distribuída ao longo da parede, de forma a melhor representar o impacto. Uma rampa de $55^{\circ}$ é um bom caso de encosta íngreme e pode ser usado como exemplo. No instante 1,8 segundos temos o pico da força resultante com 285,5 N. A Figura 39 apresenta a força para cada ponto material, conforme calculado.

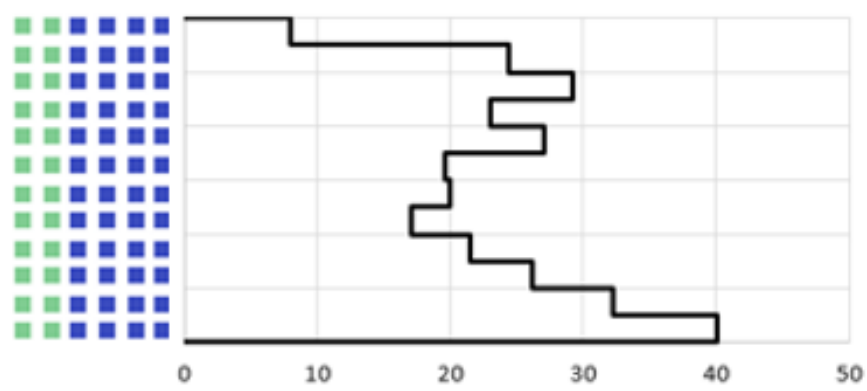

Força $(\mathrm{N})$

Figura 39 - Força na parede para $55^{\circ}$ de inclinação no instante de pico 1,8 segundos 
4.

4.4

Areia em plano inclinado 3D

O modelo experimental foi executado com uma caixa de areia com $0,3 \mathrm{~m}$ de largura. Desse modo, o modelo em 3D apresenta a mesma geometria. A Figura 40 apresenta o modelo em 3D, com a largura no eixo $\mathrm{z}$, sendo as imagens para os tempos $0,0 \mathrm{~s}, 0,5 \mathrm{~s}, 1,0 \mathrm{~s}, 1,5 \mathrm{~s}$ e $2,0 \mathrm{~s}$.
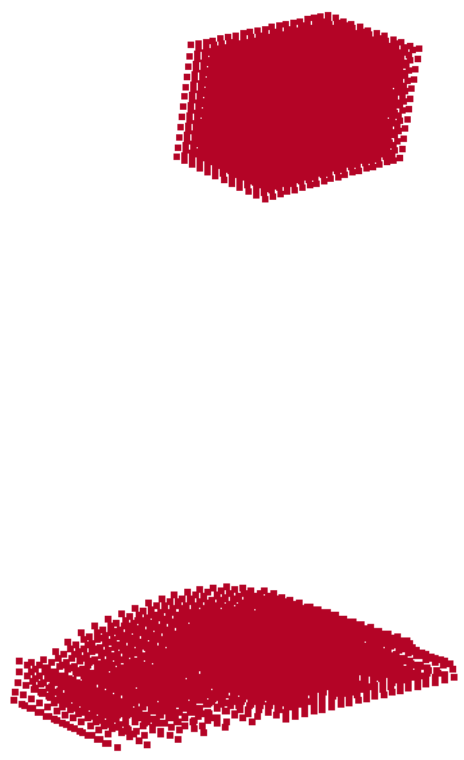

A

$-\frac{x}{2}$

M

2
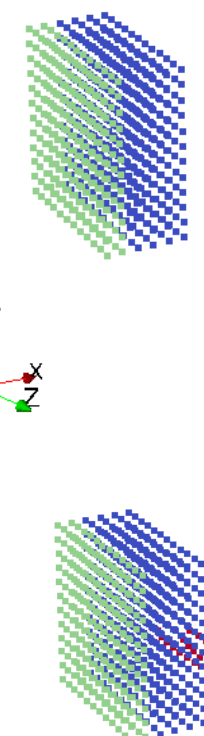

$\triangle$

$-2$ 
4.

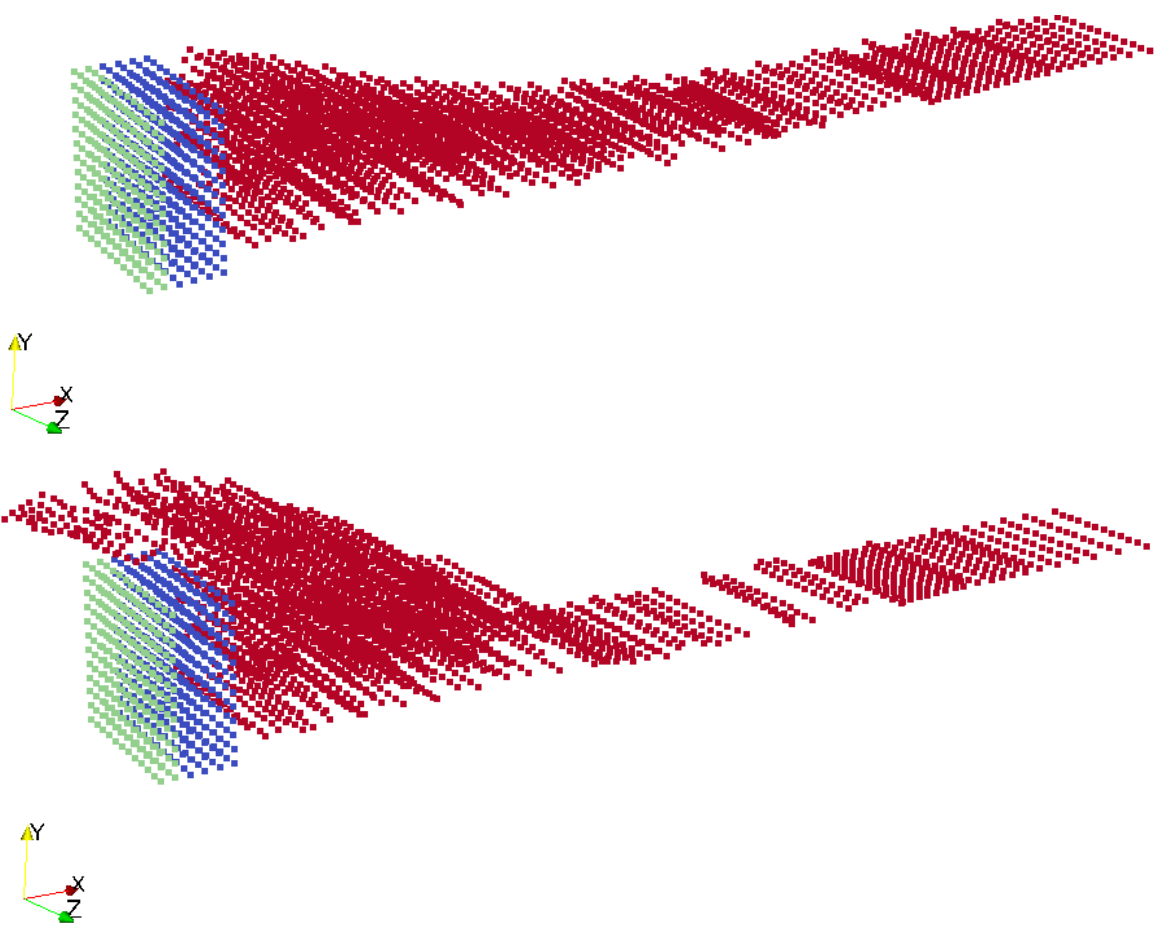

Figura 40 - Representação do modelo 3D MPM (grid 0,05 m) com escala de cores por material

a.
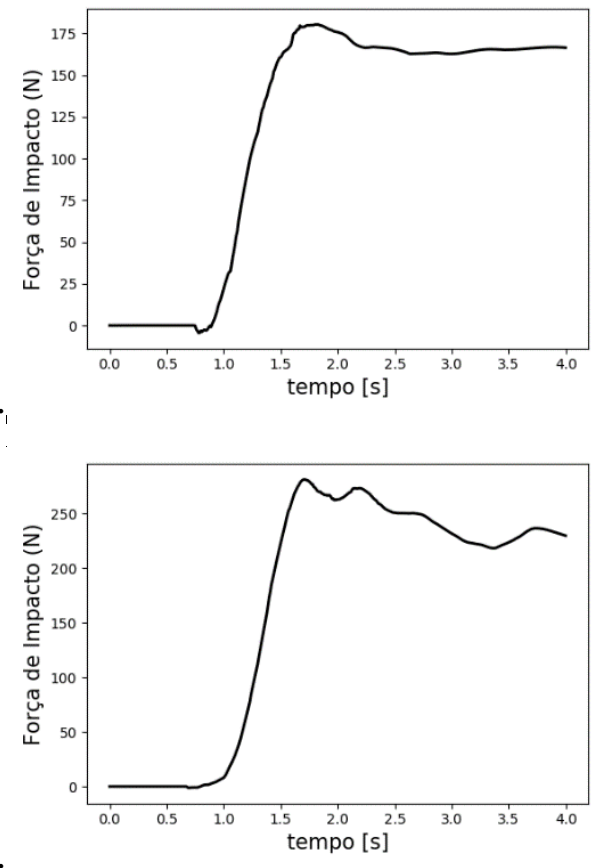

b.

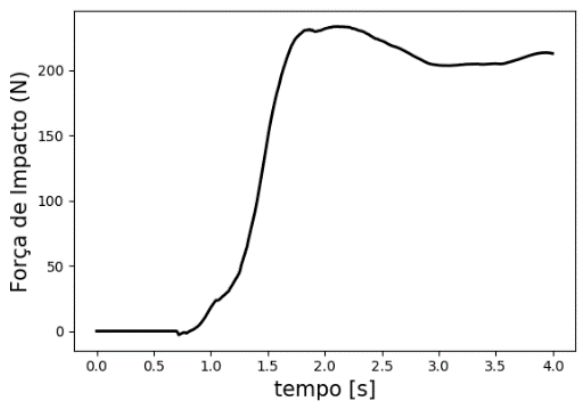

d.

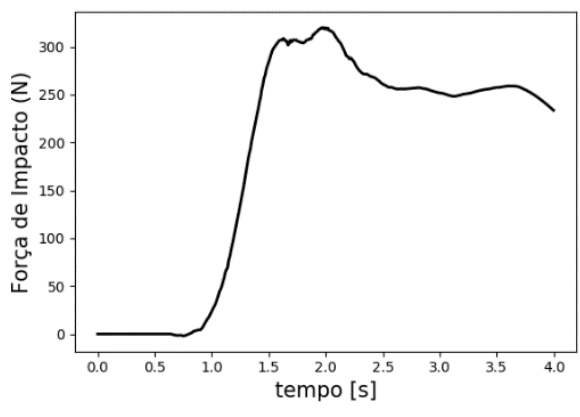


4.

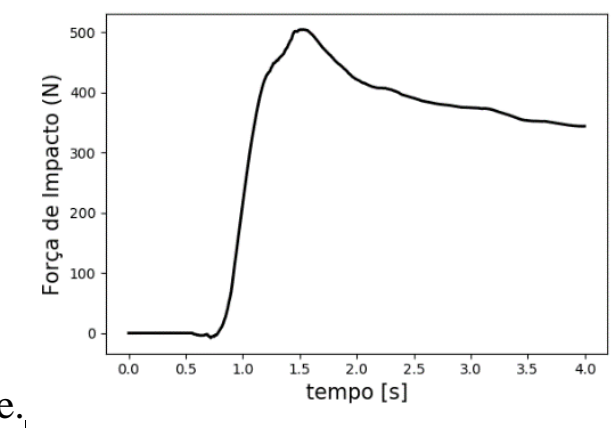

Figura 41 - Força de Impacto (N) no tempo com inclinação de:

a. $45^{\circ}$ b. $50^{\circ}$ c. $.55^{\circ}$ d. $60^{\circ}$ e. $65^{\circ}$

No caso em que o modelo é simétrico na direção z, espera-se que os resultados em 3D sejam similares aos em 2D, o que pode ser observado na Figura 42. Para geometrias mais complexas é recomendada análise em 3D. Além disso, em casos de contenção de solo no meio ambiente, outros parâmetros devem ser avaliados, como altura necessária do muro, planejamento do solo que venha a sobrepor o muro e local em que o material irá se instalar.
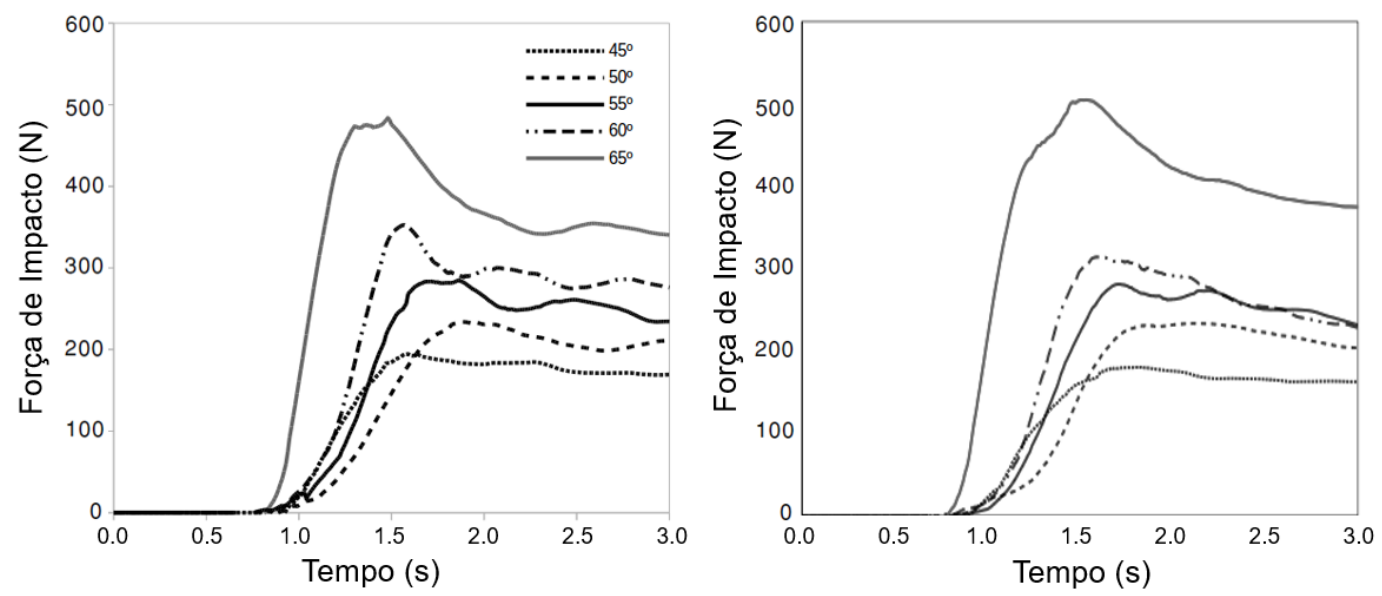

Figura 42 - Resultados com cálculo pelo MPM 2D (esquerda) e MPM 3D (direita) 


\section{5. \\ Conclusão}

O Método do Ponto Material é uma ferramenta que utiliza métodos numéricos para cálculo de deformações e tensões em diferentes tipos de material. É indicado para materiais dependentes do histórico de tensões e apresenta capacidade de modelar grandes deformações. Contudo, para o cálculo de fator de segurança, não é o modelo mais adequado por três principais motivos: utiliza o fator de redução requer inúmeras iterações para encontrar a alteração no comportamento do material; tal alteração requer interpretação do engenheiro responsável, visto que o MPM calcula grandes deformações; e os resultados são dependentes da malha, o que pode tornar o processo ainda mais demorado para se avaliar e calcular.

O cálculo da força de impacto é adequado considerando conceitos simples de elasticidade e modelagem de uma célula de carga, podendo esse modelo ser usado para cálculo de uma parede de retenção em encosta real. Para melhores resultados, é necessária uma análise de convergência de resultados com a malha.

As imprecisões encontradas na comparação com os experimentos são coerentes com as dificuldades de modelagem, como a impossibilidade de definir atrito no contorno. Para uma encosta, a superfície de ruptura é encontrada naturalmente pelo modelo, por isso não apresenta tal inconveniente.

Em um caso real, é recomendado o uso da modelagem em 3D se considerada a complexidade do meio ambiente. Um terreno irregular, com dificuldade de obtenção de parâmetros para modelagem e várias variáveis a serem quantificadas, não deve ser simplificado para modelagem em $2 \mathrm{D}$, que só é recomendada em caso de estado plano de deformação.

Cabe destacar que a implementação do algoritmo de contato no código é indicada para futuros trabalhos, a fim de que se possa definir melhor a relação de dois materiais, lembrando que o algoritmo de contato proposto por Bardenhagen et al. (2000) calcula eficientemente contato, atrito e separação. É necessária verificação da interação no contorno entre areia e base e interação entre estrutura a areia. 


\section{6. Referências Bibliográficas}

BARDENHAGEN, S.G.; BRACKBILL, J.U.; SULSKY, D. The material-point method for granular materials. Computer Methods in Applied Mechanics and Engineering 187: (3-4) 529-541, 2000.

BARDENHAGEN, S.G.; GUILKEY, J.E.; ROESSIG, K.M.; BRACKBILL, J.U.; WITZEL, W.M.; FOSTER J.C. An improved contact algorithm for the material point method and application to stress propagation in granular material. Computer Modeling in Engineering \& Sciences 2: (4) 509-522, 2001.

CAMARGO, J.T. Análise limite tridimensional como um problema de otimização cônica quadrática: aplicação em estabilidade de taludes. Rio de Janeiro. 114p. Dissertação de Mestrado - Departamento de Engenharia Civil, Pontifícia Universidade Católica do Rio de Janeiro, 2015.

CECCATO, F.; SIMONINI, P. Granular flow impact forces on protection structures: MPM numerical simulation with different constitutive models. Procedia Engineering 158: 164-168, 2016.

DRUCKER, D.C.; PRAGER, W. Soil Mechanics and Plastic Analysis on Limit Design. Quartely Applied Mathematics, 10: 157-165, 1952.

FERNADÉS, F.; VARGAS, E. Jr.; VELLOSO, R. Q. A study of collapse in slopes using MPM and NLA (Numerical Limit Analysis). 2nd International Conference on the Material Point Method for Modelling Soil-Water-Structure Interaction p.323-330, 2019.

GABRIELI, F.; CECCATO, F. Impact of dry granular flows on a rigid wall: discrete and continuum approach. Procedia Engineering 158: 152-157, 2016.

GLOBO, Jornal Online G1. Pousada é soterrada em Ilha Grande, no RJ. Disponível em: <http://g1.globo.com/Noticias/Rio/0,MUL1431940-5606,00

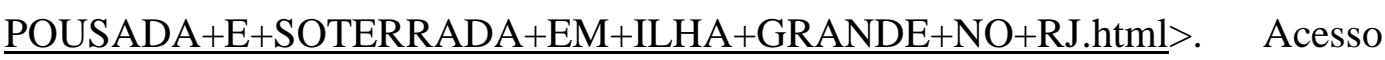
em 26/12/2018. 
6.

GRIFFITHS, D.V.; MARQUEZ, R.M. Three-dimensional slope stability analysis by elasto-plastic finite elements. Géotechnique, 57: (6) 537-546, 2007.

GUTIERREZ, L.L. Formulação e algumas aplicações do MPM (Material Point Method) em problemas de geotecnia em condições estáticas e dinâmicas. Rio de Janeiro. 102p. Dissertação de Mestrado - Departamento de Engenharia Civil, Pontifícia Universidade Católica do Rio de Janeiro, 2016.

HAGEMAN, L.J.; WALSH, J.M. HELP, a multi-material eulerian program for compressible fluid and elastic-plastic flows in two space dimensions and time. vol. I, Contract Rep. AD0726459, Systems Science and Software, La Jolla, CA, 1971.

HARLOW, F.H. A machine calculation method for hydrodynamic problems. Tech. Rep. LAMS-1956, Los Alamos Scientific Laboratory, 1955.

HARLOW, F.H. The particle in a cell method for hydrodynamic calculation. LA-2139, Los Alamos Scientific Laboratory, 1957.

HOOKE, R. Lectures de Potentia Restitutiva, Or of Spring Explaining the Power of Springing Bodies. Royal Society, St. Pauls Church-Yard, 1678.

HU, W.; CHEN, Z. A multi-mesh MPM for simulating the meshing process of spur gears. Computers \& Structures 81: 1991-2002, 2003.

HU, W.; CHEN, Z. Model-based simulation of the synergistic effects of blast and fragmentation on a concrete wall using the MPM. International Journal of Impact Engineering. 32: 2066-2096, 2006.

JOHNSON, G.R. EPIC-2, A computer Program for Elastic-Plastic Impact Computations in 2 dimension plus Spin. Honeywell Inc., Hopkins, Minnesota, Contract Report ARBRL-CR-00373, 1978.

JOHNSON, G.R. EPIC-3, A Computer Program for Elastic-Plastic Impact Calculations in 3 Dimensions. Honeywell Inc., Hopkins, Minnesota, Contract Report ARBRL-CR-343, 1977.

LAMBE, T. W.; WHITMAN, R. V. Soil Mechanics. NewYork: John Wiley \& Sons, 1969. 
6.

LI, F.; PAN, J.; SINKA, C. Modelling brittle impact failure of disc particles using material point method. International Journal of Impact Engineering 38: 653-660, 2011.

LIAN, Y. P.; ZHANG, X.; LIU, Y. An adaptive finite element material point method and its application in extreme deformation problems. Comput. Methods Appl. Mech. Engrg. 241-244: 275-285, 2012.

LIU, Y.Z.; QIUA, X.M.; MA, H.L.; FU, W.W.; YU, T.X. A study of woodpecker's pecking process and the impact response of its brain. International Journal of Impact Engineering 108: 263-271, 2017.

MACKENZIE-HELNWEIN, P.; ARDUINO, P.; SHIN, W.; MOORE, J. A.; MILLER, G. R. Modeling strategies for multiphase drag interactions using the material point method. Int. J. Numer. Meth. Engng. 83: 295-322, 2010.

MAST, C.M. Modeling Landslide-Induced Flow Interactions with Structures using the Material Point Method. Seattle. Tese de Doutorado - Civil and Environmental Engineering, University of Washington, 2013.

MA, S.; XANG, X.; QIU, X.M. Comparison study of MPM and SPH in modeling hypervelocity impact problems. International Journal of Impact Engineering 36: 272-282, 2009.

MORIGUCHI, S.; BORJA, R.I.; YASHIMA, A.; SAWADA, K. Estimating the impact force generated by granular flow on a rigid obstruction. Acta Geotechnica 4: 57-71, 2009.

MPM-PUCRIO, 2017-2019. Material Point Method code developed at Civil Engineering Department of Pontifical Catholic University of Rio de Janeiro, Rio de Janeiro, Brasil. DOI: 10.5281/zenodo.2598757

NAKASHIMA, H.; SHIOJI, Y.; KOBAYASHI, T.; AOKI, S.; SHIMIZU, H.; MIYASAKA, J.; OHDOI, K.. Determining the angle of repose of sand under low-gravity conditions using discrete element method. Journal of Terramechanics 48: 17-26, 2011.

NGUYEN, V. P. Material point method: basics and applications. Cardiff Unitversity, Department of Civil Engineering, 2010. 
6.

SCHÄFER, M. Computational Engineering - Introduction to Numerical Methods. Technische Universität Darmstadt. Springer-Verlag Berlin Heidelberg, 2006.

SULSKY, D.; CHEN, Z.; SCHREYER, H.L. A particle method for historydependent materials. Comput. Methods Appl. Engrg. 118: 179-196, 1994.

SULSKY, D.; ZHOU, S.J.; SCHREYER, H.L. Application of a particle-in-cell method to solid mechanics. Comput. Methods Appl. Engrg. 118: 179-196, 1994.

SULSKY, D.; ZHOU, H.L. Axisymmetric form of the material point method with applications to upsetting and Taylor impact problems. Comput. Methods Appl. Engrg. 139: 409-429, 1996.

SULSKY, D.; ZHOU, H.L. A particle method with large rotations applied to the penetration of history-dependent materials, in: Symposium on Advances in Numerical Simulation Techniques for Penetration and Perforation of Solids. The American Society for Mechanical Engineers, New York, AMD 171: 95-102, 1993. SULSKY, D.; ZHOU, H.L. The particle-in-cell method as a natural impact algorithm, in: Advanced Computational Methods for Material Modeling. The American Society for Mechanical Engineers, New York. AMD 180, PVP 268: 219 229, 1993.

WANG, Y.; BEOM, H.G.; SUN, M.; LIN, S. Numerical simulation of explosive welding using the material point method. International Journal of Impact Engineering 38: 51-60, 2011.

WIEZCKOWSKI, Z. The material point method in large strain engineering problems, Comput. Methods Appl. Mech. Engrg. 193: 4417-4438, 2004.

WILKINS, M. L. Calculation of elastic-plastic fow. Lawrence Livermore Laboratory Report UCRL-7322, Revision I.

WILKINS, M. L.; FRENCH, J.; GIROUX, R. A Computer program for calculating one-dimensional hydrodynamic flow; KO code. Lawrence Radiation Laboratory Report UCRL, 1969.

XU, B. and LOW, B.K. Probabilistic Stability Analyses of Embankments Based on Finite-Element Method. J. Geotech. Geoenviron. Eng. 132: 1444-1454, 2006. 
6.

YORK II, A.R.; SULSKY, D.; SCHREYER, H.L. The material point method for simulation of thin membranes. International Journal for Numerical Methods in Engineering 44: 1429-1456, 1999.

ZHANG, H. W.; WANG, K. P.; CHEN, Z. Material point method for dynamic analysis of saturated porous media under external contact/impact of solid bodies. Comput. Methods Appl. Mech. Engrg. 198: 1456-1472, 2009.

ZHANG, X.; CHEN, Z.; LIU, Y. The Material Point Method: A ContinuumBased Particle Method for Extreme Loading Cases, Elsevier Inc, 2017. 